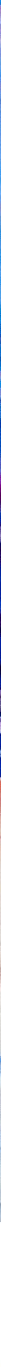

\title{
TRANSFORMATIONAL MOMENTS IN SOCIAL WELFARE
}

What Role for Voluntary Action?

GEORGINA BREWIS, ANGELA ELLIS PAINE, IRENE HARDILL, ROSE LINDSEY AND ROB MACMILLAN 
GEORGINA BREWIS, ANGELA ELLIS PAINE, IRENE HARDILL, ROSE LINDSEY AND

ROB MACMILLAN

\section{TRANSFORMATIONAL}

MOMENTS IN

SOCIAL WELFARE

What Role for Voluntary Action? 
First published in Great Britain in 2021 by

Policy Press, an imprint of

Bristol University Press

University of Bristol

1-9 Old Park Hill

Bristol

BS2 8BB

UK

$\mathrm{t}:+44(0) 1179545940$

e: bup-info@bristol.ac.uk

Details of international sales and distribution partners are available at policy.bristoluniversitypress.co.uk

(C) Bristol University Press 2021

The digital PDF and ePub versions of this title are available Open Access and distributed under the terms of the Creative Commons Attribution-NonCommercial 4.0 International licence (https://creativecommons.org/licenses/by-nc/4.0/) which permits adaptation, alteration, reproduction and distribution for non-commercial use without further permission provided the original work is attributed.

British Library Cataloguing in Publication Data

A catalogue record for this book is available from the British Library

ISBN 978-1-4473-5720-9 hardcover

ISBN 978-1-4473-5721-6 OA ePub

ISBN 978-1-4473-5723-0 OA PDF

The right of Georgina Brewis, Angela Ellis Paine, Irene Hardill, Rose Lindsey and Rob Macmillan to be identified as authors of this work has been asserted by them in accordance with the Copyright, Designs and Patents Act 1988.

All rights reserved: no part of this publication may be reproduced, stored in a retrieval system, or transmitted in any form or by any means, electronic, mechanical, photocopying, recording, or otherwise without the prior permission of Policy Press.

Every reasonable effort has been made to obtain permission to reproduce copyrighted material. If, however, anyone knows of an oversight, please contact the publisher.

The statements and opinions contained within this publication are solely those of the authors and not of the University of Bristol or Bristol University Press. The University of Bristol and Bristol University Press disclaim responsibility for any injury to persons or property resulting from any material published in this publication.

Bristol University Press and Policy Press work to counter discrimination on grounds of gender, race, disability, age and sexuality.

Cover design by Dave Worth

Front cover image: iStock/sbelov 


\section{Contents}

List of figures and illustrations $\quad$ iv

List of abbreviations $\quad$ v

About the authors vi

Preface vii

one Transformational moments?

$\begin{array}{lll}\text { two } & \text { Researching voluntary action and welfare }\end{array}$

three Positioning voluntary action in social welfare 44

four Social welfare needs $\quad 65$

five Working together in a mixed economy of welfare 92

$\begin{array}{lll}\text { six } & \text { Making room for voluntary action } & 120\end{array}$

seven Challenging the moving frontier? 141

$\begin{array}{ll}\text { Notes } & 157\end{array}$

$\begin{array}{ll}\text { References } & 167\end{array}$

$\begin{array}{ll}\text { Index } & 181\end{array}$ 


\section{List of figures and illustrations}

\section{Figures}

1.1 Timeline showing key dates from the 1940s 12

1.2 Timeline showing key dates from the 2010s 21

2.1 The Discourses of Voluntary Action research at a glance 29

2.2 Discourses of Voluntary Action organisational partners 31

2.3 Reflections on Mass Observation directive respondent characteristics 36

2.4 Accessing the archives of voluntary organisations 37

\section{Illustrations}

2.1 Front cover of the Mass Observation Bulletin reporting the results 28 of research into public views on charity, 1947

3.1 Covers of Age UK's election manifestos from the 2010s 45

4.1 Members of uniformed youth movements helping older people, late 1940s 66

5.1 NCSS's annual report 1948-9 with a positive vision of opportunity 93 for the voluntary movement

6.1 Cover of the 1944 publication Old Age in the New World prepared 121 by the NOPWC for a series on post-war planning

7.1 Imagery from Children England's campaign for a 'childfair state', 142 launched in 2018 


\section{List of abbreviations}

$\begin{array}{ll}\text { ACCH } & \text { Associated Council of Children's Homes } \\ \text { MO } & \text { Mass Observation } \\ \text { MOA } & \text { Mass Observation Archive } \\ \text { MOP } & \text { Mass Observation Project } \\ \text { NABC } & \text { National Association of Boys' Clubs } \\ \text { NAGC } & \text { National Association of Girls' Clubs } \\ \text { NCSS } & \text { National Council of Social Service } \\ \text { NCVO } & \text { National Council of Voluntary Organisations } \\ \text { NCVYS } & \text { National Council of Voluntary Youth Services } \\ \text { NOPWC } & \text { National Old People's Welfare Committee } \\ \text { OCR } & \text { Optical Character Recognition } \\ \text { WVS } & \text { Women's Voluntary Service }\end{array}$




\section{About the authors}

Georgina Brewis is Associate Professor in the History of Education at UCL Institute of Education, University College London.

Angela Ellis Paine is Research Fellow at the Third Sector Research Centre at the University of Birmingham.

Irene Hardill is Professor of Public Policy in the Department of Social Sciences at Northumbria University.

Rose Lindsey is Senior Research Fellow in the Faculty of Social Sciences at the University of Southampton.

Rob Macmillan is Principal Research Fellow at the Centre for Regional Economic and Social Research at Sheffield Hallam University. 


\section{Preface}

This book is the outcome of a research collaboration between historians and social scientists together with partner organisations. We seek to examine how debates around voluntary action compare in different historical moments of economic and social transformation. It is the product of an Economic and Social Research Council (ESRC) study called Discourses of Voluntary Action carried out between 2017 and 2020. The thinking behind the study, however, goes back well before this into the early 2010s just as the UK Conservative-led Coalition government's austerity programme was in full swing. The focus of the eventual research project and this book is on debates that took place during the 1940s and 2010s, which we refer to as transformational moments in the development of the welfare state in England.

Informally, we referred to these decades as the bookends of the welfare state, comparing the establishment of the comprehensive social democratic welfare state in the 1940s with the significant retrenchment and restructuring underway in the Coalition's programme in the 2010s. Was this the end of the welfare state? And what role would voluntary action be expected and willing to play beyond this? We opted eventually for a more open-ended description, of transformational moments, conceptualising the 2010s as a yet unresolved process of rethinking the welfare state. We concluded the study with the idea that a more thoroughgoing and explicit conversation is 
urgently needed about the future of welfare, the role of the state, and the contribution of voluntary action.

Of course, since our study ended, and as this book was being written, the world turned upside down with the emergence and rapid spread of COVID-19. Existing assumptions about the role and scope of the state were cast aside in the urgency of introducing public health restrictions, economic support schemes and wider social welfare support. There seemed to be a new appreciation of the role of voluntary action in its multiple guises - volunteer mobilisation, mutual aid support groups, formal charities and community groups. In the ongoing devastation, new forms of social change seemed possible.

Reflecting on the astonishing period since early spring 2020, and knowing that the implications ahead of the 'Covid decade' (British Academy, 2021) will be far reaching, open and unknown, it seems that the transformational moment of the 2010s, in terms of the welfare state and voluntary action, will extend well into the 2020s. We offer this book, then, in the hope that it may help inform ongoing and future debates about the role, position and contribution of voluntary action in social welfare. If COVID-19 has taught us anything, it is that newly exposed human vulnerabilities and exacerbated social inequalities demand an intense and soul-searching deliberation on the way we seek to address needs and rebuild a genuinely social security.

We would like to emphasise that this book has been a collaborative venture, in two senses. First, it has involved joint work among the five of us as researchers and authors, each bringing our own subject and methodological experience and knowledge in a shared spirit of enquiry. The book is the outcome of multidisciplinary work covering history, geography, sociology and social policy.

Second, it has involved the partnership and highly valued expertise and reflections of others, whom we would like to acknowledge, while absolving them of any responsibility for the outcome. We are extremely grateful for the support and 
engagement from our research project partners: Age UK, Children England, Mass Observation, NCVYS, NCVO and UK Youth; and from the wise counsel of members of the project steering group: Sarah Aitchison, Kate Bradley, Justin Davis Smith, Kathy Evans, Véronique Jochum, Angela Kitching, Kirsty Pattrick, Susanne Rauprich, Marilyn Taylor (who expertly chaired the group), Kayleigh Wainwright and Dan Wincott. Thank you also to Alan Malpass (Sheffield Hallam University) for historical expertise and research assistance on state narratives, Oliver Moss (Northumbria University) for behind-the-scenes support for the project, Christina Silver for advice on qualitative analysis, Amy Howe (UCL) for digitisation, Angela Scott (UCL) for design work and colleagues within each of our institutions who have supported us throughout. We would also like to thank the anonymous reviewers of the book proposal and manuscript, and our editors at Policy Press. The project and this book would not have been possible without this wider collaborative support, nor without funding from the ESRC (grant reference ES/N018249/1) to whom we are extremely grateful.

Georgina Brewis (University College London) Angela Ellis Paine (University of Birmingham) Irene Hardill (Northumbria University) Rose Lindsey (University of Southampton) Rob Macmillan (Sheffield Hallam University) 



\section{ONE}

\section{Transformational moments?}

\section{Introduction}

This book argues that the 2010s witnessed the most significant renegotiation of social welfare provision in England since the consolidation of the welfare state in the 1940s. William Beveridge asserted in his landmark 1942 report Social Insurance and Allied Services that 'a revolutionary moment in the world's history is a time for revolutions' (Beveridge, 1942: 6). This book considers these two decades, the 2010s and the 1940s, as two transformational moments in which the boundaries between voluntary action, the state, family and the market were rethought.

Although the 1940s saw the restructuring of welfare provision, which resulted in the post-war state assuming primary responsibility for the delivery of social welfare services, this did not rule out a continued role for voluntary-provided social services and the involvement of volunteers. In the late 1940s, when the so-called 'moving frontier' between state and voluntary welfare provision shifted, a period of intense debate about the nature of voluntary social service and its future direction in England ensued. It is now widely accepted that the war years and Labour government (1945-51) laid down 
the principal institutions of what has been called the 'classic welfare state' (Digby, 1989). Yet how far the 1940s debate on voluntary action influenced the design of social welfare policy, and how far it signalled an important period of adjustment and renewal for voluntarism has never been fully investigated.

The same concept of a 'revolutionary moment' or turning point was used to describe the context in which welfare services were reshaped in England in the 2010s under the Coalition and subsequent Conservative governments (Brindle et al, 2014; Lawton et al, 2014; Welby, 2018). From 2010, the Coalition government embarked on a 'restructuring of Beveridgean proportions' (Taylor-Gooby, 2012: 62). The 2010s were shaped by a politics of austerity that sought to restrict welfare benefits and strengthen sanctions in the social security system, far-reaching changes that some consider amounted to the dismantling of the welfare state - as part of a 'dismembering' of the state itself (El-Gingihy, 2016; Toynbee and Walker, 2017; Alston, 2019). Such developments had profound implications for individual citizens, as well as consequences for voluntary action. However, during the 2010s the debate about the relative roles of the state, voluntary action and other actors in welfare provision was muted in comparison to the 1940s. Until the COVID-19 emergency began in 2020, just as we were writing this book, there was scant attempt to reach a consensus in terms of who should be responsible for providing social welfare services in the 21 st century and what levels of need they should be meeting.

The 1940s and 2010s were also transformational decades for the voluntary movement in England. The social upheaval caused by the Second World War (1939-45) led to greater public awareness of need, accelerated trends towards cooperation between voluntary organisations, and strengthened partnerships between the voluntary movement and statutory sector. Driven in part by a desire to present a more united voice to government, the 1940s saw the emergence of new 
umbrella bodies working in specific areas of welfare, particularly older people's services, children's services and the youth sector (Figure 1.1). In contrast, the 2010s were marked by the contraction, closure and merger of several long-standing voluntary sector infrastructure bodies, alongside a growing concern to strengthen voluntary sector leadership, governance and regulation. Changing funding regimes, including a shift away from state support for infrastructure agencies that had marked the New Labour years (1997-2010), contributed to competition and fragmentation within the voluntary sector, affecting its collective voice (Macmillan, 2013; 2016).

This book contends that there is value in considering these two transformational moments together. Exploring how different narratives for the role and contribution of voluntary action in welfare provision were articulated and contested in both periods enables these narratives to be seen as discursive interventions, seeking to shape moving frontiers between the state, voluntary action, commercial providers and others. Alongside contributing to knowledge about the present and the past, this analysis can provide valuable insights into potential welfare futures, even more important in the light of COVID19. We build on scholarship that 'highlights the dangers of ahistorical social policy analysis' and argues for the need to understand current shifts within the wider historical context (Lambie-Mumford, 2019: 9; see also Means and Smith, 1998). The book is unique in giving equal weight to both historical and contemporary evidence, placing both within the same conceptual framework.

This introductory chapter briefly introduces the scope of the research underpinning this book and offers definitions of key terms, before presenting a short review of relevant literature on the moving frontier and the mixed economy of welfare. The final two parts of the chapter provide an overview of key social policy developments during each transformational moment, set within their wider social, political and economic contexts. 


\section{Scope and definitions}

This book suggests that revisiting debates about the role, position and contribution of voluntary action to social welfare is timely. Examining both the 1940s and 2010s, the book analyses narratives emanating from the voluntary movement (through archival records from voluntary organisations), the general public (collected by social research organisation Mass Observation $(\mathrm{MO})$ ) and the state (through parliamentary debates, speeches and policy papers). It examines four areas of voluntary action: children's services, youth, older people's services, and the voluntary movement or sector as a whole. In focusing on voluntary organisations which seek to represent these areas, the purpose is not to provide organisational histories, but to see them as windows into the debates that were taking place within these different welfare fields. The book draws on an interdisciplinary research project in which we have worked collaboratively with partners (Chapter Two). The focus on the 1940s and the 2010s is not to suggest that events in these decades emerge from nowhere, completely breaking from the past; rather that they represent two key moments in the development of the welfare state, and voluntary action, positioned within longer trajectories of change.

Defining voluntary action is complex, and never more so than in a period of increasingly blurred boundaries between public, private and voluntary sectors. Like other scholars we use the term 'voluntary action' as a catch-all to encompass the work of voluntary organisations, volunteers and activists (Davis Smith, 2019: 3). The book adopts the term 'voluntary movement' to refer to the collective work of voluntary organisations in the 1940s, following the widely accepted practice of the time, and because it would be anachronistic to apply today's preferred phrase 'voluntary sector'. Other terms which crop up in our source material include 'third sector', now seen as inextricably linked to the New Labour years, and 'civil society', which came to be the preferred term of 
the Coalition and Conservative governments of the 2010s. In both time periods, however, the public was probably more familiar with the concept of 'charity', and this terminology is reflected in the questions asked of respondents by $\mathrm{MO}$ in both decades.

This study does not seek to examine in detail the whole field of social welfare. Education and healthcare, for example, fall largely outside its remit. It focuses instead on three fields of welfare - children, young people, older people - where previously unrecognised or hidden need was being revealed for the first time during the mid-twentieth 20th century, and where need continued to exist in the 2010s. These three fields were included in the list that Beveridge (1948: 226) considered to be 'needs that remain in a social service state', where responsibility was likely to be shared by the state and voluntary organisations.

Equally this study does not seek to cover the whole of the UK: its focus is predominantly on developments in England. As John Stewart (2019: 26) notes, it is important to recognise that the UK has never been a 'unitary state' and that Scotland, Wales and, from the 1920s, Northern Ireland retained some degree of 'welfare autonomy'. In the 1940s, the key institutions of the welfare state, including the NHS, were created by separate pieces of legislation for the different nations. Since 1999, policy relating to the voluntary and community sector has been a non-reserved area across the nations that form the UK jurisdiction. While England, Wales, Scotland and Northern Ireland share some of the same drivers underpinning volunteering and voluntary sector policy, the rhetoric surrounding their deployment has become distinct (Alcock, 2012). The Big Society discourse, for example, was not adopted in Scotland. These changes are complex and bound up with the wider geographies of devolution (Woolvin and Hardill, 2013).

In the inter-war period, the emergent voluntary movement had a UK-wide focus, although steered by the National Council 
of Social Service (NCSS), a supposedly national movement, it had a distinctively English flavour. The Depression and Second World War were important periods for the development of devolved infrastructure bodies. In 1934 the South Wales and Monmouthshire Council of Social Services was formed to support Welsh communities struggling with the impact of unemployment. It became known as the Wales Council for Voluntary Action in 1980. The Northern Ireland Council for Social Services (now the Northern Ireland Council for Voluntary Action) was founded in 1938, while an independent Scottish Council of Social Service (now the Scottish Council for Voluntary Organisations) was formed in 1942, with financial backing from the NCSS, after an initial delay caused by the war (Davis Smith, 2019: 89). Nonetheless, concepts of 'British' or 'national' identity were then, and continue to be, deployed uncritically in much writing on voluntary action, as we touch upon in Chapter Three.

\section{Frontier and borderland: researching the mixed economy of welfare}

Adopting the language of 'frontier' and 'borderland' to conceptualise the moving boundary between voluntary action and state welfare provision has a long history (Llewellyn Smith, 1937; Bourdillon, 1945; Beveridge, 1949). The term moving frontier appears to have first been used by Anne Bourdillon (1945: 2) in her introduction to a volume produced for the Nuffield Social Reconstruction Survey, but has widely been attributed to a 1949 House of Lords speech by Beveridge. Similarly, the argument that the role played by voluntary organisations, commercial providers, the family and other actors in social provision in the UK amounts to a 'mixed economy' of welfare is now widely accepted. This is sometimes known as 'welfare pluralism' (Hadley and Hatch, 1981; Johnson, 1987). Early to mid-20th-century commentators on welfare were acutely aware of this mixed provision, and keen to understand the role that voluntary social service played and 


\section{TRANSFORMATIONAL MOMENTS?}

would play in any future 'social service state' - Beveridge's preferred term for what we generally now call the welfare state (Harris, 1997: 452) - as well as to map out the boundaries of statutory-voluntary partnership. Elizabeth Macadam (1934) famously identified a close partnership between private philanthropy and state action, which she called the 'new philanthropy'. A decade later, GDH Cole wrote a 'retrospect' of voluntary social service in which he considered it a 'great mistake' to suggest that as state action expanded, the scope of voluntary social service would necessarily contract; rather the boundaries would continue to be remade (Cole, 1945: 29). A similar theme of transition and evolution marked Beveridge's so-called 'third report' Voluntary Action (Beveridge, 1948) as well as the writings of the leading post-war scholar of social policy Richard Titmuss (Titmuss, 1958; Stewart, 2019).

In the era of the classic welfare state, however, which lasted from the 1940s until the mid-1970s, there was a tendency for scholars to overemphasise the role of the state and to view the history of voluntary action simply as a stage in the development of the welfare state (Thane, 1982; Stewart, 2019). In his survey of the history of voluntary action in England, for example, David Owen conceptualised the post-war voluntary movement as 'junior partners in the welfare firm' (Owen, 1965: x). Others recognised the role of voluntary organisations in pioneering welfare services and activities which were then taken over by local government, but without fully acknowledging the continued place of volunteers and voluntary organisations in delivering, managing and modifying such services after 1945 (Fraser, 2003; Thane, 1982; Lowe, 2005). Helping to shape this narrative, the 1978 Wolfenden Committee on The Future of Voluntary Organisations judged the voluntary sector 'to have been marking time' in the immediate post-war years (Wolfenden, 1978: 20). Frank Prochaska (2006: 93) depicted a voluntary movement in 'disarray' in the 1940s, reeling from 'blow' after 'blow' of state welfare expansion. In contrast, Rodney Lowe (2005) described an 'uneasy consensus' in 
the post-war welfare state in which the practical benefits of continued voluntary involvement in welfare provision were reluctantly accepted in three main areas: unpaid volunteers within statutory services, self-help groups (particularly for children and older people), and, most contentiously, charities that continued to provide social services such as children's homes, domiciliary care for older people or work with 'problem families'. Debates over the place of voluntary social services did not go away, however. A series of inquiries in the 1950s and 1960s considered the place of voluntary organisations or volunteers in state welfare services, including Younghusband which reported in 1959, Seebohm in 1968 and Aves in 1969. There were also some attempts to investigate the public's views on this topic (Morris, 1969). Written in the Thatcher era, Maria Brenton's examination of the historical development of the 'voluntary sector in British social services' was produced in the context of an upsurge of interest in the potential of non-governmental alternatives to the delivery of social services (Brenton, 1985).

Geoffrey Finlayson revisited the concept of the moving frontier in the 1990s and the term subsequently became widely used in academic discussions about social welfare in the UK, and in other national contexts (Finlayson, 1990; 1994; and see, for instance, Powell, 2019). Martin Gorsky (2014) proposed that since the 1990s a substantial rethinking of British welfare history has occurred, in which scholars have sought to 'emancipate the subject area' from an earlier teleological approach and to offer a range of revisionist takes on social policy. Finlayson (1990), Jose Harris (1990), Bernard Harris (2004; 2010), Jane Lewis (1995; 1996; 1999a) and others began to argue that far from it being a story of linear development, there had always existed a 'mixed economy' of welfare in which the state, the voluntary movement, the family and the market had played different roles at different points in time. Voluntary associations were integral to the 19th-century conceptualisation of the state, when they were 
'buffer institutions' between the citizen and the state (Thane, 1990: 1-2). Nick Deakin and Justin Davis Smith (2011) suggested that the history of voluntary action has been shaped by those, on both left and right, anxious to sustain the 'myth' of the Labour Party's hostility to voluntary action. The history of voluntary action is now a flourishing field of inquiry, with much new work rejecting declinist narratives (as epitomised by Prochaska, 2006), and arguing for recognition of the continued vitality and adaptability of voluntary action after 1945 (Hilton and McKay, 2011). Nonetheless, few scholars have revisited the role of voluntary action in the design of social welfare policy in the 1940s or investigated the nature and extent of the debate on voluntary action in this period (though see Means and Smith, 1998; Grier, 2001; Hayashi, 2013).

\section{Welfare and social policy reform in the 1930 s and 1940 s}

The Second World War and its aftermath were to have major implications for the future of statutory, commercial and voluntary welfare provision. However, we must recognise how far the social policy changes that emerged at this time built on earlier reforms. Legislation introduced by the Liberal government of 1906-11 had powered a 'parallel expansion of statutory and private welfare' in the inter-war years, most clearly seen in insurance and health care markets, which offered purchasers a wide range of choice from proprietary and mutual providers (May and Brunsdon, 1999: 277). By 1939, 42 per cent of the population was covered by the state national insurance scheme, but as dental, hospital and optical care was excluded, the majority of this group were also purchasing additional private insurance. During the 1930s Depression, the unemployment insurance system and other statutory welfare services expanded to deal with the crisis, but were subject to considerable limitations (Harris, 1995). Successive Conservative-dominated national governments (at first led by Ramsay MacDonald and, after 1935, by Stanley Baldwin) relied 
on a deepening partnership with the voluntary movement. For example, the government channelled significant sums to the 'Depressed areas' through the NCSS for a range of occupational and recreational schemes for unemployed men and women (Brasnett, 1969; Harris, 1995; Davis Smith, 2019). While these initiatives 'made an important contribution to social and cultural lives' of the unemployed, they did little to 'relieve the underlying problem of mass unemployment' (Harris, 2004: 211). This perceived over-reliance on the voluntary social service movement in place of government action to create jobs was criticised by many on the left (Wilkinson, 1939; see also Finlayson, 1990).

The social upheaval of war, particularly the experiences of large-scale evacuation from major cities, revealed serious shortcomings in existing welfare services and stimulated demand for wholesale welfare reform. The war led to the recognition that people could end up in poverty through no fault of their own, accelerating a move away from traditional, piecemeal welfare provision (Harris, 2004). Media coverage about the inadequacies of existing services together with heightened public interest in social issues meant pressure for reform began to build across several policy areas (Holman, 1996; Thane, 2018). In his contribution to the official history of the war, Titmuss (1950: 506) argued that, by 1945, government had come to accept responsibility for the health and well-being of the entire population.

While the 1940s are well understood as transformational for welfare services in England, they are not always recognised as a key decade in laying the coordinated groundwork for the formation of what would later be called the 'voluntary sector'. The NCSS embodied the idea of partnership and coordination between the state and the voluntary movement, and within different traditions across voluntary action (Davis Smith, 2019). In 1938, after the Munich crisis accelerated preparations for war across government and civil society alike, the NCSS took the initiative in setting up a 'Standing Committee of Voluntary 
Organisations in Time of War', which included a hundred of the principal national voluntary organisations. This committee began making plans for how the voluntary movement 'could be of service to the nation', which it was ready to implement on the outbreak of war. From 1938, the NCSS was also conducting pilots of Citizens' Advice Bureaux to offer advice and support to people during wartime. By the end of the first month of the war, 381 bureaux had opened; financial aid from government came in 1940 (Brasnett, 1969: 101). Similarly, the creation of the Women's Voluntary Service (WVS) in 1938, to mobilise women volunteers to help with evacuation and the impacts of likely air raids, is an example of growing partnership between voluntary and statutory services. WVS was a hybrid organisation, receiving government funding to cover core running costs and mobilising up to a million volunteers by the middle of the war (Hinton, 2002).

In May 1940 Neville Chamberlain's government fell and was replaced by a cross-party coalition under Winston Churchill; as the leader of the opposition, Clement Attlee was brought into the Cabinet. The new government placed renewed emphasis on post-war planning and reconstruction, which was part of boosting civilian morale at a pivotal moment in the war (Bew, 2016; McKinstry, 2019). Subsequent wartime social policy accelerated wider welfare reform (Figure 1.1). The Old Age and Widow's Pensions Act, introduced in summer 1940, prompted what the Times called a 'remarkable discovery of secret need' among older people (Titmuss, 1950: 516). New supplementary pensions for old people and widows would be administered by the Assistance Board, thereby removing the stigma of the hated Poor Law. The change resulted in hundreds of thousands of older people coming forward to claim the new benefit, revealing previously unrecognised levels of poverty and poor housing conditions (Rowntree, 1941; Harris, 2004). Here, too, was a new opportunity for voluntary action and for voluntary-statutory partnership (Means and Smith, 1998). Organisations and individuals concerned about the problems 


\section{Figure 1.1: Timeline showing key dates from the 1940s}

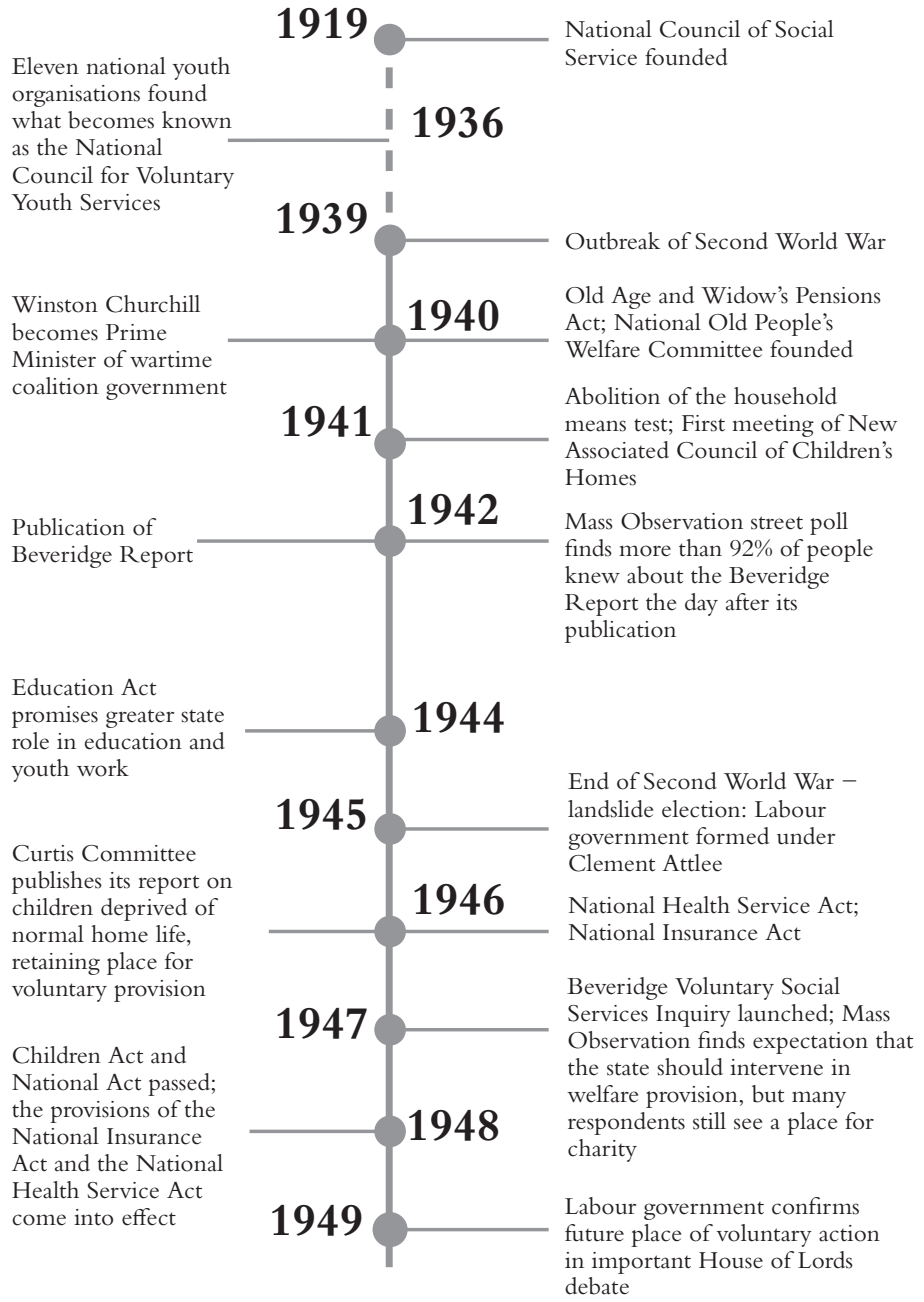

faced by older people during wartime came together as a committee of the NCSS, chaired by Eleanor Rathbone MP, to form what became known as the National Old People's Welfare Committee (NOPWC). The abolition of the household means 


\section{TRANSFORMATIONAL MOMENTS?}

test in 1941 for individuals receiving help from the Assistance Board was another important step away from a local system of poor relief towards a 'national system for the relief of poverty' (Harris, 2004: 285).

The war focused new-found public attention on children and young people. Child care professionals seized the unique opportunities presented by evacuation and wartime disruption to study children in a variety of settings (Grier, 2001: 236). Serious shortcomings in children's services were thus revealed, particularly in residential care for children who were 'deprived of a normal home life'. One of the most ardent campaigners on this topic was Lady Allen, widow of a Labour peer, whose forceful letter to the Times in July 1944 called for government investigation of the 'repressive conditions that are generations out of date' in voluntary and local authority children's homes, and prompted a public outcry (Allen, 1944). The high-profile case of 12-year-old Dennis O'Neill, who was killed by his foster father in January 1945, further added to the growing public outcry. A public inquiry into the care of looked-after children was chaired by Myra Curtis and reported in 1946. This work impacted on that of another umbrella voluntary group created in wartime, the Associated Council of Children's Homes (ACCH), which first met in November 1941 when four of the largest charities then providing residential care for children in the UK came together: Dr Barnardo's Homes, the Catholic Child Welfare Council, the Church of England Waifs and Strays Society (afterwards the Church of England's Children's Society) and the National Children's Home and Orphanage (later known as Action for Children). These four organisations were responsible for over 33,000 children and argued that, hitherto, legislation affecting children had been passed without any consultation with them.

Increased attention was also focused on young people as the war sparked regular moral panics about wayward youth. There was growing recognition that the social and physical needs of young people, the vast majority of whom left school at 14, 
had been neglected. The Board of Education's assumption of a 'direct responsibility' for 14 to 20 -year-olds through the 1939 creation of the Youth Service therefore presented both a challenge and an opportunity to the voluntary organisations, which at that point were delivering most leisure and training services for young people. Other significant reforms included the Coalition government's Education Act 1944, which introduced free secondary education for all, extended local authorities' role in leisure-time provision and was designed in due course to raise the school leaving age to 16. The Standing Conference of National Voluntary Youth Services, which had originally been formed in 1936 by 11 national voluntary youth organisations in association with the NCSS, including the National Association of Boys' Clubs (NABC) and the National Association of Girls' Clubs (NAGC), helped its member organisations to navigate this changing landscape and to uphold the idea of statutory-voluntary partnership (Green, 1986).

In June 1941, Beveridge was appointed to lead a government inquiry into social insurance and turned what was expected to be a low-key, technical exercise into an investigation resulting in a blue-print for the post-war welfare state (Harris, 1997; Lowe, 2005; Timmins, 2017). When it was published in December 1942, people queued in the winter cold to get hold of the Beveridge Report, which eventually sold over 600,000 copies. Published just after the important military victory at El Alamein, the report signalled 'a new phase of optimistic restructuring of social policy' (Alcock, 1999: 204). Beveridge identified five giant evils - squalor, want, ignorance, idleness and disease - which he argued had to be slain on the road to reconstruction. His plan proposed a free-at-the-point-ofentry national health service, comprehensive social insurance through the state, and non-means-tested family allowances, and was predicated on full employment. Beveridge's own caution about the 'revolutionary' changes he proposed is significant for understandings of the mixed economy of welfare. He noted that his plans were to be a "natural development from the 
past. It is a British revolution' and relied on maintaining the pre-war system of contributory insurance with payments from employers and the state (Beveridge, 1942: 31). The reception of the Beveridge Report has often been cited as evidence of wartime consensus, although this is not necessarily how it was seen at the time (Harris, 2004). The report won Labour backing but left the Conservatives deeply divided, prompting a split within the wartime coalition over the issue of implementation (McKinstry, 2019). It did, however, receive widespread support among the public. Despite Conservative resistance, in April 1943 Churchill was persuaded to establish another committee to investigate the practicalities of implementing Beveridge's recommendations (Harris, 2004).

The May 1945 general election was framed around postwar reconstruction but was bitterly fought, with 'little sign' of consensus between major parties (Thane, 2018: 187). It was Labour's ambitious programme of social and economic reconstruction, including a promise to implement much of the Beveridge plan, which helped secure its first landslide majority (Thane, 2018). Alongside the nationalisation of key industries and utilities, Attlee's new government introduced a swathe of reforms which set up the key institutions of the welfare state. In England and Wales, important legislation included the National Insurance Act 1946, the National Health Act 1946, the Children Act 1948, the National Assistance Act 1948 and the Town and Country Planning Act 1949. One key departure from the Beveridge plan involved ending the role, held since 1911, of voluntary organisations and commercial companies as 'approved providers' of national insurance, thus sounding the 'death knell for mutual aid friendly societies', as Beveridge lamented (Lewis, 1999b: 261). However, predictions that the Labour victory would see the demise of either commercial or voluntary welfare service provision were not to materialise. Sustained lobbying by powerful interests ensured commercial provision was built into the welfare state: fee-paying education survived, private medical practice continued, the 
private business status of dentists, pharmacists and opticians remained, and while the life insurance industry faced greater regulation, it too was allowed to continue (May and Brunsdon, 1999). The ability, indeed the right, to purchase education, healthcare, housing or pensions 'has never been seriously questioned' in England (Stewart, 2019). Similarly, the Labour government sought to retain a role for voluntary organisations and volunteers in welfare provision, both in principle and on practical grounds.

Voluntary action was considered important by many within the labour movement for promoting active citizenship and as training for democracy. Attlee's own roots were in the university settlement movement and others in the Cabinet had sympathy for voluntarism (Grier, 2001; Deakin and Davis Smith, 2011; Bew, 2016). Moreover, the economic situation limited what the government could achieve, leading to ongoing reliance on voluntary organisations for welfare delivery. Such provisions were built into the new legislation. The National Assistance Act 1948, for example, which finally abolished the Poor Law, gave new powers to voluntary organisations to deliver services (Chapter Six). The achievement of the post-war Labour administration in establishing the enduring institutions of the British welfare state, notably the muchloved NHS, and in extending the social 'safety net', should be seen in the context of both austerity and the mixed economy. Public spending on welfare grew, but growth was at a rate which 'both contemporaneously and retrospectively has been exaggerated' (Tomlinson, 1995: 212). Moreover, the extent to which the post-war welfare mix retained an important place for voluntary action, and commercially provided welfare, has also been under-appreciated.

\section{Turning points and transformational moments, 1951-2010}

Before jumping to our next transformational moment, it is important to consider the intervening period, if only briefly. 
The decision to compare the 1940s and the 2010s builds on a growing literature which draws parallels between these two periods. Some of this scholarship was driven by a desire to mark the 75th anniversary of the publication of the Beveridge Report and to reflect on the giant evils as manifest today (Brindle et al, 2014; Armstrong, 2017). However, social policy analysts have also repeatedly made the case that the 2010s were marked by welfare reforms the scale of which had not been seen since the 1940s (Taylor-Gooby, 2012; Beatty and Fothergill, 2013; Lambie-Mumford, 2019). None of this is to deny the significance of other transformational periods for the mixed economy of welfare, which are very briefly reviewed here (see also Lindsey and Mohan, 2018). As scholars including Anne Digby (1989) and Robin Means and Randall Smith (1998) point out, discussion about the changing welfare mix has been bedevilled by a tendency by some on the left to imagine a 'golden age' of the classic welfare state and by some on the right to deride and reject the achievements of this era.

Within these decades, the 1960s have been identified as significant for the voluntary movement with a 'rediscovery of poverty' prompting the formation of a new wave of charities, including Child Poverty Action Group and Shelter. The 1970s were also important. The social democratic welfare state lasted from the 1940s until the mid to late 1970s, when the 1973 oil crisis, economic stagnation and subsequent growing unemployment led to the break-up of the post-war welfare consensus. In 1976 Labour abandoned its commitment to full employment. Thane (2018: 322) suggests that the welfare state reached its 'zenith' in the late 1970s, in terms of both expenditure and range of state services.

The election of Margaret Thatcher's government in 1979 led to a decisive shift towards a neoliberal approach to welfare and 'low-tax market-centred presumptions' which have broadly framed policy making ever since (Taylor-Gooby et al, 2017). The welfare state was envisaged less as a solution to poverty 
and more as part of the problem. A pressing concern for the Thatcher and Major governments was the question of welfare dependency, in which recipients of welfare were held to be morally and socially 'diminished' by receiving support, and proposed solutions were to limit and reduce welfare spending (Drakeford, 2007: 65). Cuts and restructuring of contributory benefits had the effect of increasing the use of means-tested benefits in a period of rising unemployment, so overall the cost of social security continued to grow through the 1980s and 1990s (Alcock, 1999). Reforms to social security introduced by Norman Fowler, while billed as 'the most substantial' since the Beveridge Report, in fact turned out to be less significant (Alcock, 1999: 212). There were also minor reforms to eligibility for the state pension coupled with strong support for the expansion of private pensions. In the context of an ageing population, the late 1980s and early 1990s saw an extensive debate about the 'future affordability of the welfare state' in which older people were viewed as a potential 'burden' (Means and Smith, 1998: 323).

Far-reaching changes were being made in other areas too. The late 1980s saw the transfer of public utilities to private ownership, reversing the nationalisation of the Attlee years, attempting to create a market for energy and water supply, while quasi-markets were developed in education, social work and healthcare (Le Grand and Bartlett, 1993; Drakeford, 2007). Reforms sought to bring in a wider range of providers. The most significant legislation of the time was the NHS and Community Care Act 1990. This enabled NHS and local authority social service departments to develop local provision for health and social care by contracting with a range of organisations to deliver these services. The Act 'transformed social service departments from the direct providers of services to care managers: they were to identify the needs of individuals and open tenders, for which the private and voluntary sectors should compete' (Jones and Lowe, 2002: 195). It thus marked 
a 'major shift' in the relations between the voluntary sector and the state, as well as signalling a change in the way public funding was channelled to voluntary organisations in a move away from grant funding to contracts (Alcock and Scott, 2007: 89). One key effect of the Act was the marketisation of older people's residential care, and an increase in local authority and state spending in this area (Glennerster, 2007).

In terms of welfare reform the New Labour era was marked more by continuity with the previous Conservative administration's rule than change. Successive Labour governments after 1997 did not reverse public service markets, and in some cases developed them. The continued expansion of occupational welfare (including pensions, healthcare, maternity pay, counselling) and commercial welfare (including life insurance, private healthcare) was encouraged (Alcock, 1999; Brunsdon and May, 2019). Between the late 1990s and the 2000s, Labour succeeded in establishing a 'policy consensus on the expanded role of the third sector in public service delivery' (Lindsey and Mohan, 2018: 30). New Labour's 13 years in office were marked by prominent support for an expanded 'third sector', including not only voluntary and community organisations, but also more commercially oriented forms of social enterprise, cooperatives, and mutual organisations (Alcock, 2011). The policy framework was encapsulated by a 'Compact' between government and the sector, introduced in 1998, and underpinned by increased investment in the sector, particularly for 'capacity building' (Macmillan, 2013). The New Labour period saw a rise in the profile of voluntary action 'to rival, if not outstrip, that at any point in the previous century' according to Alcock (2011: 158), and what Kendall (2009: 67) identified as 'unprecedented, deliberate and sustained horizontal policy hyperactivity' associated with the third sector's 'mainstreaming'. In terms of a transitional moment for the mixed economy, however, the New Labour era is not as significant as that which followed. 


\section{The 2010s, social welfare and voluntary action}

The 2010s decade was bookended by an inconclusive general election in May 2010, which resulted in the formation of the first coalition government at Westminster since the Second World War led by David Cameron and Nick Clegg, and the election of an 80-seat Conservative majority government under Boris Johnson in December 2019. In 2010, Liberal Democrats joined the dominant Conservative Party in a coalition that was to be shaped by the politics of austerity. This had its origins in the fallout from the global financial crisis of 2007-8, which was rapidly reframed from a financial crisis to a 'fiscal crisis of the welfare state', leading to cuts in public spending unprecedented since 1945 (Gough, 2011: 50). As Hugh Bochel and Martin Powell (2016) note, the three main parties were not that far apart at the time of the 2010 election, with policies that aimed at cutting the deficit and greater use of the market within the NHS and social care, albeit proposing different speeds and different balances of tax increases. In office, the dominant theme of the Coalition's social policy was a reduction in public expenditure (Bochel and Powell, 2016). However, cuts were not spread evenly across policy areas, with spending on pensions and healthcare prioritised over that on children and families, housing and local government (Bochel and Powell, 2016). There was also significant regional variation (Kitson et al, 2011). Overall, there was a shift away from a focus on structural causes of poverty, with emphasis instead placed on notions of individual responsibility, tied up with 'a resurgence of discourses around deservingness' (Lambie-Mumford, 2019: 9; see Chapter Four). Coalition social policy intensified a New Labour focus on 'making work pay' by reducing benefits and increasing conditionality (Bochel and Powell, 2016). The Welfare Reform Act 2012 introduced Universal Credit, restricted Housing Benefit and strengthened sanctions in the social security system (Figure 1.2). For example, between 2009 and 2014 there was a threefold increase in the use of benefit 


\section{Figure 1.2: Timeline showing key dates from the 2010s}

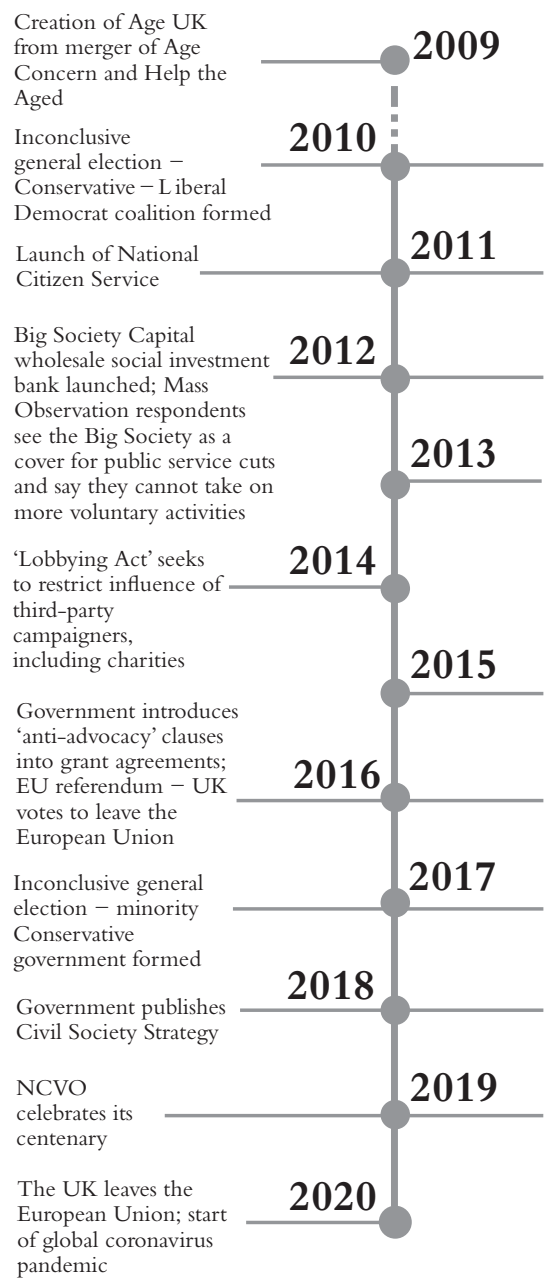

Creation of Age UK Aged

Inconclusive general election -

Launch of National

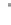

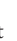

Observation respondents

see the Big Society as a

cover for public service cuts

and say they cannot take on

'Lobbying Act' seeks

to restrict influence of

third-party

campaigners,

including charities

Government introduce

'anti-advocacy' clauses

into grant agreements;

EU referendum - UK

votes to leave the

European Union

Inconclusive general

election - minority

Conservative

government formed

Government publishes

Civil Society Strategy

\section{NCVO}

celebrates it

2020
Launch of Big Society Agenda

Open Public Services White

Paper signals greater role for voluntary sector in running public services

Welfare Reform Act introduces key reforms to benefits system

First roll-out of

Universal Credit begins

Conservatives win general election, with small majority

Closure of National Council for Voluntary Youth Services after 80 years

House of Lords Select Committee on Charities published report; merger of Ambition into UK Youth

Mass Observation respondents are critical of the performance of the welfare state; Civil Society Futures independent inquiry published report

December 2019

Conservatives win general election 
denial as a penalty for failing to follow stringent rules (Oakley, 2014, cited in Taylor-Gooby et al, 2017). At first, such moves appeared to be in tune with a hardening of public opinion on matters such as benefit sanctions, although more controversial policies such as the so-called 'bedroom tax' or outsourced fitness-to-work tests were less well received (Defty, 2016).

The Coalition proposed far-reaching, fundamental restructuring of the welfare state, including 'the substitution of private for-profit and not-for-profit agencies for state services' in social housing, social welfare, health, education and other public services (Taylor-Gooby, 2012). The influential 2011 Open Public Services White Paper saw the state itself as a problem, marked by a supposedly outdated approach to delivering public services. Instead, it was suggested, opportunities should be opened for a wider range of organisations to provide innovative solutions to welfare needs. The NHS, for example, was opened to for-profit and not-for-profit providers through the 'Any Qualified Provider' scheme following the Health and Social Care Act 2012 (Bochel and Powell, 2016).

David Cameron came into government promoting the idea of the 'Big Society', and, unusually for a serving prime minister, his first speech considered voluntary action. Set alongside the 'open public services' agenda, there was the potential to significantly increase the role of voluntary action in social welfare. However, the new government also made significant cuts to the voluntary sector, particularly to voluntary sector infrastructure bodies. Commissioners of public services were asked to consider social benefit and well-being alongside cost, but there is little evidence of significant expansion of welfare provision by the voluntary sector during the Coalition period (Bochel and Powell, 2016). The Big Society remained a problematic concept, difficult to sell to a wider public, and began to fade from view after a couple of years. There was also interest in new ways of giving money and time, from the Innovation Fund to the National Citizen Service (Lindsey and 
Mohan, 2018). Voluntary organisations that spoke out about the negative effects of austerity were interpreted by government as too political, with concerns about this seemingly reinforced by the passing of the 2014 'Lobbying Act' (Transparency of Lobbying, Non-Party Campaigning and Trade Union Administration Act 2014) and a growing critique of governance and leadership in the voluntary sector (see Chapter Three).

The election of a majority Conservative government under Cameron in May 2015 seemingly marked a vindication of the politics of austerity. The new government promised changes to the scale and scope of the state and introduced further cuts, again aimed largely at local government and working-age people, unequally distributed across England and Wales (Beatty and Fothergill, 2016; Taylor-Gooby et al, 2017). While this period saw significant social policy change, particularly in the field of disability benefits, the topic of welfare reform faded from media headlines as the Brexit crisis unfolded from 2016 to 2019. This contributed to an apparent vacuum in domestic policy and decision making, as evidenced in the repeated delays to pursuing meaningful and much-needed reform of social care. The second half of the 2010s were marked by growing political polarisation on issues of welfare; as the Labour Party, for example, took a turn to the left after 2015 under its new leader Jeremy Corbyn. By the end of the decade, the UK appeared to many commentators never to have been more divided (Armstrong, 2017: 170). Taylor-Gooby et al (2017: 49) argue that the UK's decision to leave the European Union after the 2016 referendum, in which a majority of 52 per cent voted to leave, was shaped in part by a 'popular welfare chauvinism and a mistrust of the political establishment'. Cameron was replaced as prime minister by Theresa May in summer 2016, but the challenge of the Brexit negotiations left little space for social policy reform, particularly after the loss of the government's working majority following the snap election in May 2017.

The impact of the cuts to public services and reforms to benefits under both Coalition and subsequent Conservative 
governments had significant implications for voluntary organisations. Austerity increased the demand for the services of many voluntary organisations at the same time as reducing their resources, undermining any wider ambitions to increase their role and contribution. One very visible aspect of the voluntary sector's response has been in the expansion of food banks. Starting in 2010 the Trussell Trust Foodbank Network grew rapidly to 1,235 distribution sites by 2019 , alongside an estimated 842 independent food banks (Loosptra et al, 2019). Lambie-Mumford (2019: 9) argues that the growth of food charity is the 'embodiment' of the longer trajectory of social policy change since 2010. Indeed, the concept of 'Food Bank Britain' made its way into popular culture as a proxy for the impacts of austerity on individuals (see Chapter Four).

As the impact of austerity on the poorest unfolded, some voices within the voluntary sector began to argue for a reform of social welfare. Such criticism was unsurprisingly not welcomed by government, and concerns were voiced that voluntary organisations were being silenced through measures like the aforementioned 'Lobbying Act' (2014) and the 2016 introduction of 'anti-advocacy' clauses into contract and grant agreements (Chapter Three). The picture was not helped by a series of 'charity scandals' relating to fundraising and safeguarding which made media headlines in the second half of the decade. The 2010 s were also marked by a greater blurring of sector boundaries that has more resonance with the pre-1939 welfare mix than the period of the 'classic welfare state' (see Chapter Five). By the end of the 2010s, the newly favoured term 'civil society' was held to include many different actors from voluntary organisations through to mission-driven businesses. Returning to the idea of a moving frontier, Davis Smith (2019) identifies a new stage of 'this shifting frontier' which occurred around the time of the formation of the Coalition government in 2010. The 'decoupling' (Macmillan, 2013) of the voluntary sector and the state, pursued by both Coalition and Conservative governments, has ironically 


\section{TRANSFORMATIONAL MOMENTS?}

occurred during a period in which the voluntary sector is urged to take on a greater role in the delivery of welfare services.

\section{About this book}

This book highlights the relevance of history to contemporary policy discussions, and we hope it will contribute to scholarly debates across history and the social sciences, as well as having implications for policy making and practitioner audiences. The book was completed during the COVID-19 pandemic in 2020 and 2021, during which time the UK government adopted a range of economic welfare support measures unprecedented in peacetime, while at the same time the voluntary and community sector was mobilised to meet new need across the four home nations (Macmillan, 2020). Commentators repeatedly drew parallels with the 1940s. The discussion throughout this book speaks directly to further restructuring and rethinking of the welfare mix, with implications for voluntary action.

The chapters in this book build upon one another, becoming more specific, detailed and analytical as it moves towards its conclusion. While each can be read alone, there is added value in reading them together and in order. Chapter Two discusses the theoretical framework that underpins this study and outlines its methodological approach. In Chapter Three, we present two high-level, overarching narratives, evident in both time periods, about the role, position and contribution of voluntary action. Subsequent chapters examine in greater detail the basic premises upon which these narratives are built. Chapter Four examines how different narratives about the role of voluntary action are made in relation to different understandings of the type of welfare needs that should be met, how these should be met, and the broader context in which they are embedded. Chapter Five returns to the idea that voluntary action is always positioned in relation to others, particularly the state, but also commercial and other providers of welfare, and explores the evolution of relationships within 
this mixed economy. Chapter Six examines in more detail the ways in which narratives are strategically deployed during periods of unsettlement to make and shape room in social welfare by focusing on one specific example, or what we call an emblematic moment, for each time period. We conclude in Chapter Seven by revisiting the notion of the moving frontier, calling for a more nuanced understanding which recognises the complex and contested nature of the fluid and permeable boundaries between voluntary action, the state and others. The debate about voluntary action's place within the 21 stcentury welfare mix is ongoing, and we aim to both highlight the urgency of that debate while also providing unique insight to help inform it. 


\section{TWO}

\section{Researching voluntary action and welfare}

\section{Introduction}

The findings presented in this book are drawn from an empirical study of the ways in which different groups of actors discussed the role, position and contribution of voluntary action during the two transformational decades of the 1940s and 2010s. The study focused on three narrative voices public, state and voluntary - through identifying, selecting and analysing documentary sources associated with each set of actors across both the 1940s and 2010s. The research focused on the social policy fields of children, youth and older people's services, each of which reflect areas of need identified by Beveridge (1948) in his Voluntary Action report and which re-emerged with some urgency in the 2010 s (Armstrong, 2017). The fourth field of activity is the voluntary movement as a whole (Figure 2.1). We accessed state narratives through reviewing documents such as white and green papers, speeches and parliamentary debates produced by different state actors; voluntary narratives through documents such as the annual reports, board papers, policy position statements and consultation responses of key voluntary organisations operating 


\section{Image 2.1: Front cover of the Mass Observation Bulletin reporting the} results of research into public views on charity, 1947

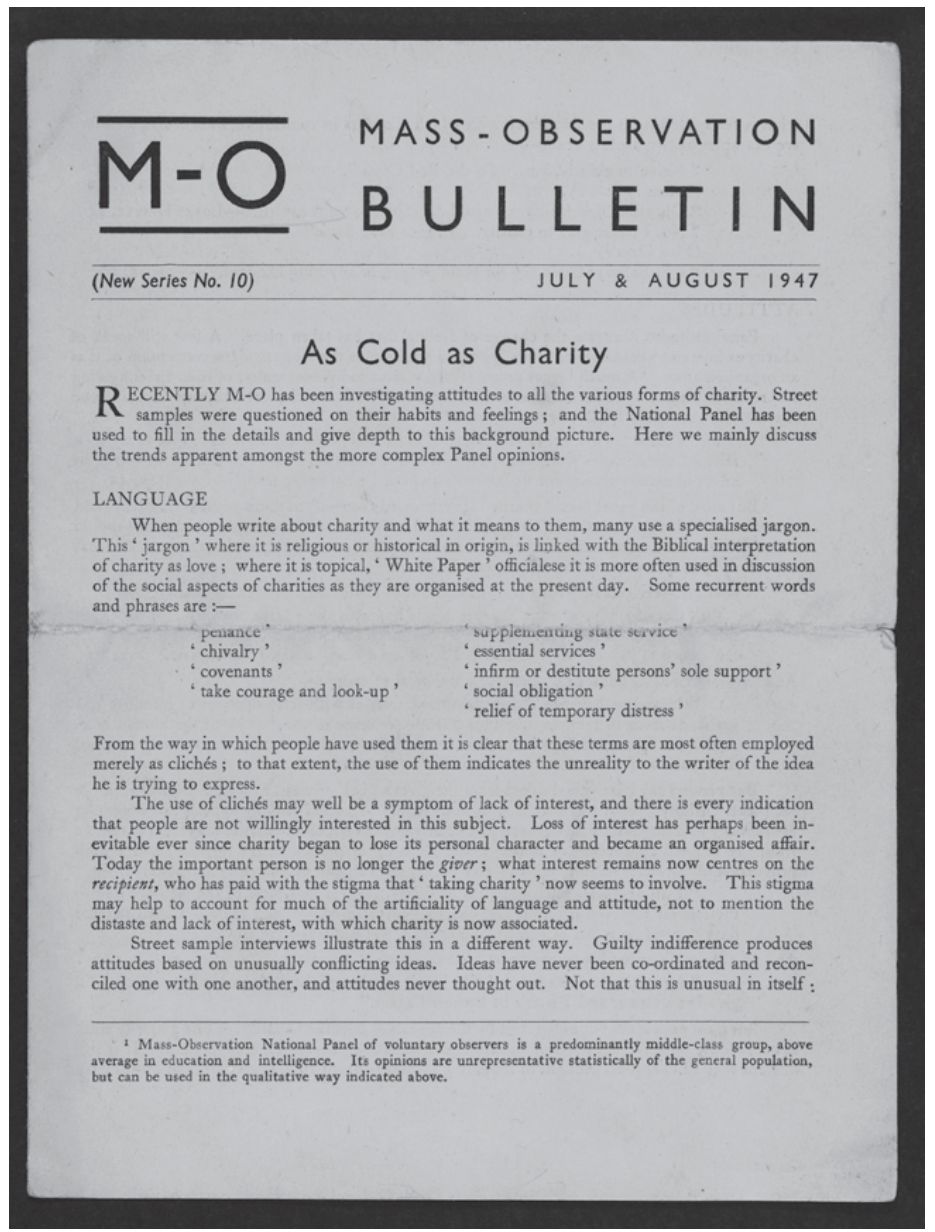

in each of the four fields; and public narratives through the written responses of the general public to MO directives.

This chapter is divided into three parts beginning with a discussion of the approach adopted by the study, followed by 


\section{Figure 2.1: The Discourses of Voluntary Action research at a glance}

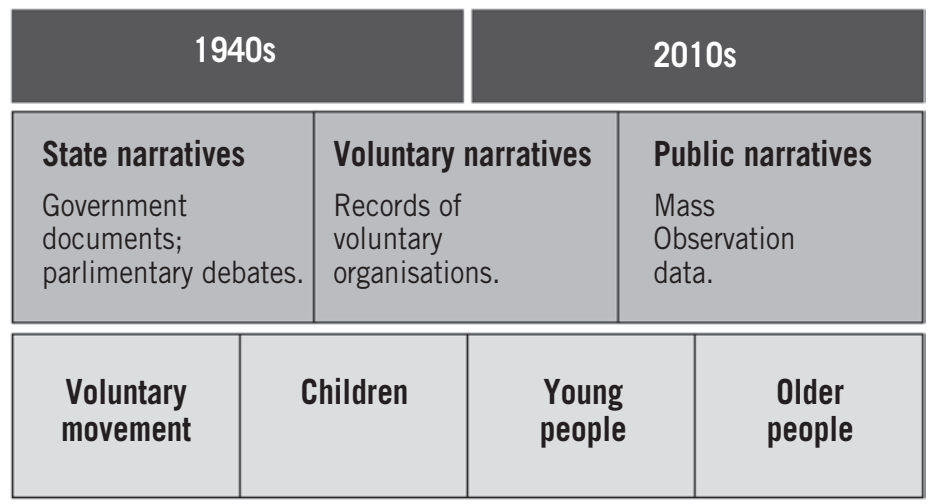

a description of the methods it employed, and ending with a discussion of the conceptual framework that guided the analysis.

\section{Approach}

The research adopted an interdisciplinary approach, which entailed integrating knowledge and methods from different disciplines, synthesising approaches to link the 1940s and the 2010s. For example, methodological approaches from human geography, sociology, social policy and history were integrated to analyse contemporary and historical sources, thereby contributing to an emergent tradition that recognises and promotes the relevance of history to contemporary policy making and practice. The research team brought skills and different substantive understandings to the diverse materials. Social science methods were applied to the collection and analysis of the historical and contemporary data and records; and theoretical approaches from sociology and political science were used to develop a conceptual framework.

The study also adopted a collaborative approach (Hodgkinson et al, 2001; Bannister and Hardill, 2014; Banks et al, 2019), working closely with various stakeholders. We developed 
partnerships with key umbrella voluntary organisations in each of the four key fields of activity, each of which originated in or before the 1940s and were still operational in the 2010s. We collaborated with the National Council of Voluntary Organisations (NCVO), a key organisation for the voluntary movement as a whole, Children England for children's services, the National Council of Voluntary Youth Services (NCVYS) until its closure and afterwards UK Youth for youth services, and Age UK for older people's services. In the 1940s, these organisations were actively involved in shaping the 'social service state' (Beveridge, 1948), and in the 2010s they sought to tackle the social issues that emerged with austerity, responding to and serving an increase in unmet need (see Figure 2.2 for a brief background on each; see also Chapter One). These organisations were not analysed as case studies; and our intention was not to produce organisational histories (most already have a published institutional history, even if some are somewhat out of date: see Brasnett, 1969; Roberts, 1970; Green, 1986; Davis Smith, 2019). Rather, these organisations were treated as research partners, and as windows into the ways in which voluntary sector actors were thinking and talking about the role and contribution of voluntary action in welfare provision across the two time periods. We collaborated with these organisations to access and interpret the documents through which these narratives were constructed and articulated. We also worked in partnership with the Mass Observation Archive (MOA), the organisation responsible for preserving and making accessible the materials gathered through the two different iterations of the MO social research project.

Working collaboratively facilitated the mobilisation of different types of knowledge (Flyvbjerg, 2001), enabled through various knowledge-sharing activities (Bannister and Hardill, 2014). It helped to ensure the quality, validity and impact of the research, and it was realised at all stages 


\section{Figure 2.2: Discourses of Voluntary Action organisational partners}

The National Council for Voluntary Organisations was founded as the National Council for Social Service in 1919. The NCSS played a key role in establishing many high-profile organisations which later became independent charities. It changed its name in 1980 to emphasise the distinction between the voluntary activities of its members and the work of local government social services departments. In the 2020s the NCVO is the largest network for charities and volunteering in England, with over 14,000 members.

The National Council for Voluntary Youth Services was established in

1936 by 11 national voluntary youth organisations as the Standing Conference of National Juvenile Organisations. In the 2010s its network included over 175 national organisations and regional and local networks working with and for young people. It closed in 2016, shortly after the start of this research study, following a series of cuts to its funding.

UK Youth began life in 1911 as the National Organisation of Girls' Clubs, and by the 1940s was known as the National Association of Girls' and Mixed Clubs to reflect its increasing co-educational focus. In 2017 it merged with Ambition, which was founded as the NABC, in 1925. Both the NAGC and NABC were founder members of the NCVYS.
Age UK has its origins in the 1940s through the establishment of the NOPWC, initially formed as part of the NCSS. It gained independence in 1970 when it took on the new name Age Concern. Age UK was created in 2009 following the merger between Age Concern and the 1960s' organisation Help the Aged. In the 2020s its network includes Age Cymru, Age NI, Age Scotland and some 130 local Age UKs throughout England, and Age International.

Children England was established as the Associated Council of Children's Homes (afterwards the National Council of Associated Children's Homes) in November 1941 by four of the largest charities then providing residential care for children in the UK: Dr Barnardo's Homes, the Catholic Child Welfare Council, the Church of England Waifs and Strays Society and the National Children's Home and Orphanage, with others soon joining. It became Children England in 2009 and in the 2020s operates as the leading 'children's specialist' membership body for voluntary and community organisations working with children, young people and families. 


\section{Figure 2.2: Discourses of Voluntary Action organisational partners (continued)}

The Mass Observation Archive was set up in 1970 as a charity with the aim of curating M0 materials (Sheridan et al, 2000). The first iteration of MO had its origins in 1937, with the publication of letters in The New Statesman by its founders, inviting volunteers to be involved in a new mass observation science project (Moran, 2007). The letter proposed an 'anthropology of home' and 'science of ourselves'. It led to the initiation of a variety of projects, including a national panel of self-selecting volunteer writers who contributed written responses to 'directives' - a list of often unrelated questions sent out to writers on a monthly basis. This writing project ran from 1937 to the mid-1950s. The archive of mid 20th-century writing was rediscovered and transported to the University of Sussex in the late 1960s. The second iteration of the Mass Observation Project was launched in 1981. Initially known as the 'Inflation Project', it recruited a national panel of self-selected volunteer writers who agreed to respond to questions or 'directives' sent to them by the MOA three times a year. Since 1983 these directives have been comprised of themed sets of questions on everyday life in Britain. The size and makeup of the panel have fluctuated over the last 40 years; in 2018 there were approximately 400 writers. 
of the study: from design to completion. When preparing the research proposal, for example, the team had numerous conversations with staff at each of the potential partner organisations to build relationships, collectively develop the research questions, and discuss access to the documents. At the start of the study, this collaboration was underpinned by the signing of a memorandum of understanding with each organisation (Brewis, 2022). We met regularly with key staff to identify, locate, contextualise and interpret the materials (Mills, 2013) and to discuss emerging findings and their implications. A steering group was established which brought together the research team, partner organisations and other stakeholders to help guide the research. The steering group actively engaged in all stages of the study, including reviewing documents, assisting with developing frameworks for analysis, and planning dissemination activities. We ran a series of participatory workshops with our partner organisations and with wider stakeholders to discuss emerging findings, their validity and implications; and have shared drafts of all publications with partner organisations for review and comment. Finally, we have continued to work with partners beyond the end of the project to improve the long-term preservation and research access to organisational archives.

\section{Data collection methods}

As already noted, the research was based on the analysis of documents produced by our three sets of actors: the state, voluntary organisations and the public. The same data collection methods were employed across all three narrative voices, although the nature of the documents collected differed in source, format, language and intended audience. Here we focus on how we gained access to and prioritised relevant documents, and the work required to prepare the documents for analysis. 


\section{Accessing relevant documents}

Identifying, accessing and prioritising relevant documents for our three sets of actors was a significant challenge, although the scale of the task and the precise issues faced varied. While we present them here as three separate sets of actors with associated documents, in reality boundaries were blurred. In particular, there was overlap between state and voluntary sector narratives, with, for example, documents reporting on speeches given by state actors located within the records of voluntary organisations, and consultation responses and evidence submissions from voluntary organisations found within the state records.

For public voices we worked closely with the MOA drawing on the MO writers' views of the public on charity produced in the 1940s and 2010s, in response to questions posed in directives (see Figure 2.2). For the 1940s, the responses to three directives sent out in 1947, a year or so ahead of the implementation of major legislation that underpinned the welfare state, were most relevant. The directives which offered the closest fit to the research focus were sent out in April, May and June 1947 and focused on: charity and giving; voluntary work undertaken by the writers and writers' views on voluntary social services; and on the need for new social services. However, water damage had affected responses to the May and June directives, resulting in many poorly preserved, partial scripts, only 41 of which could be used in the study. For this reason, the study concentrated on 142 responses to the April 1947 directive. For the 2010s, we worked with the MOA to commission a new directive, issued in April 2018, on charity and the welfare state. This repeated some of the questions posed in 1947, and produced 118 in-depth written responses. The material from the $1940 \mathrm{~s}$ was accessed in a digital format, through Mass Observation Online. The MOA was able to share some material from the 2010s that had been submitted electronically, the remainder was accessed by physically visiting the MOA at The Keep in Sussex and making copies. Access to and prioritisation of 
relevant documents relating to public narratives of voluntary action was, therefore, relatively straightforward. However, it is important to reflect upon the nature of the voices being heard through this method, the characteristics of participants, and what this means for the limitations of the study (see Figure 2.3 for more detail).

For state voices (a term we use as shorthand to encompass the voices of actors from the UK government in Westminster and the opposition), we identified and collated various official documents, policy papers, research reports, ministerial speeches, press releases, green and white papers and the resulting legislation, parliamentary debates and committee inquiries. Documents from the 1940s were collected through searches of dedicated websites such as legislation.gov.uk and Historic Hansard, and through access to specific records at The National Archives at Kew. Documents relating to the 2010s were accessed through two main sources: first, the gov. uk platform of government websites, where we focused on relevant offices and departments, such as the Office for Civil Society and the Department for Education; and second, parliamentary proceedings and committee inquiries, which we accessed through targeted searches of the UK Parliament website, which provides comprehensive access to proceedings in both the House of Commons and House of Lords (through Hansard) as well as to the work of parliamentary committees. We searched websites using terms such as 'charity', 'voluntary organisation' and 'social enterprise' to identify hundreds of potentially relevant items. Given the accessibility of online information, a far greater volume of material was available from the 2010s compared with the 1940s. All accessed documents were then catalogued and skim read, with the most relevant for the project's concerns about the role, position and contribution of voluntary action being selected for more detailed analysis.

To access voluntary sector voices, we gathered documents, including annual reports, board papers and minutes, communications to local branches or member organisations, 


\section{Figure 2.3: Reflections on Mass Observation directive respondent characteristics}

Mass Observation writing is reflective, subjective, contemporary and retrospective (Sheridan et al 2000; Harrison, 2014; Lindsey, 2020). Responses to directives are shaped by the form in which questions have been posed (Lindsey, 2020) and by the values and backgrounds of writers. Metadata available on writers through the MOA and the Mass Observation database can help provide insights into respondents' ages; regions of domicile; political orientation; occupations; and class identities. There were no available data on ethnicity of writers in the 1940 s or the 2010 s.

Forty per cent of the panel writers in 1947 were women and 60 per cent men. Respondents were located across the UK, although the greatest proportion were from England, and the majority were between the ages of 36 and 45. Many writers were recruited from left-wing publications (Stanley, 1981). In terms of their reported political identities, just 15 per cent of writers responding to the April 1947 directive identified as supporters of the Conservative Party, 15 per cent identified as Liberals, and 61 per cent identified as being left of centre. A range of different professions were represented but a large proportion of writers came from lower middle class origins or had occupations that were typically lower middle class (Stanley, 1981; Hinton, 2013).

The 2010s panel, which was relatively fluid, with writers joining and leaving across each calendar year, was over-represented by women (in 2018, 60 per cent of replies to our directive were from women and 40 per cent were from men, a reversal of the proportions in 1947), and by people in professional occupations (see Lindsey, 2020). Although there was a more even spread in the ages of writers compared to 1947, there were fewer writers under the age of 36 responding in 2018 . Writers in the 2010s came from across the UK, but the greatest proportion were from England. The 2018 directive asked writers which political party best represented their views at the time of writing: 77 per cent responded, revealing a broad range of political allegiances, including Conservative (23 per cent), Labour (29 per cent), Lib Dem (13 per cent), Green ( 8 per cent), SNP (3 per cent) and UKIP (3 per cent). 


\section{Figure 2.4: Accessing the archives of voluntary organisations}

\begin{tabular}{|c|c|}
\hline $\begin{array}{l}\text { The NCVO's archive is deposited } \\
\text { at the London Metropolitan } \\
\text { Archives, although at the time } \\
\text { of writing it only contains } \\
\text { documents up until 1996. We } \\
\text { worked with colleagues at the } \\
\text { NCVO to identify and select } \\
2010 \text { s material directly from the } \\
\text { organisation's current records, } \\
\text { which are stored in-house and } \\
\text { are referred to as the NCVO } \\
\text { private archive in this book. }\end{array}$ & $\begin{array}{l}\text { The NCVYS collection was donated } \\
\text { to UCL Special Collections in } \\
\text { association with this project } \\
\text { and is now publicly accessible. } \\
\text { An additional deposit of digital } \\
\text { documents was made after the initial } \\
\text { cataloguing. The UK Youth archive } \\
\text { is at the University of Birmingham, } \\
\text { within the Cadbury Research Library } \\
\text { Special Collections. More recent } \\
\text { UK Youth documents, including } \\
\text { the entire Ambition archive, are } \\
\text { kept in-house and are referred to in } \\
\text { this book as the UK Youth private } \\
\text { archive. }\end{array}$ \\
\hline $\begin{array}{l}\text { All Children England's documents } \\
\text { were stored in-house. We } \\
\text { acquired surviving archival } \\
\text { material, dating back to the } \\
1940 \text { s, which was deposited } \\
\text { at UCL Special Collections, } \\
\text { and worked with the current } \\
\text { staff team to select 2010s } \\
\text { source material from physical } \\
\text { and online storage systems. } \\
\text { Documents from this collection } \\
\text { are referred to in this book } \\
\text { as coming from the Children } \\
\text { England Archive. }\end{array}$ & $\begin{array}{l}\text { All Age UK's documents were stored } \\
\text { in-house. We acquired surviving } \\
\text { archival material dating back to } \\
\text { the } 1940 \text { s, which was taken on } \\
\text { temporary deposit at UCL Special } \\
\text { Collections for the duration of the } \\
\text { research. Additional material was } \\
\text { accessed at the British Library. We } \\
\text { worked with colleagues at Age UK to } \\
\text { identify and select records relating } \\
\text { to the 2010s. Documents from this } \\
\text { collection are referred to in this book } \\
\text { as coming from the Age UK Archive. }\end{array}$ \\
\hline
\end{tabular}

policy position papers and responses, research reports, consultation responses, press releases and occasional correspondence from the archives of our voluntary sector partner organisations (see Figure 2.4). As far as possible, we sought to gather similar materials for the 1940s and 2010s. The archival records of these organisations, however, varied considerably both in their scope and their preservation. Prior to this project, the NCVO and UK Youth were the only 
organisations to have formally deposited their records in a public archive (see Brewis et al, forthcoming, for a discussion) and neither of these collections contained documents from the 2010s. In addition, the NCVYS archive was donated to UCL upon the closure of the organisation in 2016 just as this study was commencing, with an additional deposit of digital documents made during the study period. All other collections were privately held by the organisations, in various states of consolidation and preservation, and maintained as a mix of paper-based and digital materials. We worked closely with each of the voluntary organisations to identify and access potentially relevant documents. Access to these private collections depended on establishing trust with partners, drawing on the team's strong track record of voluntary action research as well as experience of previous archival 'interventions' (DeLyser, 2014; Brewis et al, forthcoming). Not all the organisations had retained full sets of minutes for the 1940s, and in some cases the physical condition of poorly stored records made access difficult. A further challenge was that several of the bodies were set up originally as umbrella or coordinating committees, rather than independent organisations with their own recordkeeping processes. In order to fill some of the gaps in archival records, additional documents such as printed reports and publications were accessed from the British Library. Records from William Beveridge's 1947-8 Voluntary Social Service Inquiry, which are held as part of the Beveridge Papers at the London School of Economics, were also accessed. For the 2010s, the main issue was the need to work with partners to identify the most relevant sources from among thousands of possible documents, often stored across several online filing systems and accessible through different people. Securing access to potentially sensitive papers such as current board minutes was also problematic, and not possible in all cases. We have used the term 'co-curation' to describe the dynamic and interactive approach adopted with our voluntary organisation partners to 
access, identify, collate, select, prepare and interpret archival materials (Brewis et al, forthcoming).

\section{Data preparation}

Once identified, the documents collected representing the three narrative voices were then collated, further prioritised and prepared for analysis. We began by skim reading and cataloguing each document, with only the most relevant being selected for more detailed analysis. In this way the team reduced potentially tens of thousands of documents to a more realistic set of several hundred for full analysis. Material that was not originally created or already available in digital format was digitised - that is, most of the 1940s sources and some 2010 s material - and scanned with Optical Character Recognition (OCR) software to create readable and searchable word and pdf documents. Some documents, such as handwritten $\mathrm{MO}$ responses, were transcribed.

The sources we selected and analysed - 'our data' - whether published or unpublished are referenced in endnotes in this book, to distinguish these from other literature we reference. We have sought to attribute all source material accurately, but it has not always been possible to assign page numbers, for example, where these were not included in the original document or where OCR software has been used to create new documents. We also illustrate each chapter with one image selected from the archives that we accessed.

\section{Analysis}

Thematic analysis was employed. A common coding frame was developed to guide analysis for all three narrative voices across both time periods. The coding frame was informed by our key research questions, our conceptual framework, discussions with our project partners, and our initial skim reading and sampling of material, thus creating a mix of inductive and 
deductive codes which were developed iteratively across the initial stages of analysis. The same basic coding frame was used for the analysis of the historic and contemporary data. However, additional codes were developed in response to the specifics of each period and each narrative voice. This approach necessitated frequent team meetings and discussions to share analytical findings and guide the next stages of analysis.

Analysis also included a consideration of the different ways in which the authors of the various documents sought to convey a particular set of messages to their intended audience. The focus was on identifying the various narratives that were produced and articulated, exploring how these were constructed, and to whom they were addressed. The integrated analyses of the two time periods, the 1940s and 2010s, identified similarities and differences in the narratives produced by these different sources of data across these two periods, and looked for change and continuity in these narratives over time, while also ensuring that the context and integrity of each dataset was maintained (Moran-Ellis et al, 2006).

\section{Theoretical lenses}

The research design and analysis were underpinned by a conceptual framework drawn from three theoretical approaches which helped inform our understanding of the importance of narratives in signposting and articulating change. First, we drew on social origins theory. This develops the idea of 'civil society regimes' where the non-profit (voluntary) sector is seen as embedded in specific national contexts, with its size and role linked to different welfare regimes - liberal, social democratic, corporatist and statist (Esping-Andersen, 1990; Salamon and Anheier, 1998). Cross-national differences in the non-profit sector are argued, broadly, to be the historic product of the balance of class forces. The UK is considered a liberal regime, with a comparatively large non-profit sector and low welfare spending (Salamon and Anheier, 1998: 228-9); 
but retaining some social democratic regime features, based on 'pro-state attitudes fostered by the government's wartime successes and working class mobilisation' ( $p$ 241). Social origins theory provided a useful starting point for the study, raising questions, for example, about the extent to which the changing balance of class forces can help account for shifting narratives between the 1940s and 2010s. However, it is somewhat reductionist, providing a rather static account of regimes drawn from contemporary data and broad-brush historical reflection (Kendall, 2003). The UK's characterisation as a liberal non-profit regime with social democratic elements is, however, suggestive of the need for a more dynamic and historically sensitive account of voluntary action in relation to the welfare state.

Strategic action field theory offered a second approach which addresses these concerns (Fligstein and McAdam, 2011; 2012). Field theory sees society as a complex array of overlapping fields, with fuzzy and porous boundaries (for example a single organisation, a network, a sector, or an issue- or policy-based configuration of actors). Struggles over the boundary between the state and the voluntary sector - the moving frontier encapsulating the respective roles of voluntary organisations and others in the provision of social welfare services - form one area of contention within a field. Field change occurs through 'unsettlement', both from ordinary internal shifts like competition and innovation, but also from rarer exogenous shocks, such as war, economic crisis and pandemics, each acting 'like a stone thrown in a still pond, sending ripples outward to all proximate fields' (Fligstein and McAdam, 2011: 9). The 1940s and 2010 s could both be considered as periods of 'unsettlement', 'transformational moments' in the welfare state, when roles and expectations have been in flux. Strategic action fields theory therefore lead to questions such as: to what extent, and how, do different narratives about the role of voluntary action in welfare service provision reflect field-shaping discursive interventions and a changing configuration of actors? 
Thirdly, discursive institutionalism helped inform understandings of the importance of narratives in shaping the voluntary sector (Schmidt, 2008). While strategic action field theory tends to highlight issues of power, resources, interests and struggle, it has comparatively less to say about the role of ideas and narratives. At moments of crisis, unsettlement and field change, narratives become important field-shaping interventions, in the ways in which they organise ideas, evidence and argument to make sense of contemporary developments and frame imaginable futures. But Fligstein and McAdam (2011: 7) also refer to the 'social skill' involved in securing the cooperation of others through the persuasive construction of identities and coalitions. In political science, discursive institutionalism draws attention to the ways in which actors are mobilised through discursive frames and thus how change is narrated, with strategic purpose, as seen, for example, in the 'crisis narratives' of the 1978-9 'Winter of Discontent' (Hay, 1996; 2010), and more recently with the competing narratives of the 2008 financial crisis and its aftermath (Gamble, 2009; 2014). Narratives of events and fields are also involved in a struggle for 'room'; as dominant 'common sense' ways of articulating change and providing persuasive and settled visions for the future. In this perspective, therefore, the way in which narratives embody specific worldviews, and the work they seek to do to advance positions in a field, come to the fore.

\section{Summary}

This book adopts an interdisciplinary approach integrating theories, knowledge and methods from different disciplines, using a synthesis of approaches to link the 1940s and the 2010s. The research team worked collaboratively with voluntary organisations that were active in both the 1940s and 2010s and the MOA to examine how different narratives were articulated during these transformational moments. Elsewhere, in Brewis et al (forthcoming), we have suggested that the 
dynamic, interactive and collaborative approach adopted with our voluntary organisation partners should be considered 'co-curation'. Comparison of discussions from the 1940 s and 2010s can enable new understandings of historical and contemporary debates.

How, then, can we understand debates about the place of and room for voluntary action in social welfare during 'transformational moments'? Having described both the overall historical context of the 1940s and the 2010s, and the methodological and theoretical basis for our research in this area, we begin the exploration of the findings in the next chapter with the presentation of two overarching narratives - evident in both time periods - on the role, position and contribution of voluntary action. 


\section{THREE}

\section{Positioning voluntary action in social welfare}

\section{Introduction}

Across both decades, our study identified a range of roles for voluntary action that fit with five hypothetical roles for the non-profit (voluntary) sector internationally identified by Salamon et al (2000): service; innovation; advocacy; expressive and leadership development; community building and democratic society. In the sources for our research, voluntary action was, for example, described variously as: a provider (and funder) of a diverse range of welfare services; a source of experience, expertise and innovation in welfare provision; fulfilling important campaigning, lobbying and advocacy roles; enabling and supporting groups and individuals to express their views and concerns and have a say in decisions affecting them; and as a form of active citizenship, social action and contributor to civil renewal and community cohesion.

Across these many different roles and contributions, we identified two overarching narratives. The first positions voluntary action at the heart of democratic society: it is a fundamental part of who we are as a nation, regardless of whether this is articulated as England, Britain or the UK. The second 
Image 3.1: Covers of Age UK's election manifestos from the 2010 s
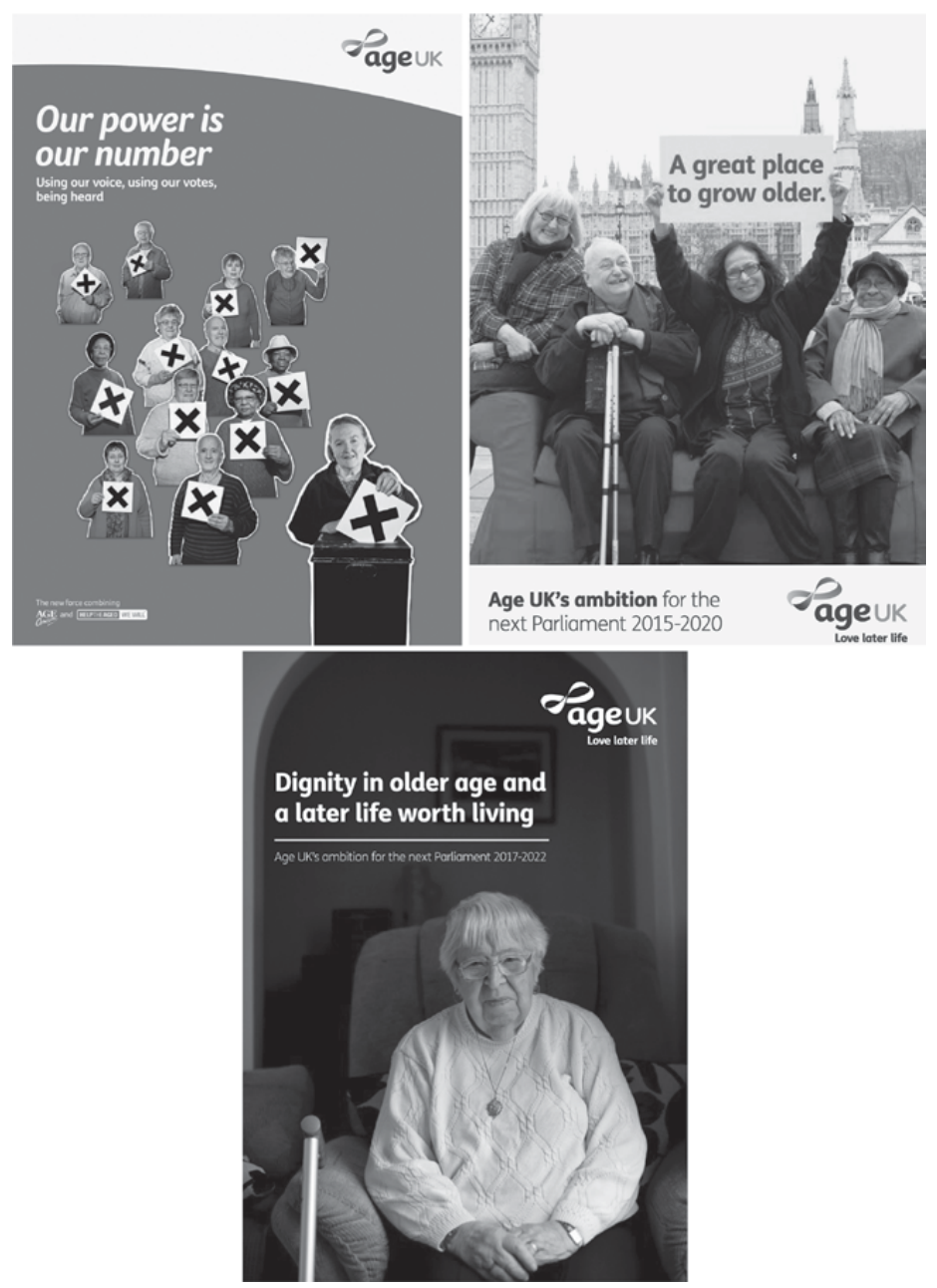

Source: Reproduced courtesy of Age UK. 
positions voluntary organisations as key actors in the provision of welfare: it is part of what we do to meet a diverse range of needs within society. As we detail later, these two broad narratives can be found in both time periods and across all sets of actors. They act as narratives highlighting voluntary action's importance as an essential component of society.

This apparent consensus and continuity, however, masks considerable difference. While there was agreement that voluntary action is both a manifestation of, and an essential contributor to, democratic society, there were significant differences in emphases between and within time periods. There was a broad consensus regarding the role and contribution of voluntary organisations in the provision of welfare services. But a desire, among some, to preserve the position of voluntary organisations as service providers in the 1940s in light of an expanding state was replaced in the 2010s by a concern about the retraction of the state creating an enhanced role for voluntary organisations in service provision.

This chapter discusses these points of consensus and divergence on these two overarching narratives regarding the role and contribution of voluntary action, drawing directly on evidence from across the study. We conclude with the suggestion that claims about the fundamental roles of voluntary action assume greater significance at moments when those very roles are felt to be under threat.

\section{It is part of who we are: voluntary action, democracy and society}

\section{A broad consensus}

There is a broad consensus that voluntary action is a fundamental part of who we are as a democratic society; an idea that cuts across both time periods and holds true between different sets of actors. It is noteworthy that while the focus of this study has been on England, the claims here often refer to a broader notion of imagined Britishness. Voluntary action is conceived as a fundamental element of the British way of 
life, in all its growing and shifting diversity. Voluntary action is both a manifestation of, and an essential contributor to, democracy and/or a 'good' or 'strong' society; it is conceived of as a fundamental right but also a responsibility.

Such narratives were found in state sources across both time periods. In 1947, for example, Attlee spoke of a British 'tradition of voluntary effort' ${ }^{1}$ which went beyond class. In the House of Lords debate on Voluntary Action for Social Progress in 1949, voluntary action was described as 'the very lifeblood of democracy'. ${ }^{2}$ Volunteers were heralded as fundamental to healthy, democratic society, and voluntary organisations as 'schools in the practice of democracy', or as important 'debating ground[s]'. 3

Similar sentiments were repeated by state actors in the 2010 s. In a House of Lords debate in 2010, for example, the role of voluntary organisations was argued to be 'absolutely crucial' in the creation of resilient communities. ${ }^{4}$ A 2017 House of Lords report on charities noted that 'Charities are the eyes, ears and conscience of society ... their work touches almost every facet of British civic life'. ${ }^{5}$ Consensus across the political spectrum on this broad point was suggested by the civil society strategies published by both main political parties in the late 2010s. The ministerial foreword to the (Conservative) government's 2018 Civil Society Strategy, for example, praised the voluntary 'organisations, large and small, which hold our society together', 6 while the opening paragraph of Labour's strategy stated: 'Civil Society is part of the fabric of our nation. It includes community groups, voluntary organisations, faith groups, campaigns, social movements, social enterprise and social action. Without a thriving civil society, democracy can't work' ${ }^{7}$

Similarly, in the 1940s voluntary organisations were keen to promote their work as essential for democratic society, particularly when writing in the context of total war against dictatorships. The annual reports of the NCSS, for example, frequently suggested that the voluntary social services were 
'a manifestation of democracy in action'. 8 They argued that the work of individual voluntary organisations, and voluntary action more broadly, would continue after the war because they were essential for life in a free democracy. Meanwhile, the NCVYS's forerunner argued that 'The aim of Education in the schools is good citizenship; the aim of Education in the Voluntary Organisations is that and more; it is the living of the Good Life'.

Similar concepts were echoed by voluntary organisations in the 2010s. This was seen most notably through references to the role of voluntary organisations in campaigning and advocacy work, as well as their contributions to the creation of a strong, or 'good', society. Voluntary action was depicted as 'essential to a healthy democracy' ${ }^{10}$ and important for ensuring a 'wider range of voices are heard' in public debate. ${ }^{11}$ In 2017, for example, the NCVO argued that 'Charities' role in providing a voice and informing public debate, either by raising awareness or by influencing change, is valued by the British people and makes our democracy one of the strongest in the world'. ${ }^{12}$

Meanwhile, $\mathrm{MO}$ writers discussed the concept of voluntary action and charity as a 'civic responsibility'. The great floods of March 1947 were, for example, used by many as an example of a 'public duty' to help. Although there were few working class writers responding to this directive, one writer from working class origins wrote a polemic on charitable giving, arguing that working class people were more generous and more empathic in their giving to those in need: 'It is very true that the poor help the poor', ${ }^{13}$ reflective of the notion that giving was part of who we are. In the 2010s, writers talked of an 'instinct' to help those in need. Accounts of voluntarism, written in April 2012, demonstrated a wealth of voluntary action, showing volunteering to be part of a civic core in England (Lindsey and Mohan, 2018). Many of those responding to the April 2018 directive saw charity as 'vital', with some also conceptualising it as being part of a British national identity: 'I think charity in the UK has always been one of our strengths as a country'. ${ }^{14}$ 


\section{Challenge versus consensus: differences between groups of actors}

There is broad agreement then, across different sets of actors and time periods, that voluntary action is fundamental to British democracy and society: it is part of who we are. This is a normative discourse: this is what a 'good' or 'strong' society and a 'healthy' democracy looks like. Not everyone, however, agreed: Walter Hannington, founder member of the Communist Party of Great Britain and National Organiser of the National Unemployed Workers' Movement, for example, dismissed the NCSS conceptualisation of a spirit of voluntary service as essential to the good life as having little meaning beyond a 'Mayfair drawing room' (Hannington, 1937: 201). Further, while there was agreement on the overarching narrative, there were important differences in emphases within it between the sets of actors.

Voluntary sector actors, for example, tended to focus on voluntary action being part of democratic process, to which they contributed directly through their policy influence, campaigning, and advocacy activities, and indirectly by acting as conduits for the engagement of their members and beneficiaries. Some voluntary organisations argued that it was a 'unique' role of charities to help amplify the voices of their beneficiaries within decision-making processes. Even within the voluntary sector, however, there were variations, reflecting the different roles and positions of different organisations. Narratives relating to the role and contribution of voluntary organisations to democratic processes appeared more central to those organisations which worked directly with service users, than for bodies whose role was mainly to support other organisations.

Within state narratives, the overarching message was similar, but there was less sense of challenge. The role of voluntary organisations in enabling members of the public - particularly more marginalised individuals and communities - to engage in democratic processes was recognised. ${ }^{15}$ There was less 
recognition, however, of voluntary action's direct role in democratic processes through its campaigning, advocacy and policy functions. Indeed, these roles have at times been directly criticised by some state actors (as discussed later). Overall, state narratives have tended to focus more on voluntary action, particularly in the form of volunteering, as being part of a British way of life, part of a free and strong, or 'Big', society, rather than emphasising its democratic function within society. It has been more about consensus and harmony than challenge. Voluntary action, state narratives have tended to suggest, is altruistic, brings people together, creates bonds, and builds relationships, trust, reciprocity and therefore social capital: it 'symbolises a strong society, it also reinforces a strong society'. ${ }^{16}$ Conservative MP Jacob Rees Mogg (controversially) suggested, in a radio broadcast about the rising use of foodbanks, 'to have charitable support given by people voluntarily to support their fellow citizens, I think is rather uplifting and shows what a good, compassionate country we are' (cited in a Guardian Online article by Walker and Butler, 2017). During a House of Lords debate in 2010, a Conservative peer, Lord Taylor, argued:

\begin{abstract}
Charities and other voluntary and community organisations also play a role in creating bonds and driving social capital among volunteers within the organisations. It is common to hear people talk of charity work strengthening their sense of purpose and well-being, and giving them opportunities for building friendships. The freedom for any of us to set up such organisations - to take action on what we believe is important - should be seen and cherished as a fundamental right. ${ }^{17}$
\end{abstract}

While voluntary action was framed here as a 'fundamental right' (a point also argued by voluntary organisations ${ }^{18}$ ), there was also emphasis within state narratives on voluntary action as a 'responsibility'. These discussions echo wider debates on citizenship, which have, arguably, seen a shift from an emphasis 
in the 1940s on rights to basic welfare and full participation in society, to a more conditional understanding of citizenship in the 2010s, which emphasises that rights come with responsibilities and benefits with behavioural conditionalities (see Marshall, 1950; Dwyer, 2000; 2004). While rights were emphasised in terms of freedoms to establish and take part in voluntary organisation, responsibilities tended to be emphasised in terms of individuals taking part in voluntary action to address needs.

Among the public, voluntary action as part of democratic society was less central to the ways in which MO writers talked about the role and contribution of voluntary action in welfare, with views varying considerably with class and political orientation. Writers tended to focus more on voluntary action being part of a national instinct, as an expression of concern, care, compassion, love, duty and personal responsibility. And for some this was problematic as it was considered to be paternalistic. For others, voluntary action was expressed as a class-based responsibility to the less fortunate (see Chapter Four). The contributions of voluntary action to a specifically democratic society were given less emphasis. That said, as we shall go on to discuss in the next section, in the 2010s there was greater recognition among the public of the role of voluntary action in holding government to account.

\section{Undermined but needed more than ever: changes over time}

While there was a suggestion across both the 1940s and 2010s that strong representation within democratic society was an issue for voluntary organisations at points in time during which (new) needs were being identified or amplified, there were also important differences in emphasis between the two time periods.

In the 1940s concerns were expressed that the expansion of the welfare state might erode the role and position of voluntary action within society; that the place of voluntary action as an 
important part of the British way of life would be undermined as the state took on increasing responsibility for meeting needs. As Fred Messer, MP and Chair of the NOPWC, argued at the organisation's 1947 conference:

In all voluntary work there was a stream of good will which had no other object than to serve the people. There was a desire to make what contribution could be made by the individual to the welfare of others. If we dammed that stream of goodwill we should destroy one of the finest characteristics of this people. ${ }^{19}$

Messer continued, however, that this 'must not be misunderstood as a belief that poverty should continue just for the sake of relieving it'. ${ }^{20}$ This statement hints at tensions between a recognition of the importance of voluntary action as part of a way of life and a suggestion that voluntary action is only warranted as long as needs persist. This tension is apparent in the narratives of different actors, but particularly among those on the left of the political spectrum.

Among voluntary organisations there was a recognition in the 1940s of the importance of joining forces - working together - to represent the views and interests of those whom they supported within the development of welfare policy. The Standing Committee of Voluntary Organisations in Time of War, for example, emphasised the need for greater cooperation to become part of the 'permanent fabric of the voluntary movement'. ${ }^{21}$ Indeed, the NCSS argued that it had a 'special responsibility for promoting partnership between State and voluntary effort'. ${ }^{22}$ In general, the tone was supportive and collaborative, with working together extending not just across different organisations within the voluntary movement, but to government too.

The 2010s were marked by a more combative tone, with greater emphasis placed on the role of voluntary action in holding government to account and challenging its decision 
making. There was much discussion of the role of voluntary action in 'representing', 'defending', 'challenging', 'fighting', 'battling' and 'tackling'; sentiments that were far less evident in the 1940s. This shift resulted in part from heightened concerns in the 2010s about the effects of austerity, the erosion of welfare rights, and the state's abdication of its responsibility for meeting needs (see Chapters Four and Five). In this context, the role of the voluntary sector in challenging the state, upholding people's rights, being the voice for those who are marginalised, and resisting any transfer of responsibilities was amplified.

A narrative emerged within $\mathrm{MO}$ writing of charities as the 'people's voice', in highlighting unmet social need in the context of austerity, and 'challenging government' decisions and 'failures' (see Chapters Four and Five). Voluntary organisations, some suggested, were well positioned for this role, due to their embeddedness within local communities which, ensured they understood the issues: 'Charities are near enough the "people's voice". Because they work in the community they are best placed to access the unheard and unseen and to promote their voice to government. ${ }^{23}$ Indeed, one writer suggested it was 'their duty to lobby government, to tell them what's working and what needs to be in place'. ${ }^{24}$ Such sentiments were far less evident in the 1940s writing.

The underlying suggestion was that the state was failing to meet welfare needs, and voluntary action had a role to play in holding government to account, challenging decisions, and acting as a voice for those in need, and (for some) stepping in to fill the gaps left by a withdrawing state (see Chapter Five). Such sentiments were also clearly presented within voluntary sector narratives. There was, however, a concern among $\mathrm{MO}$ writers about the ability of charities to perform this role if they were over-reliant on government funding - whether they could properly challenge and hold government to account, and whether they should or should not be filling these gaps in provision. The public were not alone in raising questions. 
In 2012 and 2014 the right-wing think tank the Institute of Economic Affairs published two reports (Snowdon, 2012; 2014) which decried the use of public funds by charities to lobby and campaign for government action. With references to public choice theory, it was suggested that government was paying 'sock puppet' charities effectively to lobby for more government, at taxpayers' expense. These reports were cited favourably by ministers on several occasions, and the suggestion that charities should not stray into the realm of politics was reflected in Conservative policy and rhetoric. In January 2014 the 'Lobbying Act' contained measures designed to restrict the possibility that third-party campaigners, including charities, could have undue influence on the outcome of elections. Meanwhile, backbench Conservative MPs became increasingly vocal in their criticisms of charity campaigning. In June 2014, for example, Conservative backbench MP Conor Burns reported Oxfam to the Charity Commission for what he described as its 'overtly political' tweet about the 'perfect storm' of austerity and food poverty. ${ }^{25}$ Then, in September 2014, the Minister for Civil Society, Brooks Newmark, was reported to have said: "The important thing charities should be doing is sticking to their knitting and doing the best they can to promote their agenda, which should be about helping others' ${ }^{26}$ In February 2016 government announced the introduction of anti-advocacy ('gagging') clauses into grant agreements, which restricted the use of public funds for campaigning. ${ }^{27}$ Matt Hancock, as Minister for the Cabinet Office, said in Parliament that 'we are committed to ensuring that taxpayers' money is used for the good causes for which it is intended and not wasted on Government lobbying Government'. ${ }^{28}$

The Lobbying Act, anti-advocacy clauses and associated fears of losing funding should they speak out were met with widespread concern by many within the voluntary sector, which interpreted these changes as overt 'threats' to the role of voluntary action as a fundamental part of democratic society. 
Such threats were then compounded by wider developments. During the 2010s austerity was viewed as having significantly affected the resources available to voluntary organisations some organisations closed (the NCVYS being a case in point), others had less unrestricted income available to draw upon for roles beyond those which they were contracted to deliver thus reducing their capacity to participate. At the same time, spaces for engagement in deliberative forums with government and local councils - such as national-level Strategic Partners Programmes and Local Strategic Partnerships - were closed. There were, voluntary actors argued, fewer opportunities to engage in policy making and broader democratic processes.

Many within the voluntary sector became convinced that successive governments in the 2010s had undermined voluntary action's role in the democratic process - a role defined by the NCVO as giving 'a voice for their beneficiaries and their cause, as key contributors to the public policy discourse'. ${ }^{29}$ At a time when bold claims were being made about the value of the fundamental role for voluntary action, this very role was seen as being threatened. Voluntary organisations suggested that both 'the ability and willingness of the voluntary sector to speak out ${ }^{30}$ had been affected, and that this 'could have a knock-on restrictive impact for individuals' ability to engage politically'. ${ }^{31}$ This was not something, however, that the sector took lightly. As the NCVYS, for example, argued, 'campaigning is embedded in the history of voluntary organisations in the UK, we have no intention of being silenced'. ${ }^{32}$

In summary, while our sources show that voluntary action has been perceived as a fundamental part of who we are over both time periods, this changed during the 2010s and some elements of it appeared to be under threat. Further, this 'threat' to the role of voluntary action in democratic society was explicitly linked to organisations' roles in the delivery of welfare services. We turn now to consider this second overarching narrative: voluntary action is part of what we do to meet needs. 


\section{It is part of what we do: voluntary action, service delivery and meeting need}

This second narrative encompasses the delivery of welfare services but also extends to how society meets a wider set of needs related to spending leisure time meaningfully, engaging in opportunities for learning and development, providing mechanisms to bring people together, and giving outlets to people's desire to help others. A virtuous circle is suggested by these narratives, with voluntary action being part of who we are, and part of what we do as an active expression and embodiment of this, for example charity is perceived as 'an outlet for human kindness'. ${ }^{33}$ Through expressions of voluntary action, skills and confidence can be developed and communities and society are strengthened, reinforcing voluntary action as part of who we are. The government's 2018 Loneliness Strategy, for example, argued that the voluntary sector can 'create strong, integrated communities and challenge obstacles that isolate people or groups. In its delivery of services and projects, it can equip people and communities with the knowledge and skills to recognise loneliness and tackle it'. ${ }^{34}$

In the 1940s there were many references to the voluntary movement being of 'service to the nation', specifically in meeting the unexpected and evolving needs of wartime but also in the reconstruction after the war. Across specific fields - including children's home providers, youth services and older people's welfare - voluntary organisations made repeated assertions about their invaluable contributions to service provision. In part, this reflected widespread concerns that their role might be eroded as state provision increased. More generally, there was recognition that even with a newly expanded role, the state alone could not meet all need - that there would still be a place for voluntary action (and indeed private, individual action). Such sentiments were reflected in the narratives of all sets of actors. There was an emphasis on voluntary organisations as 'supplementing' the greater 
state provision, with voluntary action praised, particularly by political leaders, for 'humanising' services in contrast to supposedly 'impersonal' statutory provision. Voluntary action was talked about in terms of innovating and pioneering finding new ways to meet needs which might later be 'absorbed by statutory bodies [while] voluntary services explore in other directions'. ${ }^{35}$ While the state was constrained, it was suggested, by 'what public opinion will allow' or not being 'prepared to make the mistakes which are inevitable in pioneering work', voluntary action was 'unhampered by these considerations' and so could 'concern itself with any kind of social problem and, upheld by convictions which may be still strange to the mass of citizens, can absorb the shock of setbacks and disappointments'.36

Turning to the 2010s, a dominant narrative - among all sets of actors - was of an expanded role for voluntary organisations in delivering public services. At the start of the decade, the Coalition government was developing the idea of 'open public services', ${ }^{37}$ within which voluntary organisations would play an important part, alongside private sector organisations and individuals and families. A joint letter from the Minister for the Cabinet Office and the Minister for Civil Society in 2010, for example, signalled a desire for an expanded role for voluntary action within a new 'Big Society' by calling for 'voluntary, community and social enterprise sector organisations [to] have a much greater role in running public services' ${ }^{38}$ There was a continued emphasis, among all sets of actors, on the role and contribution of voluntary action in innovation and finding new ways to deliver services, including through providing more personalised or 'relational' (Cottam, 2011) approaches to welfare.

\section{Recognising the limits of voluntary action: concerns about form, quality and quantity}

While the role of voluntary action in meeting need was recognised within this overarching narrative, our sources also 
expressed limits as to what voluntary action could, or should, do. We observed this across both time periods and among all actors, but with noteworthy differences in emphasis.

During the 1940s, concerns were raised about both the capacity and the quality of voluntary services: about voluntary action's ability to meet the growing level of need, equitably, and to do so to a high standard. The reliance on unpaid volunteers was an important feature of these debates. For example, suggesting that many volunteers lacked the knowledge required to deliver welfare services effectively, one $\mathrm{MO}$ writer argued that 'social services such as these are more of a menace than a service'. ${ }^{39}$ At the same time, however, there was also growing concern about the 'growth of the salariat' in voluntary social services. ${ }^{40}$ Evidence submitted to Beveridge's Voluntary Social Service Inquiry also pointed to concerns about money being wasted by the NCSS and other organisations, and descriptions of the voluntary movement as a 'chaotic field'. ${ }^{41}$

The question of capacity was, it was widely agreed, best met through an expanded role of the state. This is in line with the broader theoretical argument that government provision of welfare services is an institutional response to different kinds of voluntary failure (Salamon, 1987 - see Chapter Five). The issues of quality and efficiency were to be addressed, in part at least, through professionalisation, training and a new inspection regime.

Perhaps more fundamentally, however, there was a deeper concern in the 1940s about the very notion of 'charity'. This was expressed most clearly by members of the public. Even among those who were supportive of the role of voluntary action in general, there was a suggestion that charity was all too often paternalistic, 'cold' and unreliable, and should no longer be necessary: 'The accepted meaning of Charity, something given grudgingly by someone in a good position to an unfortunate. This word charity stinks in my nostrils. ${ }^{42}$ Indeed, MO titled its bulletin summarising the research 'As Cold as Charity' (see Image 2.1). ${ }^{43}$ The following passage 
from one $\mathrm{MO}$ writer captured well the tensions within many narratives at the time: 'It is difficult here to separate what one feels about charity from what one thinks. I have a soft spot for "charity" emotionally, but I think it should not be needed \& that the better developed society becomes the less need there will be for charity. ${ }^{44}$

During the 2010s, concerns about both the capacity and quality of voluntary action resurfaced. As one $\mathrm{MO}$ writer argued, 'it is haphazard and should not be relied upon as a total solution to anything,. ${ }^{45}$ During the second half of the decade, questions were increasingly posed about the quality of leadership and governance within the voluntary sector: there was a suggestion of a 'leadership deficit'.

Following the collapse of Kids Company in 2016, for example, the government was quick to defend its own role in funding the organisation over many years, expressing disappointment that the charity had failed to become sustainable (BBC News, 2015). At the time, Kids Company's problems were framed in terms of leadership and governance failures, a position reinforced in reports by the Public Accounts Committee $^{46}$ and the Public Administration and Constitutional Affairs Committee. ${ }^{47}$ The latter concluded that 'the board failed to protect the interests of the charity and its beneficiaries, despite its statutory responsibility to do so'. ${ }^{48}$ A subsequent court ruling has since exonerated the board of trustees from these allegations of mismanagement (Butler, 2021). Similarly, in 2016 the House of Lords select committee inquiry into charities brought concerns about governance to the fore, concluding that there was a need to 'strengthen' leadership and governance as well as to increase regulation of the voluntary sector. While such disquiet was mostly seen in state narratives, similar concerns for 'inconvenient truths' within the voluntary sector, including a 'leadership deficit', were at times echoed. ${ }^{49}$

However, the 2010s also saw another, more fundamental, concern raised which questioned not only the ability of voluntary action to provide welfare services, but the 
appropriateness of it doing so. A dominant message from government (embodied in legislation such as the 2011 Localism Act) was that centralised, top-down approaches to delivering public services were broken and outdated ${ }^{50}$ and that the state should enable communities and individuals to meet their own needs while encouraging voluntary action to play a greater role in providing welfare services (see Hadley and Hatch, 1981 for similar discussions in the 1980s). However, many voluntary sector actors and the general public questioned whether charities should be filling the gap in provision left by a retreating state. These were not practical worries about the limits of voluntary action in terms of quantity or quality, but ideological concerns about social welfare and the appropriate role for voluntary action in welfare provision. Rather than 'supplementing' statutory services, voluntary action was described as 'replacing' them, or often as 'filling gaps' as the state was cut back through welfare reforms and austerity-driven cuts to services, and for many this was problematic (see Chapter Five for a fuller discussion).

\section{In search of distinctiveness: growing contestation}

Relatedly, alongside questions about the limitations of voluntary action, across both time periods we also saw concern about its distinctive contribution, particularly in the delivery of welfare services. It is in the 2010s, however, that these discussions appear to have become more active and contested.

During the 1940s, there was a search for distinctiveness evident in the narratives of all sets of actors. This was generally positively framed: while the state's role was to ensure uniformity and equity in welfare provision, voluntary action had a clear complementary role to play in humanising services, mobilising volunteers and engendering a sense of ownership within statutory services, innovating to develop new ways of meeting need that could then be taken up by the state, and filling gaps 
in areas of need that were either too great for the state to cover alone or which were felt to lie outside its remit. As one MO writer noted, voluntary action 'lavish[ed] tremendous care (and even extravagant care) on the individual where care does not properly fit into the State plan'. ${ }^{51}$

During the 2010s, we noticed a heightened concern to recognise the distinctive contribution of voluntary action to service delivery, but with important differences between our sets of actors. Within state narratives two potentially conflicting positions are evident. On the one hand, there was discussion of voluntary action's distinctiveness in terms of its innovative capacity and potential 'closeness to service users'. ${ }^{2}$ On the other hand, government talked of being 'sector neutral', particularly in debates on the 'open public services' agenda, which suggests a lack of distinctiveness: 'We do not have an ideological presumption that only one sector should run services: high quality services can be provided by the public sector, the voluntary and community sector, or the private sector'. 53

To a limited extent, MO writers in the 2010s echoed the ideas that were so prevalent in the 1940s about the distinctiveness of voluntary action in terms of its ability to innovate. This was set alongside an enduring recognition of the ability of voluntary action to meet 'niche need', of the more personalised approach of voluntary organisations, and of their ability to work with people beyond the reach of the state. As one writer argued, 'Charities are so relevant in our country because they provide the emotional support the welfare state cannot presently give'. ${ }^{54}$ An overarching anxiety, however, among these writers was that distinctions became blurred when voluntary organisations offered services that were provided by the state and that this might lead to growing inequalities in access. As one noted, 'I think that the situation is very confusing and difficult for everyone when there is a variety of organisations giving different services. It causes disparity in the support people get. ${ }^{55}$ 
Some writers believed that charities should not be providing services that they saw as the responsibility of the state, often expressed along the lines of 'Charities should be in addition to not in place of public services'. ${ }^{56}$ Others, however, adopted a more nuanced position, suggesting that the state and voluntary organisations should work together to deliver welfare services, but with each fulfilling different roles. As one writer put it, '[charities] can add value to government-led services by providing specialist input and additional facilities, often using well-motivated and trained volunteers' ${ }^{57}$

Perhaps unsurprisingly, it is in the voluntary sector narratives that we saw the strongest arguments in favour of distinctiveness. These concentrated along several lines, including the unique ability of voluntary organisations to reach marginalised individuals who otherwise would not access services; to intervene early and prevent the escalation of needs; to provide local, trusted, specialist (as opposed to universal), flexible and innovative services; and to provide better-quality and more personalised services by drawing on their expertise, insights and service user involvement. ${ }^{58}$ The desire across the voluntary sector to recognise distinctiveness coincides with the concerns of the general public that voluntary organisations were to be used to fill gaps left by a retreating state: that is as a replacement for the state, rather than as a distinct contributor alongside it. In 2010, for example, Children England argued that 'Too often our work is seen solely as an extension of the hand of the state rather than an upward expression of the needs of local communities'. 59 The dominant narrative across voluntary organisations posited that voluntary action provided a different approach and offered different solutions to the state and other providers (for example family, market - see Chapter Five). Voluntary action was not simply about topping up the state, but doing something distinct from the state. Some voluntary sector actors argued that there should be a shift in emphasis from the role of voluntary action in delivering services to its role in transforming them. ${ }^{60}$ 


\section{Summary}

Across the many different roles and contributions that voluntary action can assume within social welfare, this chapter has identified two overarching narratives. The first positions voluntary action at the heart of British democracy and society: it is a fundamental part of who we are as a nation. The second positions voluntary organisations, and volunteers, as key actors in the provision of welfare services: it is part of what we do to meet needs within society. Within different strategic action fields (see Chapter Two), the strategic purpose of these narratives can be highlighted: they seek to talk up the role of voluntary action as a core element, or even pillar, of society. In both cases the importance of voluntary action is proclaimed, as essential and distinctive. Through this, the room for voluntary action in society, overall, is celebrated, but also promoted in specific fields of social welfare. 'Talking up' becomes a key discursive intervention in struggles around the moving frontier (see Chapter Six).

The apparent consensus and continuity, however, masks considerable difference. While there was agreement among all sets of actors, for example, that voluntary action is both a manifestation of, and an essential contributor to, British democratic society, there are significant differences in emphases between and within time periods. Voluntary sector narratives tended to emphasise the campaigning and advocacy roles of voluntary organisations in holding governments to account and creating a more democratic society, while state narratives tended to focus on the more consensual, 'helping' role of volunteers and voluntary organisations in building a 'bigger' or better society. Within this broad consensus, the desire to preserve the position of voluntary organisations as service providers, observed in sources from the 1940s - even against a backdrop of an expanding state - was replaced in the 2010s by suspicions about an expanded role for voluntary action in the context of a retracting state. Claims about the fundamental 
role of voluntary action in society appeared to assume enhanced significance at moments in time when those very roles were under threat. In the 1940s, the primary threat was to the voluntary movement's service delivery role; in the 2010s the threat was to the voluntary sector's involvement in democratic processes - to its campaigning, advocacy and policy roles. This came when arguably the scale of welfare reform and rising levels of need in the 2010s suggested the sector's campaigning role was needed more than ever (see Eikenberry, 2009 for a related discussion).

Across both time periods there was a suggestion that voluntary organisations have a distinct ability to reach the most marginalised, to advocate on behalf of those most in need, to innovate and to provide a more humanised approach. For some, this was a reason to promote voluntary organisations, for others it was not. Underpinning these differences are important questions of how voluntary action is understood - what is being imagined when different actors talk of voluntary action, charity and voluntary organisations - ideas about the distinctiveness of voluntary action, and whom/what it is being compared to and distinguished from. More deeply, they reflect different ideological positions about the nature of need, as we go on to discuss in Chapter Four, and who should be responsible for meeting it (see Chapter Five). Through these discussions, the narratives themselves can be seen as part of an active struggle to 'make room' for voluntary action (and/or individual voluntary organisations) within contested fields of welfare provision (see Chapter Six). 


\section{FOUR}

\section{Social welfare needs}

\section{Introduction}

Narratives on the role of voluntary action are often wrapped up in, or based upon, fundamental understandings of (unmet) need. These views address the type of welfare needs that should be met, and how they should be met. They are of course shaped by the broader context in which they are embedded. Across both time periods, there were some points of agreement regarding growing levels of need, and parallel discussions of deserving and undeserving welfare recipients. Beyond that, however, there were significant differences between time periods, and among different sets of actors.

This chapter explores how these different narratives around welfare needs were constructed and articulated by the public, by voluntary organisations, and by state actors in both the 1940s and 2010s. It compares views on what welfare needs were, whose needs should be met, and whose responsibility it was to meet these needs. The chapter develops the argument that there was a contrast between the two decades, with the 1940s being a period of consensus and the 2010s being one of polarisation. We conclude with reflections on the implications of this change and contrast for the role of voluntary action. 
Image 4.1: Members of uniformed youth movements helping older people, late 1940 s

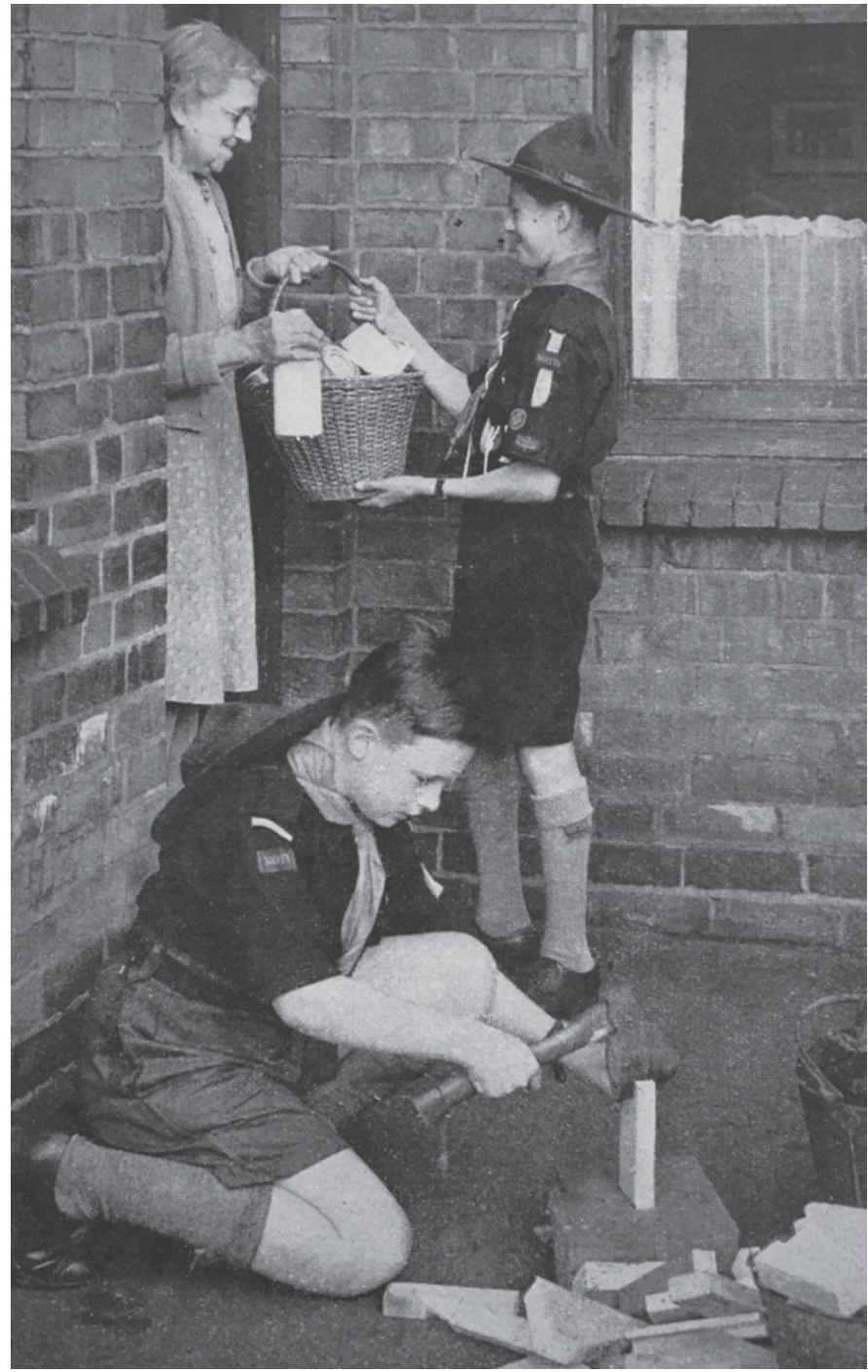

Source: In the Service of the Community, a 1950 publication illustrating the breadth of work undertaken under the aegis of the NCSS. Reproduced courtesy of NCVO. 


\section{New and expanding needs: a point of connection across time}

In both the 1940s and the 2010s and across all three sets of actors, a connecting narrative centred on the emergence of new and newly visible unmet need.

\section{0s: consensus on significance of unmet needs}

The Second World War brought into focus some of the pre-existing social welfare needs of children, young people and older people, which had previously been invisible to, or overlooked by, state agencies, the media and the public (see Chapter One). Beveridge's 1942 report provided a memorable description of national social welfare needs as stemming from five giant evils - want, disease, idleness, ignorance and squalor. The report was well researched - drawing heavily, for example, on Rowntree's work on poverty and paradigms of need - and displayed a comprehensive understanding of social welfare needs. Within this, Beveridge highlighted the needs of older people. Older people's welfare was perhaps the most important of all the problems of social security, but as Beveridge later noted, also the most difficult (Beveridge, 1948: 226). The Beveridge Report, however, was not received without criticism - it ignored well-researched paradigms for meeting need and relieving poverty (Glennerster and Evans, 1994: 61), particularly findings on the relationship between poverty, low wages and high rents (Rowntree, 1941; Lowe, 1994).

The public, polled by MO in 1942 (Jacobs, 1992b), and consulted through MO directives in 1947, appear to have been in broad agreement with Beveridge's assessment. More than 60 per cent of $\mathrm{MO}$ writers expressed their support for Beveridge's recommendations, seeing it as an opportunity to create a better society and as offering a 'renewed faith in democracy' (Jacobs, 1992b: 22). Surviving scripts from the May and June 1947 directives, which specifically asked about social welfare needs and services, suggest that writers had little 
first-hand experience of need or contact with those in need. Moreover, social welfare needs were referenced, implicitly, by many writers from across different political persuasions as being in two groups, needs which were 'relevant to me' (the writer) and needs which were 'relevant to others' (this phenomenon is also noticeable in responses to the 2018 directive). As Mike Savage (2010: 60) has noted, although many $\mathrm{MO}$ writers 'identified with left-wing political causes, ... by contrast their interest and sympathy with ordinary people seems much less marked'.

Voluntary organisations contributed extensively to debates on need during the 1940s. Indeed, there is clear evidence that government turned to the voluntary movement to supply information and insight on specific welfare needs, for example of children or older people. The resulting responses and cooperation arguably contributed to the apparent, broad, consensus in views in this decade. Voluntary organisations' articulations of welfare needs were shaped strongly by their members' particular interests, and blind spots. Before the war, NCSS, for example, concerned itself with the evolving needs of local communities, particularly those affected by social changes such as the creation of new suburban housing estates, the challenges facing rural communities, and the problems of unemployment. In 1938-9, the organisation moved rapidly to coordinate the voluntary movement's war effort in partnership with government.

Youth organisations focused on working class young people aged 14 to 21 who left school to take up part- or full-time employment. Poverty, poor housing and limited education were factors that affected young people's work, and a major concern during wartime was for their employment conditions and the housing situation of those living and working away from home. Through a study of young people in industry that was commissioned by the Ministry of Labour, the NCVYS provided evidence to government which effectively raised the profile of the social welfare needs of young people. ${ }^{1}$ Much 
thinking, however, seemed to be underpinned by an enduring worry about juvenile delinquency. The social upheaval caused by the war also highlighted significant unmet welfare needs among children. Pressure began to build for reform, particularly in residential care for children, prompting the formation of a new umbrella body representing the largest charitable providers of children's homes: the Associated Council of Children's Homes. ${ }^{2}$ The Council chose to celebrate 'the opportunity afforded by the awakened national conscience concerning child-welfare' ${ }^{3}$ However, it also sought to defend members' interests. At a meeting in January 1945, the chair opened with 'a vigorous and balanced vindication of the Residential Children's Home System, and indicated certain advantages it had over foster-home arrangements, e.g. a wider liberty, a more generous upbringing, and generally more stabilised conditions'. ${ }^{4}$

In common with both Beveridge and $\mathrm{MO}$ writers, the voluntary movement also came to recognise that older people were emerging as a key group in need: 'war has created many new trials and anxieties for old people', reflected the NCSS. ${ }^{5}$ Indeed, in October 1940, the NCSS convened a conference of organisations and individuals concerned with the welfare of older people, which led to the formation of the NOPWC with an initial membership of 18 national voluntary organisations and government departments, and a remit 'to study the needs of old people'. 6 The Committee focused its first efforts on the effects of the Blitz and - following requests to help with the evacuation of older people out of London from the Ministry of Health $^{7}$ - an investigation into the conditions and experiences of evacuated older people. From the outset, a key plank of the NOPWC's work was research into the specific, unmet welfare needs of older people. The key areas of need identified included: poor housing conditions and overcrowding; poverty; ill-health and lack of appropriate healthcare for older people; the role of family in providing both help and hindrance to older people; loneliness; lack of meaningful occupation; and 
other social needs of older citizens. As we will illustrate later, it is striking how many of these problems were still relevant 70 years later.

The 1940s, then, saw an emerging consensus among these different sets of actors that unmet welfare needs were significant, and increasingly so, both among the population, and particularly for certain groups, including older people, working class young people, and children deprived of a normal home life. Voluntary organisations were successful in both articulating the needs of their beneficiary groups and providing evidence of these needs to inform state narratives and secure policy responses. This broad agreement triggered responses from central and local government and from established and newly founded voluntary organisations. It led to the development of new welfare legislation by the wartime coalition, followed by a raft of policy and legislative changes brought in by the subsequent post-war Labour government (as discussed in Chapter One).

If the 1940s set the parameters for a comprehensive stateled welfare regime which contributed to increased social mobility, rising levels of affluence, and increased average life expectancy in subsequent decades (Marshall, 1950; Measor and Williamson, 1992; Squires, 1992; Howe, 2008; Savage, 2010), by the 2010s things had changed dramatically. The 2010s became a decade of economic, social and demographic change for England. The average life expectancy for men and women slowed unexpectedly and decreased for women over the age of 85 (Institute of Health Equity, 2017). The United Nations Special Rapporteur Philip Alston, visiting the UK in 2018, noted a growth in poverty: '14 million people, a fifth of the population, live in poverty. Four million of these are more than $50 \%$ below the poverty line, and 1.5 million are destitute, unable to afford basic essentials' (Alston, 2019: 1). By 2012 it was suggested that inequality (in terms of share of income taken by wealthiest) was back to 1940s levels (Dorling, 2019). Like the 1940s, the 2010s witnessed rapid changes linked to 
welfare needs. Unlike the 1940s, however, inequality, poverty and unmet needs continued to rise throughout the decade.

\section{0s: recognition of growing levels of unmet need}

Voluntary sector narratives about need in the 2010s had much in common with those produced in the 1940s. Particularly resonant were the narratives, produced by the NCVO, Age UK, the NCYVS and Children England, that focused on the growth in unmet need for older people, young people and children. Indeed, there are some striking similarities in the issues that these groups focused on in the 2010s compared to the 1940s. They included housing and homelessness; unemployment and precarious employment, particularly for young people (with a growing concern, for example, about the gig economy and that 'a two-tier jobs market is rapidly emerging' ${ }^{8}$ ); social care; health/ill-health; loneliness; and poverty. Cutting across these issues was a broader concern for the growing level of inequality and an awareness that certain groups within the population were experiencing far more rapidly rising levels of unmet need than others.

Children England, the NCVYS and UK Youth, for example, all raised concerns about the growing levels of need being experienced by families, children and young people, particularly within more deprived parts of the country. They campaigned for government to address growing levels of child poverty, ${ }^{9}$ educational inequalities, ${ }^{10}$ youth unemployment and the growing gap in the employment rate between young and older workers, ${ }^{11}$ and issues of homelessness and home ownership. Meanwhile, Age UK campaigned and provided evidence of issues such as pensioner poverty, ${ }^{12}$ inadequate housing, loneliness (which it characterised as 'a scourge of our busy, modern society' ${ }^{13}$ ) and increasingly complex health and social care needs.

While in broad agreement about growing levels of need, state narratives in the 2010 s were dominated by a core 
argument that there were individuals who were economically and socially inactive - in essence, an underclass - who were not participating in British society. This argument was a central tenet of the 'Breakthrough Britain' reports by the Conservative think tank the Centre for Social Justice, which identified 'five pathways to poverty': family breakdown, worklessness, serious personal debt, addiction and educational underachievement, likened to Beveridge's five giant evils. ${ }^{14}$ The key argument employed was that governments had become fixated on income levels and poverty lines without understanding the wider social circumstances experienced by those in poverty, thus locking them out of full citizenship and participation in society. Six months after the election of a Conservative majority government in 2015, David Cameron built on this argument in a speech which signalled the launch of a forthcoming 'Life Chances Strategy' that would 'transform the lives of the poorest'. ${ }^{15}$ Cameron argued that 'It isn't so much the dreadful material poverty that was so widespread in decades gone by - though of course some still exists. Today, it is more often the paucity of opportunity of those left behind that is the greatest problem.' Cameron then spoke of the need to 'break free from all of the old, outdated thinking about poverty' arguing that 'by applying a more sophisticated and deeper understanding of what disadvantage means in Britain today we can transform life chances'. The proposed strategy encompassed a range of themes, including employment, safeguarding children, education, housing, and treatment for substance addiction. The EU referendum in June 2016 interrupted the launch of the strategy but April 2017 saw the publication of Improving Lives: Helping Workless Families, which set the scene for further investment in the 'Troubled Families' programme. ${ }^{16}$ A specific 'Life Chances Fund' was set up to promote Social Impact Bonds, where external investors would provide up-front funding for projects tackling key social problems, with reimbursement by the state if key targets were met. 
The questioning of genuine material poverty was also found in a small number of MO scripts, produced in 2018 by older, more right-wing writers. Most writers were not experiencing material poverty at the time of writing, but some shared childhood memories of poverty. However, some, who identified as being politically oriented towards the centre or the left, framed their discussion of poverty and needs within a narrative of 'rights' and 'dignity': 'Essential needs in the modern world in terms of what welfare needs to enable people to afford would seem to be: food, clean water, sewerage, healthcare, sufficient heating for winter (no 'fuel poverty'), electricity, and (increasingly so) the internet. ${ }^{\prime 17}$

Some writers remarked that, in a time of austerity, the collective definition of what constituted fundamental needs and rights was shrinking to refer to more basic needs of food, shelter and warmth. Many writers expressed the view that the needs of children and young people ought to include opportunities to progress their lives, echoing Cameron's sentiment that people should not be left behind by their experience of poverty. Yet, while there was some agreement on the need to ensure opportunity for those experiencing material poverty, there was no consensus in the 2010s on the nature of that need, or the solutions that might resolve it.

We thus saw narratives focused on the growing levels of unmet need in both timeframes, and concern from voluntary organisations and the public at these unmet needs. Across both decades, voluntary organisations played a central role in articulating the needs of their beneficiaries, and to varying extents the needs of a wider population. Voluntary organisations provided research and expert testimony to demonstrate these needs to state actors, although the extent to which this expertise was heeded differed. Meanwhile, state narratives tended to construct need around core contextual problems such as unemployment, focusing attention on individuals in need rather than its structural causes. This leads us to a consideration of discussions of authenticity of need in the 
two timeframes, and how there were considerable differences in how these narratives were framed.

\section{Deserving and undeserving welfare recipients: an enduring narrative}

An enduring narrative across both periods of time - despite significant legislative, demographic, economic and social change in the meantime - was of deserving and undeserving welfare recipients, related to notions of authentic and inauthentic need. Although judgement was not entirely absent from voluntary sector narratives, such sentiments were particularly prevalent in both public and state narratives.

As Howard Glennerster and Martin Evans (1994) note, Beveridge's report was underpinned by judgemental attitudes about those groups in need who would not be able to contribute to an insurance scheme and would need recourse to means-tested national assistance. Minutes of the first committee meeting evidence the setting up of a sub-committee for those likely to need assistance: 'Cripples, the deformed, deaf and dumb, mentally deficient and vagrants and moral weaklings' (cited in Glennerster and Evans, 1994: 59). This particularly disparaging language by 21 st-century standards (which was also reflected in terminology utilised by some voluntary organisations to describe their beneficiaries at the time) did not make its way into the final report. The Beveridge Report's use of language, its focus on the insurance of working men supporting female homemakers, its juxtaposition of the concept of 'contributions' with the concept of 'assistance' and accompanying conditionality for those not contributing, however, fed into long-standing public discourses of the deserving and undeserving poor. These have existed for hundreds of years. For example, the 1494 Vagabond and Beggars Act, the 1536 Act for Punishment of Sturdy Vagabonds and Beggars, and the 1552 Poor Law all drew on the difference between those who were in need because of personal faults 
(such as being idle or thriftless) and those who were in need through no fault of their own.

Such a distinction can be seen in 1940s MO responses by writers of different political persuasions. For example, one 1940s panellist wrote that he supported a welfare state, but believed that idlers should not receive support: 'A good thing if wisely distributed as a palliative, but we should aim at a social state where the workers get the best \& the idlers the worst conditions and money has no power over lives. ${ }^{18}$ Writing in April 1947 was often sympathetic to those experiencing 'want', with writers from across the political spectrum frequently using descriptors such as 'temporary distress' or experiencing 'misfortune' without blame. This fits with Harris's (2004: 284) observation that 'One of the most important consequences of the war was to demonstrate that people could be placed in poverty through no fault of their own'. Although this writing demonstrated some understanding, and sympathy, these distinctions also served to create a narrative of judgement - that genuine need was a temporary condition caused by unhappy accident. Implicit within this narrative is the existence of another type of less authentic need, which was often long term in nature and likely to have been self-created.

Within these MO responses was an implicit lack of trust in those whose need was very visible, particularly beggars who made personal approaches for charity. Although several writers noted that at the time of writing, in 1947, these solicitations were less numerous than they used to be, personal approaches for help were socially awkward and embarrassing for those approached, and many writers preferred the anonymity of either organised charity or state welfare.

These narratives have clear parallels in the 2010s. Writers from different political viewpoints responding to the $2018 \mathrm{MO}$ directive, for example, echoed earlier notions of 'no fault' and 'temporary distress', while also reproducing stories of deserving and undeserving recipients of state and charitable welfare, 
often utilising the stereotype of large, workless families, living unhealthy lives of abundance, funded by the state. While these stories provided clear examples of those whom writers thought were undeserving, there was ambivalence about people with certain unmet needs, particularly the visible needs of those living on the streets. Concern about homelessness and begging was a leitmotif in responses to the 2018 directive (alongside foodbanks, which we discuss later). Writers were concerned that people who were 'genuinely' homeless should receive help, but the writing of some was comprised of contested and contradictory discourses that mixed blame and distrust with concern, questioning the authenticity of those saying they were in need. As in 1947, there was a concern that people were abusing the system, expecting state welfare as an automatic right. There were also concerns that some people were abusing charitable help:

Currently it [charity] is relevant in some areas today (care of older people, people genuinely homeless through no fault of their own) but too wide ranging, e.g. people have been observed at food-banks whilst smoking and driving up in a car. They can take free food and then visit their local pub! ${ }^{19}$

This cross-political unity in public discourse on distrust may reflect the plethora of 24/7 inflammatory media messages that the UK population has encountered since the advent of the internet (Morrisson, 2019). It may also reflect a lower engagement with party politics compared with the 1940s, which has led to people aligning with certain political parties without necessarily understanding party positions or ideologies (Clarke et al, 2017). This may account for why the views of some $\mathrm{MO}$ writers did not necessarily align with their voting behaviours, and why they held ambivalent and contradictory views on social welfare needs and inequalities. These contradictions fit the findings of Andrew Defty (2016), 
who drew on survey data to examine public opinion on meeting welfare needs. He found consistently high levels of public support for mass public services, most notably health and education (needed by all citizens), but a hardening of attitudes towards welfare benefit recipients, with support for spending on social security benefits in seemingly terminal decline. Similarly, MO participants in 1947 were supportive of services they needed and used, but appeared less supportive or understanding of services for which they did not have a need.

Such views were also reflected in state narratives, which during the 2010s were dominated by the binary talk of 'strivers' versus 'skivers' or 'scroungers'. For example, Conservative Chancellor George Osborne argued, in a speech to the Conservative Party conference in 2012:

Where is the fairness, we ask, for the shift-worker, leaving home in the dark hours of the early morning, who looks up at the closed blinds of their next-door neighbour sleeping off a life on benefits? When we say we're all in this together, we speak for that worker. We speak for all those who want to work hard and get on.... They strive for a better life. We strive to help them. ${ }^{20}$

This narrative was a strong feature of political rhetoric across mainstream political discussions, embodied in, and reinforced by, state welfare legislation and policy, and used alongside terms such as 'welfare dependency' and 'troubled' or 'problem' families. Announcing the government's 'Troubled Families' programme in December 2011, Cameron argued:

I hate the idea that we should just expect to pay ever larger amounts in welfare to an ever larger chunk of society and never expect the recipients to change their lives. Our heart tells us we can't just stand by while people live these lives and cause others so much misery. Our head tells us we can't afford to keep footing the monumental 
bills for social failure. So we have got to take action to turn troubled families around. ${ }^{21}$

The state's rebranding of narratives of idleness as 'worklessness', and squalor and ignorance as 'troubled' or 'workless families'22 were accompanied by the introduction of new punitive modes of social welfare which reflected a hardening of state attitudes towards welfare recipients and spanned the political spectrum. Such narratives also permeated the language and rhetoric of the media, particularly the right-wing press and social media, and the public (as previously discussed) in a rhetorical feedback loop of blame. In the popular and political discourse, families with troubles were recast as 'troublemakers' (Crossley, 2018).

The voice of voluntary sector actors is more muted than others in these debates, particularly in the 2010s. Indeed, to some extent, voluntary organisations sought to rebut the distinction between deserving and undeserving poor. Age UK, for example, argued in 2010 that 'The welfare systems should not stigmatise those who cannot undertake paid work and there needs to be a recognition that people often contribute to society in other ways'. ${ }^{23}$ All the voluntary organisations in this study argued for social justice and defended the rights of marginalised and vulnerable members of society.

\section{Questions of blame: exposing differences across time and between actors}

Closely tied into narratives of deserving and undeserving welfare recipients are questions of blame, although these are rarely explicitly articulated. Here, however, there are significant differences between the 1940s and 2010s, alongside differences between actors. The voice of voluntary sector actors was more evident in wider discussions of who was to blame for rising levels of need, particularly in the 2010s.

Implicit within some of the 1940s narratives was the assignment of blame to individuals in need. Within Beveridge's 
five giants, for example, idleness, ignorance and squalor could all be interpreted as blameworthy descriptors of unnecessary need (want and disease appear more blameless). Moreover, among some actors there was a sense that voluntary organisations were also partially 'to blame' for rising levels of unmet need: it was due to the deficiencies of the voluntary movement that needs were not being met (we return to this point in Chapter Five). More generally, however, what was significant within the 1940s, across all three sets of actors, was the sense of unity created through the collective experience of the Second World War as a significant - external - contributor to need: there was agreement that the war was largely to blame for rising levels of new and unmet need.

Across the 2010s we discerned much stronger and more explicit narratives of blame - a clearer sense that rising unmet need was someone's fault - but, with no common outside force (such as war) to pin the blame on, greater polarisation was evident. The Coalition government blamed the previous Labour administration for its profligacy and mishandling of the financial crisis. It also blamed the unemployed and those dependent on, or judged to be abusing, welfare benefits. The dominant government narrative of austerity in the early to mid-2010s put forward public funding cuts as the only credible response to the financial crisis and subsequent recessions. This drew on rhetoric framed around fairness, responsibility and national unity in sharing the burden of fiscal correction: Osborne's oft-repeated claim that 'we're all in this together', which evoked and echoed the perceived national response to the Second World War.

MO writers blamed combinations of individuals, the government and/or the market, depending on their political orientation. Indeed, narratives of blame - marshalled around a sense of inequality and injustice that permeated discussion of the welfare state - were core themes in the responses of MO writers to the 2018 directive. A key narrative was of a crisis in older people's social care, with criticism aimed at 
the state for promoting market-based approaches and at the commercial sector for failing to adequately meet older people's needs. Many described poor-quality care received from private companies, either under contract with the local authority or by directly accessing private providers. Writers reflected too on the prohibitive cost of care for those who needed it but were not eligible for local authority support and the negative impact on family members who were being forced to provide informal care for relatives.

Another common theme among MO writers in the 2010s was the emergence of food banks, but here there was more of a divide in views along the lines of political affiliation. For more left-wing writers, the growth of foodbanks was blamed on a rise in social need created by the state's austerity measures, its project of punitive welfare reform and its failure to meet material needs. This placed the burden of provision onto organised, individual, charitable giving. These left-wing foodbank narratives were accompanied by concerns that individual giving and the voluntary sector would not be able to, or should not be asked to, meet the growing levels of social welfare needs - or 'philanthropic insufficiency' in Salamon's (1987) terms (see also Chapter Three). While not without empathy for those in need, for more right-wing writers, foodbanks signified the economic difficulties that the country was in, and the unsustainability of expecting the state to provide for those in need. As one rightleaning writer suggested, 'the welfare state does too much for people. It's looked to, by too many people, as a first resort rather than a last resort. They don't just expect to be provided for, but they demand it as they consider it their right. ${ }^{24}$

It is notable that the 2018 directive also saw a generational divide, with younger writers expressing frustration with older people who had been supported by the welfare state throughout their lives continuing to benefit from pensions, winter fuel allowances and, at the time, free television licences. In contrast, some older writers, or those who had elderly parents, wrote about the dashed expectations of the older generation, who 
had worked all their lives, contributed national insurance and income tax, and saved to make their old age comfortable. They had expected the state to provide for them once they reached retirement age and beyond, but were shocked to find that they would have to pay for social care. Writers expressed a form of righteous anger at effectively having to subsidise the care of those who had not been so responsible in preparing for their old age. These arguments are in sharp contrast to responses to the April 1947 directive, which saw general concern - particularly among older writers - about the welfare needs of older people, regardless of class, with no blame attached.

Meanwhile, many within the voluntary sector blamed the government, particularly its austerity politics and its pursuit of market-based approaches. A key role for voluntary organisations during the 2010s (as in the 1940s) was in regularly highlighting the growing levels of unmet need being experienced by the individuals and communities that they were supporting and representing, often associating it with austerity-related cuts to government funding and welfare services and the narrowing of eligibility criteria. Voluntary bodies spoke out about the impact of austerity on their service users or beneficiaries, at the same time as they themselves were experiencing funding cuts and navigating perceived attempts by the government to silence such criticism (see Chapter Three). Throughout the decade, for instance, Age UK drew attention to rising levels of unmet need among older people, fearing that 'years of political neglect' and 'a chronic lack of funding and the failure to reform'25 had left the care system 'crumbling', with the potential to 'permanently consign a fifth of people to poverty in old age'. ${ }^{26}$ This was having a 'devastating impact on those older people who rely on social care to live with dignity and respect'. ${ }^{27}$ Age UK pointed out that funding for older people's social care had declined by 10 per cent in real terms between 2010/11 and 2013/14. ${ }^{28}$ It also raised concerns about cuts to public spending, which were forcing local authorities to redefine their conceptualisation of need and leading many to 'restrict care to those with only the 
highest needs' at the expense of those with moderate needs. ${ }^{29}$ This redefinition meant that cohorts of older people whose needs were deemed insufficiently high to gain local authority help were going without support, or having to look beyond the state to the private sector or to the family for that support (as was evidenced in the narratives and experiences of $\mathrm{MO}$ writers in 2018).

The crises in funding, provision, access to welfare, and unmet need were echoed and repeated in the narratives of other voluntary organisations throughout the decade. Children England, for example, campaigned against child poverty, repeatedly spoke out against rising thresholds and risks of growing postcode lotteries ${ }^{30}$ for accessing welfare services, and raised concerns that cuts threatened hard-won children's rights. The state was largely identified as being to blame through, for example, austerity politics, particularly in terms of cuts to local authority funding, public service reforms, the pursuit of market-based solutions, and associated commissioning processes and practices $^{31}$ (see Chapter Six), and the displacements of risks, needs and duties from one part of the system to another rather than a recognition of interdependencies and unique roles and capacities. ${ }^{32}$ Together these developments were seen to be creating a 'perfect storm', contributing to rising demand and declining funding. ${ }^{33}$ Similarly, the NCVYS campaigned against government policies which impacted negatively on young people, arguing, for example, that funding cuts were disproportionately affecting more deprived areas and already disadvantaged young people, evidenced through rising levels of youth unemployment. ${ }^{34}$

The voluntary organisations taking part in this study and left-leaning $\mathrm{MO}$ writers shared a view that the policies of the Coalition and Conservative governments of the 2010s were largely to blame for rising levels of need. Academic and other commentators also pointed the finger at government's use of austerity measures and public spending cuts (see, for example, Hiam et al, 2018). In his 2018 visit Philip Alston challenged the 
UK government's austerity narrative, arguing that conditions of poverty and unmet need were not being driven by economic circumstances 'but rather a commitment to achieving radical social re-engineering' with 'revolutionary changes' to the welfare system and the overturning of 'the post-war Beveridge social contract' (Alston, 2019: 2). He further noted that leading and respectable voices within the UK, including charities, think tanks, parliamentary committees and the National Audit Office, had drawn attention to the needs of those living in poverty but had been ignored by Conservative administrations.

\section{Questions of responsibility: from collective to individual responses}

Alongside and implicit within these different views of who was to blame for rising levels of need in both decades, different views were also apparent on who was, or who should be, responsible for meeting needs, and at what level. In the 1940s sources we identified a broad and growing agreement that society had a collective responsibility to meet welfare needs albeit with differences of opinion as to who exactly should provide that collective response. In contrast, in the 2010s, views were far more polarised, but with a growing tendency to point towards individual responsibilities.

Beveridge's 1942 report proposed a set of collective solutions for meeting needs. These proposals were framed around a national insurance scheme for working citizens, with contributions from the individual, the employer and the state, that would provide workers and their families with unemployment and sickness benefit, family allowances, free universal health care, and old age pensions without a means test. In combination with national assistance and additional voluntary insurance, these solutions would 'make want under any circumstances unnecessary' (Beveridge, 1942: para 17). Although the report was not endorsed by the wartime Coalition government, Beveridge 'used the media of the time effectively to appeal above the heads of the Government, 
outflanking both the Treasury and the Prime Minister, Winston Churchill, in presenting his vision of the post-war work, and his detailed ideas for building it' (Hills et al, 1994: 1).

The Beveridge Report permeated public consciousness and captured the popular imagination (Jones and Lowe, 2002). By 1947, most MO writers were in favour of the state having increased responsibility for welfare. The report's proposed solution of providing a 'minimum' safety net for those in temporary need, building on ideas going back to the 1909 Minority Report on the Poor Law, may have helped to shape public views on how need should be met. However, questions about what level this safety net should be set at were evident at the time and have reverberated in discussions ever since. An emphasis on a 'minimum' of provision by the state was referenced by several writers responding to the $\mathrm{MO}$ directive on charity in 1947, before the new welfare state legislation was implemented. One writer, who had voted Conservative in recent years, described having been a strong supporter of state-provided welfare, but by 1947 she had revised her views:

I now take a somewhat modified view. A minimum of State service there should be (State service in the long run being help provided by the whole community, and paid for by taxes); no one should be deprived by lack of funds of health services; no one should have to stand begging, cap in hand, because he can't earn his own living. But it should be a minimum, not a maximum. I feel a growing tendency nowadays to take State help for granted, without gratitude, almost contemptuously. ${ }^{35}$

More generally, MO writing from the 1940s provided considerable discussion of who should be responsible for meeting welfare needs, with views expressed often reflecting political allegiances, albeit united around a sense of collective responsibility. Writers who were left-wing supported a stateprovided insurance scheme and felt in theory that all those in 
need should be provided for through public funds regardless of the context of their need. Some felt this very strongly: 'I am entirely for doing away with all promiscuous 'charity': the State must take care of all the needy'. ${ }^{36}$ Left-wing writers tended to argue that addressing need should be the responsibility of the state; but some writers, from across different political persuasions, used other (sometimes interchangeable) terminologies such as 'the country', 'the nation' or 'community'. This distinction seems important in that for some it invoked a notion of both collective and personal responsibility for those in need.

The views of some middle class, right-of-centre writers were underpinned by a paternalistic understanding of need and how it should be addressed. These writers described a sense of middle class responsibility to those less fortunate than themselves, and saw charitable giving as a middle class social norm. Most were of the view that this informal system should be retained but did not acknowledge or discuss the state and charity welfare mix that existed at the time of writing. Among all writers, a burgeoning sense of 'rights-to-come' emerged from their responses. Unlike in the 2010s, MO writers in the 1940s did not discuss the role of the private sector in providing for need.

When it came to implementing the report, however, compromise was needed. Practically, despite the deeply held commitment to extending state social services, the overall economic situation limited what the new Labour government was able to do in office. The 1940s welfare state was therefore 'an austerity product of an age of austerity' (Tomlinson, 1995: 219). As defence spending was cut back, overall public expenditure fell by over 20 per cent in Labour's first five years in office to 1950, while spending on social services increased only moderately from approximately 10 per cent of GDP to 14 per cent (Tomlinson, 1995: 209). Financial constraints led Labour to introduce the new family allowances at a lower rate than desired and even to consider charges for prescriptions and some NHS treatments (Eversley, 2001; Glennerster, 2007). Expenditure on education, for example, did not exceed 
pre-war levels until 1950 (Thane, 2018: 195). Pensions did not provide full subsistence, leaving nearly half a million older people dependent on means-tested benefits in 1948 (p 198). There was to be a continued reliance on voluntary organisations to provide support to the most needy, while commercial provision in various sectors survived.

The state's assumption of greater responsibility for its citizens was welcomed by the voluntary movement, albeit with some hesitancy over what it might mean for the future of voluntary action (see Chapter Five). ${ }^{37}$ For example, Lord Aberdare, Chair of the Council of the NABC, reflected that while the boys club movement might lose 'some of our freedom' as a result of new legislation such as the Education Act 1944, this was a price worth paying to improve young people's lives. ${ }^{38}$ The voluntary movement was keen to stress, however, that its roles in both delivering services and in pioneering solutions to new need would, and should, continue. The NCSS, for instance, called for organisations to identify 'a creative and continuing function post-war'. ${ }^{39}$

By way of contrast, in the 2010s, there was a growing polarisation of views in terms of who should take responsibility. Reinforcing trends since at least the 1980s, there was most notably an intensifying emphasis on individual responsibility for meeting welfare needs. The state, for example, increasingly pushed for individuals and communities to take responsibility for themselves, steering interventions towards voluntary methods for meeting need that seem to echo pre-welfare state approaches. Rebuilding a responsible society became a leitmotif of many speeches and initiatives, especially in the early 'Big Society' years of the Coalition government. As the 2010 general election campaign began, Cameron articulated what would become a broad governing approach:

Big society - that's not just two words. It is a guiding philosophy - a society where the leading force for progress is social responsibility, not state control. It 
includes a whole set of unifying approaches - breaking state monopolies, allowing charities, social enterprises and companies to provide public services, devolving power down to neighbourhoods, making government more accountable. ${ }^{40}$

Six weeks later, outside Downing Street, Cameron's first words as Prime Minister reinforced the ethos of responsibility:

Real change is not what government can do on its own - real change is when everyone pulls together, comes together, works together, where we all exercise our responsibilities to ourselves, to our families, to our communities and to others. And I want to help try and build a more responsible society here in Britain. One where we don't just ask what are my entitlements, but what are my responsibilities. One where we don't ask what am I just owed, but more what can I give. ${ }^{41}$

These principles informed the Coalition's subsequent legislative programme. For example, the 2011 Localism Act sought to place responsibility on communities to provide local voluntary solutions to local problems. This initiative had the potential to change public conceptualisation of how need should be met. While more affluent communities had the capacity to rise to these challenges, the Localism Act ignored the lack of resources and capacity available to distressed or deprived communities to do this for themselves (Lindsey, 2013).

While MO writers were agreed that there needed to be a solution to the rise in unmet need, views on the balance of responsibility between the state, voluntary organisations and the market varied according to political orientation. Views rather than solutions were proffered; and these were often contradictory in nature, counterbalancing what would be best in an ideal world, what writers thought they should say to fit their political orientation, and what was realistic. For example, 
many left-wing writers believed that the state should take far more responsibility for unmet need; the voluntary sector should not have to step in to pick up responsibilities that had been dropped by the state; yet they acquiesced in the state narrative of austerity, and the inevitability of subsequent cuts to public services. Right-wing writers were concerned and sympathetic about inequalities and poverty but were of the view that the state could no longer take responsibility for meeting all these needs; the state could learn from the market and adopt more business-like models; and the voluntary sector should take more responsibility (see Chapter Five).

There was also a tendency evident within $\mathrm{MO}$ writing to believe that individuals should take responsibility for their own situation. For example, while the NHS was viewed by nearly all writers as a cornerstone of the welfare state, a national treasure meeting universal national needs, some MO writers, from across different political orientations, felt that those individuals who had not taken responsibility for their own health (through smoking, substance abuse or obesity) should be denied treatment. These contradictions, about whose needs should be met and by whom, coincide with Defty's (2016) findings on public attitudes towards state welfare.

There was also concern among MO writers that the safety net was being reset at a minimum that was different to that envisaged by Beveridge. This was voiced by a Conservativevoting, yet left-of-centre, writer:

In broad terms the aims of the welfare state are to ensure that the population has its basic needs covered for shelter, food and warmth. I view the Welfare State as a safety net but I am aware that in today's economic climate it de facto necessarily has to provide for some of the essential basic needs of many members of society. ${ }^{42}$

Voluntary organisations shared this concern about a resetting of the safety net. More generally, among the voluntary 
organisations in our study, the underlying emphasis was on state responsibility for meeting welfare needs, and a concern that this was being eroded, but with a recognition that different actors had a role to play. It was suggested, for example, that the state has responsibility for welfare in terms of upholding rights (for example access to welfare), funding, regulation, quality assurance and, for some, market stewardship. It was acknowledged that a diverse mix of other actors, including voluntary organisations, private businesses and individuals, would then have a role in the delivery of welfare services (with some calling for them to do so 'responsibly'). Debates were underpinned by a concern for an erosion of (statutory) rights to welfare, and of the basic safety net, with calls for the state to maintain or uphold its (statutory) responsibility for ensuring that those rights are met, regardless of who is delivering welfare services. There was recognition that there was a lack of agreement on how needs should be assessed and where that safety net should be set, and that the state may struggle to meet its responsibilities in the context of an ageing population. This led to calls for a renewed conversation about rights and responsibilities, including how state welfare should be paid for, and what role everyone should play. The NCVO, for example, argued that 'it is time to talk again about how we work together to make our country stronger, fairer and optimistic about its future', ${ }^{43}$ while Age UK stressed that 'We cannot go on as we are and it is high time we had a proper national conversation about what our growing older population needs and deserves to live well and how we pay for it'. ${ }^{44}$

\section{Summary}

In Chapter Three we focused on how an important narrative of voluntary action is that it is part of how society identifies and meets needs, albeit in different ways. In this chapter we have examined more closely the idea of new and unmet needs in both decades and across all actors. The 1940s and the 2010s are 
united by significant enduring issues: growing levels of unmet need, which include homelessness and inadequate housing, loneliness among older people, and poverty, manifested in the 2010 s by food insecurity; and a wider questioning of who is or is not deserving of support to meet these needs. Beyond these unifying points, however, there are stark differences in attitudes towards need and the appropriate response to it.

In the 1940s, looking across the narratives articulated by the state, the voluntary movement and the public, we identified a broad consensus on the nature of need and collective responsibility for meeting it. State actors on the left argued that responsibility for addressing and meeting the needs of the 'distressed' or 'disadvantaged' was of cross-party concern, utilising discourses aimed to allay the concerns of the right, while also assuaging concerns of the public about the supposedly 'undeserving' poor. Among the general public, there were differences according to political affiliation regarding who should provide services, with some on the left ruling out a role for voluntary organisations, while some on the right placed responsibility on the shoulders of the middle classes through voluntary efforts. Overall, we conclude that the 1940s can be characterised by a convergence of views on the growing levels of need and a consensus that a collective response was necessary to meet need.

In the 2010s, points of agreement are harder to identify within and across state, voluntary sector, and public narratives. Instead more polarised views on the nature of need were apparent, particularly with regard to who was 'to blame' for people being in need, and who should be responsible for meeting their needs. These views tended to be marshalled around political orientation. On the left there was concern at the erosion of welfare state values and public services, and at the widening of differences between those who have and those who do not. On the right we saw a developing rhetoric that challenged the expectations that all needs should be met by the state. We also found evidence of growing differences in 
opinion across generations. In contrast to the 1940s, the 2010 s can be characterised by increasingly divergent views on need and response, by distrust of those in need (and a more general erosion of trust within society), and by a growing emphasis on individual responsibility for addressing need. These were accompanied by contradictory public concerns about visible needs, such as food poverty and homelessness, funding cuts faced by voluntary organisations delivering social welfare, and fears for the future role of the voluntary sector. 


\section{FIVE}

\section{Working together in a mixed economy of welfare}

\section{Introduction}

Chapter Four considered how the role and contribution of voluntary action has been influenced by understandings of need, and who should be responsible for meeting it. This chapter moves the discussion forward to consider the mixed economy of welfare provision, and the role and contribution of voluntary action to this mix. There has long been a mixed economy of welfare, in which the state, the voluntary sector and commercial providers have played a role in meeting welfare needs, alongside informal care provided by family and neighbours. However, what we understand by this welfare mix is never static. Views have shaped, and been shaped, by the nature and quality of ever-shifting relationships between key actors in this mixed economy: boundaries between different actors have, at times, been blurred; dynamic relationships between different providers have waxed and waned; and perceptions of performance and partnership have changed. This has led to fluctuations in the balance of welfare provision at different points in time. 
Image 5.1: NCSS's annual report 1948-9 with a positive vision of opportunity for the voluntary movement

\section{OPPORTUNITY AND \\ INITIATIVE}

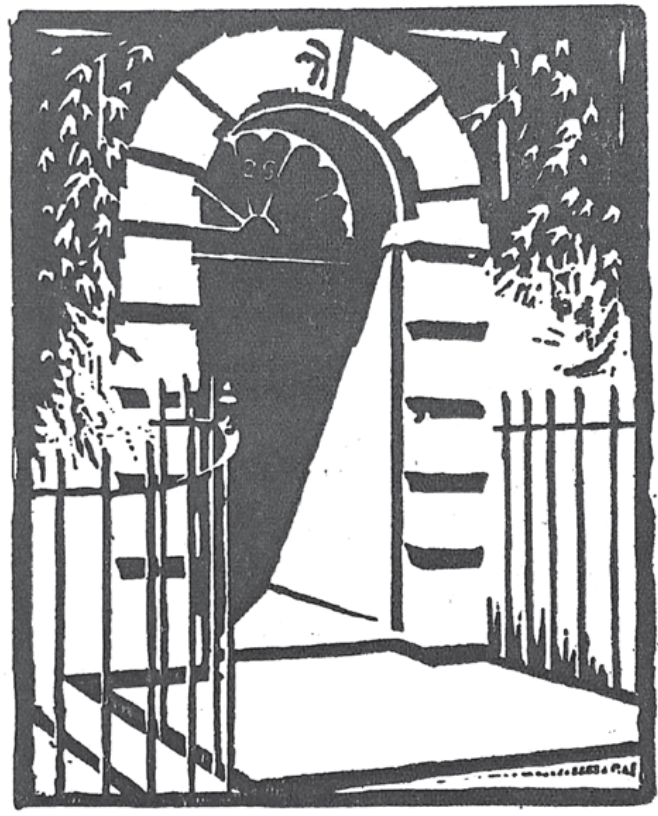

The Annual Report of THE NATIONAL COUNCIL
OF SOCIAL SERVICE
1948.49

Source: Reproduced courtesy of NCVO. 
The core argument made in this chapter is that voluntary action is nearly always positioned in relation to others. In contested fields of social welfare, the room for voluntary action is always a dynamic and relative outcome of contrasts and comparisons with other 'sectors'. While questions about the role and performance of charity have informed discussions about state welfare provision, so too have concerns about the role, performance and relationships with the state-underpinned narratives about voluntary action. Here we look beyond the state-voluntary nexus, however, to consider the relationship of voluntary action with individual citizens as well as the market. We argue that while similar sets of questions were being asked in the 1940s and the 2010s about the mixed economy of welfare, fundamentally different conclusions were reached.

\section{The 1940s: a pragmatic partnership to overcome multiple failures}

In the 1940s the expansion of state-provided services across many areas of social welfare was often contrasted with earlier policy failures. While welcomed at the time by the voluntary movement, in retrospect, government was perceived as having abdicated its responsibilities for welfare during the 1930s Depression through over-reliance on voluntary-run social service schemes (Harris, 1995; Davis Smith, 2019). Others argued that the market had failed. The dominance of commercial providers of insurance operating as 'Approved Societies' under the 1911 National Insurance Act was considered to have failed to provide for all workers (Finlayson, 1990). From the 1920s, reports condemned this association of 'medical care and private profit' and urged its replacement with a comprehensive state system (Finlayson, 1990: 197). There were, moreover, concerns about the sometimes 'deplorable' and 'shocking' quality of residential homes for older people run as businesses (Beveridge, 1948: 229). The market was failing to provide adequate care, as Beveridge noted, for 'money will not build them even a tolerable existence'. 
State expansion emerged, however, from a more immediate recognition of the voluntary movement's fundamental inability to cope with the growing scale of need (Simey, 1937): what Salamon (1987) would later identify, in more general terms, as philanthropic insufficiency. Indeed, for some on the left, the voluntarist solutions to the problems of the Depression were anathema. Jarrow MP Ellen Wilkinson (1939: 232) dismissed the social service movement as failing to launch a 'frontal attack on the problem', noting unemployed men 'do not want charity. They want jobs.' Wal Hannington, organiser of the National Unemployed Workers Movement, suggested that many working class organisations recognised the various social service schemes to be mere 'side-tracking' and 'evasion' (Hannington, 1937: 201). Some left-wing MO writers railed against voluntary solutions to welfare needs, arguing instead for the root causes of poverty to be tackled. The idea that the voluntary movement's contribution was likely to be hampered by lack of financial and human resources, poor management, and often paternalistic attitudes to those in need was also shared by many. ${ }^{1}$ Finlayson (1990: 188) summed up these arguments, reporting a widespread recognition by the 1940 s that voluntarism 'could not' deal with the overall volume of need and that it 'should not' have to cope with this need.

The expanded role of the state in welfare services during the 1940s, then, was set against arguments of voluntary failure in the 1930s, but also against longer-term critiques of the historic failure of all actors to fully meet the growing, unmet needs of all citizens (see Chapter Four).

\section{Pragmatic compromise and a strengthening of partnership}

In the context of rising needs and recognition of multiple historic failures in welfare delivery, there was a broad consensus on an increased role for the state in the 1940s (see Chapter Four). The election of a Labour government signalled strongly that there could be no going back to the 1930s, but the prevailing 
conditions of austerity determined the state's response. There emerged a widespread acknowledgement - among all our sets of actors - that even with an expanded role the state would not be able to meet all needs, and that there would inevitably be an ongoing role for voluntary action within welfare provision. Moreover, a continuing role for the commercial sector was also sanctioned. A sense of pragmatic compromise across political divides prevailed. As one MO writer argued:

Certain aspects of life must be dealt with by private as opposed to State initiative, but I feel that want of the physical means to live a reasonable existence is a State responsibility. In the application of State 'Charity', however, the greatest possible scope for private initiative should be given, I mean that the granting of state charity by Officials is on the whole a bad thing because it must of necessity be regulated by Rules and Instructions. The provision of a reasonably wide discretion by voluntary bodies is the solution to bureaucracy. Anyhow it's cheaper, because people who give generously of their time are as charitable as those who give of their money. ${ }^{2}$

In the 1940s the voluntary movement was largely supportive of the state taking greater responsibility for social welfare. Indeed, this shift was achieved in part by working in partnership with voluntary organisations. Many of the new government welfare services developed in the early part of the war - such as the evacuation programme, the Youth Service, services for older people, communal feeding - required the cooperation of voluntary organisations. ${ }^{3}$ In this way relationships were built between voluntary organisations and a wider range of government departments than had been the case pre-war, including the Board of Education, the Ministry of Health, the Ministry of Labour, the Assistance Board and the Ministry of Food. Voluntary organisations argued that they were essential to the war effort - 'at the very heart of the Battle for Britain'4 
and a 'vital sector of the war front'. ${ }^{5}$ Wartime cooperation had brought greater awareness by official bodies 'of the cardinal importance' of voluntary organisations' work. ${ }^{6}$ In 1945 the NCSS praised the Labour government's willingness to engage with the voluntary movement and identified a 'quite remarkable agreement' across all political parties about the value of the movement's contribution. ${ }^{7}$

This is not, however, to ignore the 'widespread apprehension' on the part of the voluntary movement about the future of voluntary action, not least due to the scepticism with which some left-wing politicians had approached the social service movement in the 1930s. ${ }^{8}$ Wartime confidence gave way to post-war defensiveness as voluntary organisations recognised the profound effect that the new legislation would have on their work. At its 1946 AGM, the President of the NCSS stated hopefully that 'the day of voluntary organisations was not over'. ${ }^{9}$ Likewise the Chair of the Council of Associated Children's Homes 'envisaged a time when it might be necessary to fight for [the] independence' of voluntary children's homes. ${ }^{10}$

Voluntary organisations adopted a range of approaches aimed at justifying their continued existence, most of which were oriented around their contributions in relation to the state. In this we see discursive framings which tread a fine line in accepting and acknowledging the state's new role, but not in a zero-sum fashion where the room for voluntary action in various social welfare fields was diminished or even curtailed. This appears to have involved a defensive and pragmatic strategy of working together with the state. Voluntary organisations continued to urge the concept of partnership as the only practical way to address the high levels of need likely to continue after the war. At a gathering convened for representatives of leading voluntary organisations to meet Beveridge at the start of his inquiry into voluntary action, consideration of partnership was the 'most fundamental question' discussed. ${ }^{11}$

The notion of partnership was endorsed by the press and framed positively by central and local government. Ministers 
in both the wartime coalition and subsequent Labour administration trod a difficult line in justifying the extension of state provision while also assuring voluntary leaders of their commitment to partnership. During the second reading of the Education Bill in January 1944, for example, Education Minister R.A.B. Butler noted 'voluntary agencies which are rather apprehensive on these occasions should realise that we desire to have their full co-operation under the new scheme'. ${ }^{12}$ Later Board/Ministry of Education reports repeatedly hailed the Youth Service as an example of successful partnership between government, local education authorities and voluntary organisations. ${ }^{13}$ Similarly, Assistance Board reports were peppered with references to the helpful and fruitful cooperation between the Board, local authorities and voluntary agencies and voluntary workers, in general, and the new local Old People's Welfare Committees in particular. ${ }^{14}$

In debates on the various social welfare bills in the mid-1940s, parliamentarians in both houses repeatedly raised concerns about the future role of voluntary organisations. In part this concern reflected the fact that many MPs and Lords were themselves integrated with the voluntary movement as charity patrons or board members. Fred Messer MP, who had succeeded Eleanor Rathbone as Chair of the NOPWC after her death in 1946, is an interesting example here. In one debate he noted:

I occupy a peculiar position in that I am Chairman of the North-West Regional Hospital Board, and I am also Chairman of the National Old People's Welfare Committee. That sometimes places me in a very difficult position, because with all the desire that I have to improve the hospital service, I think it would be wrong if any steps were taken to improve that service at the expense of any unfortunate section of the community. ${ }^{15}$

Government ministers sought to reassure members of both houses that the proposed legislation took account of these 
concerns. Speaking for the government, the Postmaster General, Lord Listowel, noted that the NHS was 'a typically British scheme in its effort to incorporate in the new structure all the serviceable elements of proved usefulness in the old, including, above all, the voluntary spirit and the voluntary effort'. ${ }^{16}$ The June 1949 House of Lords debate on Voluntary Action marked an important moment for voluntary organisations because it generated a reassuring statement of support for the voluntary movement from the Labour government, delivered by Lord Pakenham. ${ }^{17} \mathrm{He}$ noted voluntary organisations must be allowed to continue to 'render great and indispensable service to the community'. ${ }^{18}$ The Times newspaper weighed in, noting that while there were fields in which voluntary action was preferable to state provision, there were "many more where cooperation between public and voluntary organisations is better than exclusive action by either' (Times, 1947).

\section{Negotiating roles in an evolving mixed economy of welfare}

There was agreement that people who found themselves in need after welfare legislation had been implemented would require a welfare mix of state support and charitable help. One MO writer summed this up by arguing that voluntary action 'fills some important gaps in state planning. I do not see how we could do without it, anyway at present, \& in any case it seems necessary to supplement state service which cannot legislate for every individual case. ${ }^{19}$ There was less consensus about exactly what roles both the state and voluntary action should play, and where the boundaries between their respective responsibilities should lie: 'It is a little difficult to know where to draw the line', ${ }^{20}$ as one writer put it. Several lines of argument developed.

The state's role in England evolved to involve the provision of a core minimum of social welfare services that included health and medical care, primary and secondary education, and national insurance to cover pensions and unemployment. The state, via 
local authorities, also took on responsibility for funding auxiliary welfare services, such as home help or meals-on-wheels services, which it did not have the immediate capacity or political will to deliver; and for providing premises or making building grants to enable services delivered by voluntary providers (such as lunch clubs and youth work). The state also took on an enhanced role in the inspection and monitoring of welfare services by all providers - statutory, voluntary or commercial - although even these functions could also be devolved to responsible bodies. Speaking at the NOPWC's conference in November 1947, Minister of Health Aneurin Bevan 'was loudly applauded' for promising that the state would in future inspect privately run homes for older people and for drawing a parallel between the need for state oversight of looked-after children, made in the Curtis Report, and older people. ${ }^{21}$

Bevan further declared that through the new social welfare legislation the 'Nation was accepting responsibility where no responsibility existed'. ${ }^{22}$ Specifically, he added, 'the care of the old was not a family or individual problem but a social problem'. ${ }^{23}$ However, since not all aspects of the National Assistance Act could be implemented right away, voluntary organisations would be needed to provide auxiliary services at local level for years to come. ${ }^{24}$ Across many fields of welfare, then, voluntary organisations and volunteers continued to deliver services, while pioneering new solutions for emerging and unmet need.

Indeed, voluntary organisations were widely held to have paved the way for state services to follow, and their continued role in innovation was deemed an important counterpoint to perceived state inflexibility (see Chapter Three). The voluntary movement's experience of developing innovative solutions to meet newly revealed need was considered invaluable and this role as pioneer was widely accepted by official bodies. Lord Rushcliffe, appointed by the government to chair its wartime Voluntary Service Advisory Committee, identified the voluntary movement as representing a 'pioneering spirit' ${ }^{25}$ In 
parliamentary debates on the Bill that became the Children Act 1948, voluntary children's homes were praised as 'pioneers', and there was no suggestion that their role in delivering existing services or developing new ones should be reduced, but rather they should be supported with additional funding and greater government oversight. ${ }^{26}$ Discussion of older people's welfare in the 1940s repeatedly pointed to the 'pioneer' work of the NOPWC. ${ }^{27}$ However, there was recognition that voluntary organisations alone 'could not have provided all that was ultimately necessary' and that transferring some of the burden to the state though the National Assistance Bill had become necessary (see Chapter Six). ${ }^{28}$

This was a view understood by the public as well. For example, MO writers discussed the role that voluntary hospitals had played in laying the groundwork for the new National Health Service; though most writers felt that the provision and financing of healthcare should now be met by the state:

So many valuable aspects of our national life (hospitals) themselves were tried out first as private charity \& proved themselves. But now there is no doubt that adequate hospital accommodation ought to be provided out of national funds ... I don't answer hospital appeals as I once did because even before this new Bill I felt strongly that an adequate health service should be a national change $\&$ become an individual's right. ${ }^{29}$

Additionally, for some writers, while reliance on charity for core costs was no longer appropriate for services such as healthcare, charitable giving might continue to supplement state provision: charity could provide extras that the state could not afford to provide. Parallels can be seen with the concept (but not the terminology) of charity as an 'extension ladder' (Webb and Webb, 1911).

MO writers also suggested that charities had local knowledge and so were best placed to identify and meet local need not met 
by the state; charities could fill gaps in certain fields which were not mainstream enough to warrant state provision. Further, some writers envisaged certain scenarios, such as disasters, where there would be a need for both charity and the state to provide, financially and in other ways, for those in need. Writers listed examples where there had been both state aid and charitable giving from the public in response to urgent national need, such as the 1947 floods:

Emergencies - I thoroughly approved of the flood relief appeals recently $\&$ we sent money $\&$ a blanket. The big national disaster can only of course be met out of national taxes \& I would have felt differently if the Govt had left the matter to private charity (I am not too convinced that they are doing enough). But for those lucky enough to escape the floods to do something direct \& personal for other members of the community who had been hit, seemed only decent, also a sort of thank you offering. ${ }^{30}$

Beyond these varied roles in welfare provision, the voluntary movement sought to retain a role also in the creation of welfare policy and wider democratic processes (see Chapter Three). There was a desire for greater consultation and communication with voluntary providers about new ideas and proposed changes in specific fields of welfare. Voluntary organisations sought, and in many cases received, a seat at the decision-making table at local and national levels.

\section{Support for a welfare mix that enabled choice and competition}

Our sources were dominated by discussions of state and voluntary action in welfare provision, yet in the 1940s the mixed economy of welfare continued to involve other actors. Means and Smith (1998: 228) describe a post-war consensus that 'the family' retained primary responsibility for frail and sick older people; mostly female relatives provided an 'enormous 
amount of domestic and nursing care which far outstripped anything provided by the state or voluntary organisations'. The concern that the new 'social service state' should not sap individual effort was held by many in the government as well as in the voluntary movement: "the more the state does, the greater should be the spontaneous response from the citizen through his own organisations', suggested one NCSS report. ${ }^{31}$ This was reflected in MO writers' opinions:

[I]t would be psychologically unsound for the community to get into the attitude that everything should be done by the State. Voluntary effort to supplement essential State assistance, is, I think, most useful in promoting local initiatives and helping to provide humanitarian objectives with which the more fortunate members of the community can identify themselves. ${ }^{32}$

Nonetheless, central to the pragmatic partnership of the 1940s was the mutual recognition that the statutory sector and the voluntary movement each needed the other, and that they shared common interests against some commercial providers, and in some cases, even the family. A concern of the providers of residential children's homes in the 1940s, for example, was that the new family allowances might provide an incentive for abusive or neglectful families to retain or reclaim their children from residential care. Similarly, some of those involved in work with older people were suspicious of much family care, identifying considerable 'strain' that resulted from older people being forced to lodge with younger family members. ${ }^{33}$ The long tradition of delivering welfare services in England meant that the voluntary movement often presented itself as part of the fabric of the state. So woven in was it, that removing such provision would be difficult. Indeed, painful compromise was often needed.

Concepts that help explain how the voluntary movement was positioned in relation to other providers are those of choice and competition (we see similar themes in the 2010s, although with 
different meanings). The goal of individual choice was built into the 1940s welfare state, albeit driven more by necessity than ideology. While expansion of state old age pensions through national insurance was a key plank of the Beveridge plan, for example, it was recognised that a range of occupational pension schemes would continue. This included local and national government superannuation schemes for civil servants and teachers, as well as pension schemes run by some private firms. ${ }^{34}$ Individuals were also free to pay privately for medical or hospital care, to pay fees to educate their children, and to insure their lives through commercial schemes. For-profit residential and nursing homes were considered important for those with small private incomes, although it was recognised they would remain 'beyond the reach of many'. ${ }^{35}$ Improving choice for older people in the 1940s was seen to lie in the future expansion of local authority-provided and voluntary-run homes. ${ }^{36}$

Meanwhile, competition was, for example, built into the provision of residential care for children. Grier (2001: 239) notes that the concept of 'friendly rivalry' was used by the Curtis Commission to describe the future relationship between voluntary-run and statutory homes; the possible role of forprofit providers, which was so central to later debates, was not envisaged. The voluntary youth sector faced competition from both commercially provided leisure activities such as dance halls and cinemas, and from possible encroachment onto their territory by the state. The hundreds of thousands of young people who were members of youth clubs or uniformed associations were contrasted against the millions who went to the cinema each week (Beveridge, 1948: 139). While voluntary youth services were conceived as integral to the new Youth Service initiated by the Board of Education in 1939, the NCYVS repeatedly complained about the lack of recognition given to voluntary organisations. In its response to the Education Act 1944, members of the NCVYS protested against 'any tendency to regard the [voluntary] organisations as taking a subordinate place'. ${ }^{37}$ The document reflected that 
people might think 'that the days of the Voluntary Youth Organisations are numbered' but noted that there was value in 'variety and competition' in youth work. ${ }^{38}$

\section{A resultant pragmatic partnership and subsequent evolution}

In summary, welfare services expanded during the 1940s as part of a pragmatic partnership between the state and the voluntary movement which built on perceived failures on both sides in the 1930s and a realisation that even with an expanded role for the state, the rising scale of need necessitated joint working. This was a pragmatic partnership which recognised and allowed for the contribution of voluntary action to democratic processes, including policy development, and the delivery of welfare services (see Chapter Three). In the 1930s the NCSS had celebrated an 'increasingly close partnership' with local and national government 'for common solution' to a wide range of social problems. ${ }^{39}$ This partnership was cemented in the 1940s. Rather than resulting in the demise of voluntary action, the expansion of the welfare state contributed to a search for new and ongoing roles for voluntary action, and realisation that it would always be needed to work hand in hand with the state, and others. Concerted lobbying by voluntary bodies resulted in the adoption of amendments to legislation - including the Education Act 1944, the Children Act 1948 and the National Assistance Act 1948 - which made explicit provision for collaboration and partnership between the state and voluntary action (see Chapter Six). ${ }^{40}$

The mixed economy of welfare in England was to evolve over subsequent decades. Statutory services expanded across all the fields of social welfare under consideration, albeit alongside a continued reliance on unpaid family care that was rarely formally acknowledged. In children's services, local authorities preferred to provide their own residential children's homes and there was a shift to foster care and other forms of family support. The voluntary sector retained a significant role 
in child welfare work as individual children's home providers began to diversify their services, and in 1965 the Associated Council changed its name to the National Council of Voluntary Child Care Organisations to reflect this wider remit. The Youth Service continued to rely on voluntary organisations and volunteer leaders, although the 1960 Albemarle Report triggered an increase in state spending on youth work. In older people's services, local authority provision expanded to provide 69 per cent of residential care by the 1970s. The National Assistance Act was amended in 1962 so that local authorities could directly provide services such as meals on wheels (Means and Smith, 1998: 259). Subsequent reforms, particularly the NHS and Community Care Act 1990, involved a shift back away from state provision. Local authorities began to outsource provision of services to the voluntary sector and increasingly to the private sector. In 2014, for example, the private sector provided 64 per cent of places in residential children's homes (and ran 73 per cent of homes), local authorities accounted for 28 per cent of places and the voluntary sector provided just 6 per cent of places (Department for Education, 2014: 31). By the mid-1990s 'independent agencies', including small businesses and larger providers, accounted for 76 per cent of provision of older people's residential care (May and Brunsdon, 1999). New Labour accelerated these trends by promoting a shift away from a local authority 'one size fits all' model, advocating a 'third way' for social care which placed 'the focus away from who provides the care, and places it firmly on the quality of services experienced by and outcomes achieved for, individuals and their carers and families' (Jones and Lowe, 2002: 206).

\section{The 2010s: antagonistic collaboration in the context of state failure}

\section{Developing narratives of state failure}

The incoming Conservative-Liberal Democrat Coalition government in May 2010 initiated a new debate about the 
mixed economy of welfare. The Coalition's programme for government included a commitment to enable charities and others to 'have a much greater involvement in the running of public services' ${ }^{41}$ Conservative thinking identified the state itself as a problem, marked by a centralised, top-down and prescriptive approach to delivering public services which was 'broken' and outdated. ${ }^{42}$ The proposed solution was 'open public services', and for the state to shrink back and let others assume a greater role in welfare provision. David Cameron and Nick Clegg echoed ideas of state failure to argue that public service reform was in fact a 'progressive cause' needed to tackle unfairness. ${ }^{43}$ They addressed their critics head on: 'those who resist reform, put the producer interest before the citizens' needs, and object to publishing information about how services perform are conspiring to keep our society less free, less fair and less united'. ${ }^{44}$ The authors of the 2011 White Paper ended with a rallying cry:

Gone is the assumption that a small collection of politicians and bureaucrats have a monopoly on knowledge - and with it the idea that the state alone is equipped to run public services. Instead we recognise that the sum of knowledge held by individuals, communities, local authorities, public sector staff and the voluntary, charitable and private sectors can be the real driving force for change ... [o] ur reforms are the best way to deliver better services; indeed, they are the only way we can deliver improved, modern public services in a time of fiscal consolidation and growing demand. Waste and inertia are no longer tolerable - we need to make every penny of taxpayers' money work as hard as possible. $^{45}$

While the new government had a different vision for relationships within the mixed economy of welfare and talked of the need to 'open up' public services because the state was 
failing to meet needs, others approached the idea of state failure from different perspectives and offered different solutions.

While many within the voluntary sector agreed with a broad narrative of state failure, they argued the state was failing because of an erosion of statutory responsibilities - it was failing to meet the welfare needs of its citizens. ${ }^{46}$ As early as 2010, voluntary sector leaders recognised that the new government's spending review was about 'more than cuts' and was underpinned by a desire to change the balance between the public sector, the market and civil society. ${ }^{47}$ One pervasive narrative among voluntary organisations in the 2010s was that the austerity politics of the Coalition had pushed some statutory services almost to the brink of collapse. Children England and Age UK, for instance, both presented an increasingly strong narrative of a crisis in social care. Age UK described the social care system as being in 'terminal meltdown' 48 and identified 'a chronic lack of funding and the failure to reform' as underlying reasons. ${ }^{49}$ By 2016, Age UK argued,

The debate about the future of social care has gone beyond whether there is a crisis to how to mitigate its impact, including on the NHS, and more recently to how to prevent its total collapse - yet still the Government does not act. Older people are bound to wonder why not and we wouldn't blame them for concluding that the failure to value social care in this country is also a commentary on the value our society places on them and their yearning for a decent and dignified later life. ${ }^{50}$

In the youth sector, continued erosion of statutory provision amounted to an abandonment of universal provision for young people. The narrative here, however, was shaped by the recognition that youth services were peripheral in terms of statutory provision. Since they had never been a core statutory responsibility they were 'easy' to cut first and cut hard: 
The youth sector across [has] experienced more than f737 million of cuts to local and regional services over the last 7 years, statutory provisions have substantially diminished right across the country, and in some areas ceased to exist entirely. This environment has led to high levels of innovation in how to sustain delivery, but also as a consequence there is now a huge variability and inconsistency in how services are being maintained across England's 152 local authorities. ${ }^{51}$

The solutions proposed by voluntary organisations often involved a transformation of public services, underpinned by a reversal of austerity and more, rather than less, state involvement and funding.

This shifting welfare mix was also noted by respondents to the 2012 MO directive on the Big Society (Lindsey and Bulloch, 2013; Lindsey and Mohan, 2018), while narratives of state failure were also evident in later MO directives. As one writer noted in 2018, 'In my opinion then, the relevance of charity in Britain today is that it is compensating for the Government's negligence in looking after its citizens properly'. ${ }^{52}$ There was also anger among $\mathrm{MO}$ writers at the cuts to public spending, which were viewed as impacting on charitable capacity to deliver services.

\section{An expanded, or contracted, role for voluntary action?}

In the early 2010 s the rhetoric of the new Coalition government appeared to offer the voluntary sector expanded roles in welfare service delivery, thus continuing a trend that had developed in the 1990s and 2000s under New Labour. Indeed, voluntary organisations were increasingly expected to do more and more towards meeting social welfare need, providing services where the state was unable or unwilling. This sat alongside a greater role for private sector and informal/family carers. Evidence 
on government funding for the voluntary sector gives some indication of how this played out. According to the UK Civil Society Almanac (NCVO, 2020), there was a notable decline in the proportion of the voluntary sector's total income that came from government across the decade. Although government funding was the second most significant source of income for the voluntary sector, it represented only around 2 per cent of government spending during the 2010s. Highlighting the contradiction between rhetoric and funding realities, Children England argued: "We believe there is a significant risk that while placing a growing voluntary and community sector at the heart of Government's commissioning plans, the Coalition may more immediately preside over a period of the most substantial reduction of the sector for many decades. ${ }^{53}$

Furthermore, as we have demonstrated, the direct delivery of welfare services has only ever been one of the roles played by voluntary action (see Chapter Three). Questions began to arise as to whether an expansion of voluntary sector involvement in public service delivery had come at the cost of other roles. The NCVO, for example, was critical of government emphasis on merely transferring services to other providers, when it considered that the focus should instead be on transforming services, and the wider role that the voluntary sector might play in this.

Public service delivery cannot be improved just by transferring the organisation delivering it to another one. A radical rethink is needed to create long term positive transformation in public services. If the public sector focuses only on who delivers the service, rather than looking at changing the service itself, then any benefits to be gained from diversifying the supply of services will be restricted and limited. ${ }^{54}$

Perhaps more fundamentally, while the Coalition and subsequent Conservative administrations looked to expand the role of voluntary action in service delivery, they did not value 
the campaigning role that charities held dear. As discussed in Chapter Three, various interventions were put in place which seemed to limit voluntary organisations' freedoms, such as the Lobbying Act 2014 and 'anti-advocacy clauses', which contributed to a deepening concern within the voluntary sector that the expansion of their role in delivering welfare services may have come at the cost of their roles in campaigning, advocacy and more general democratic engagement.

Further, there were strategic and financial implications for voluntary organisations, including those taking part in this study, as the government dismantled existing partnership programmes and funding mechanisms as part of a process of decoupling itself from the voluntary sector (Macmillan, 2013). Children England, for example, had been a 'strategic partner' of the Department of Education, which under New Labour brought with it both money and influence; however, 2013/14 was highlighted as 'the first year in the organisation's history without any core grant funding from central government'. 55 These cuts contributed to a two thirds fall in income and subsequent round of redundancies and restructuring. Within youth services the impact was even starker. The umbrella bodies that were the focus of this study were not immune to the cuts experienced by the wider youth sector. After 80 years of work, the NCVYS closed in 2016, funding cuts having made the organisation unsustainable. This was followed in 2017 by the merger of Ambition into UK Youth after cuts meant it was no longer viable for both organisations to continue separately.

Among the public, some left-leaning MO writers were supportive of the idea of charitable involvement in welfare provision, supporting the idea of a mixed economy of welfare. This was conceptualised as the view that the government should provide funding for certain core needs, but delivery should be provided by charities, who, because of their expertise and knowledge of client groups and needs, were best placed to deliver these services. Resonating with writers from the 1940s, some contemporary writers also saw the role of charities as 
providing the 'extras' rather than the core needs. Many writers, from all political persuasions, perceived the role of charity as evolving into one that plugged the gaps in state provision:

The key role of charities should be to fill gaps in existing service provision or offer an enhancement on what statutory services provide. They should make things better for people, in the UK and abroad. They can never take the place of properly funded government and local authority services, however: there needs to be some sense of a basic service for everyone that is not patchy or dependent on goodwill. ${ }^{56}$

Left-leaning writers tended to view this gap plugging in a critical light, while more right-leaning writers felt this was an acceptable change in role. Some writers held a view that market values had become pervasive in welfare provision. While there was greater support for services provided by charities or the not-for-profit sector than for delivery by private companies, in general the public was largely opposed to either sector taking over from the state. A number of $\mathrm{MO}$ writers, mainly identifying as being on the left of the political spectrum, believed that the government should be solely responsible for meeting welfare need, and were largely against the idea of other actors in a mixed economy. However, as in the 1940s, there was also acquiescence from some left-wing writers that charitable involvement in funding and provision for welfare needs was necessary against an economic backdrop of spending cuts, austerity and a Conservative government.

\section{Competition, choice and public service markets}

With echoes back to the 1940s, the idea of choice was embedded in the 2010 Coalition government's five principles for reforming public services, alongside decentralisation, diversity, fairness and accountability. ${ }^{57}$ The government noted that since they 
wanted to promote choice about the services people use, 'the only way for that to happen is for provision to be opened up to a range of providers of different sizes and different sectors'. ${ }^{58}$ The government's push for choice was located in the idea of people's complex needs and greater expectations about what public services could offer. ${ }^{59}$ As discussed in Chapter Three, government spoke in 'sector-blind' terms, stressing that choice and quality were key, regardless of whether these were delivered by the public, voluntary or private sector. ${ }^{60}$ As in the 1940s, competition was perceived to be a key concept that broadened choice and increased the quality of services: 'wherever possible, public services should be open to a range of providers competing to offer a better service'. ${ }^{61}$

Following the welfare reforms of the late 1980s and 1990s, however, the development of a quasi-market in social care had dented the voluntary sector's enthusiasm for the concepts of choice and competition in welfare provision. Doubts were expressed as it became understood that there was unequal access to choice; and that in fact choice might be an additional or unwanted burden, or simply irrelevant, for some people. Age UK's policy advice, for example, reflected the diverse views of older people regarding choice and competition. It reported concern that choice might in fact further disadvantage the already disadvantaged:

Older people surveyed were fairly sceptical about the role of choice and competition in improving the quality of health services, with focus group participants expressing concern that it will severely disadvantage those who are unable or unwilling to travel distances to access alternative providers, leading them to receive 'second rate' care. ${ }^{62}$

'Crucially', Age UK argued, 'a reliable default option must remain for those whose needs and circumstances require the protection and safety-net of directly commissioned state support and services'. ${ }^{63}$ 
More fundamentally, there was widespread agreement among the voluntary sector organisations whose sources were used for this study that commissioning was highly problematic and that the market in social care, in existence since the 1990s, 'does not always work satisfactorily' ${ }^{64}$ However, the different voluntary organisations studied adopted varying positions on the idea of public service markets per se. This reflected the different ways in which markets operate within the social welfare fields we examined; but it also reflected the differing positioning and structuring of these organisations. For some, markets in social care do not and will not work. For others, there is a limit to what markets can achieve. Children England, for example, argued that market-based approaches will not work within the field of children's services, pointing out the risk of market failure. A review of the residential care market published in 2014, for example, led them to conclude that it must be considered as an inherently imperfect market, doomed to failure, ${ }^{65}$ putting 'the sense of public service and civic duty at the heart of children's services ... under threat' ${ }^{66}$ However, rather than dismissing the emphasis on public service markets entirely, some actors in the voluntary sector sought greater market stewardship by the state, for example in stimulating the care market in parts of the country where there were fewer providers. Age UK, for instance, called for the state to play more of an active role in market stimulation, regulation and quality assurance, welcoming new duties placed on local authorities to manage care markets. ${ }^{67}$

More specifically, the voluntary organisations that we studied expressed concern regarding the effect of marketisation, and associated processes such as commissioning, on the voluntary sector. For some, it was seen as presenting a significant threat to voluntary organisations' long-term viability:

Ironically perhaps, the very qualities of some modern charities that the general public have come to find most unpalatable and uncharitable - such as being 
'indistinguishable from big business'; having growing extremes between top managerial pay and front line staff; being too 'flash' and slick and brand-marketed - are precisely the characteristics that public procurement and government officials most value, and reward most often, within the 'competitive marketplace'. ${ }^{6}$

For MO writers, concerns about marketisation were expressed through the identification of problems where voluntary organisations had formed partnerships with commercial companies, such as selling insurance or other services via voluntary organisations. As one writer noted:

What worries me is the accountability of these charities; the key responsibility and what happens when the money runs out? It has been pointed out to me, that the Charities have lost their funding by the Government, which is why Age UK for example has had to go down the Commercial route. It worries me that these organisations are doing the Government's 'job' and becoming more demanding in advertising their wares in Age UK. ${ }^{69}$

More generally, while more right-wing writers tended to think the market might provide better business models, leftwing writers discussed their disagreement with the concept of private sector involvement in the delivery of welfare services. For many, this revolved around ethical concerns about making a profit out of the needs of vulnerable members of society, including care workers and those receiving care:

I don't think it works to make a profit out of the welfare state, so I am dead against private companies holding public sector contracts to provide services. The workers should be directly employed by the council and get proper employment rights and pay. It is outsourcing to private companies that leads to domiciliary care assistants 
not getting paid for travelling between shifts, etc. I know too many people who have made stacks of cash from running nursing homes. It is immoral and we shouldn't tolerate it. One of my best friends is a commissioner in adult social care and I know all the budgets are being pared to the bone. The only way some middleman is making a profit out of that is if he's cutting corners or really ripping off his staff. ${ }^{70}$

Several writers mentioned examples of outsourced services, such as the Work Capability Test used to determine who should be eligible for Employment and Support Allowance, which was being delivered by a private company: 'Private companies should not be running welfare services - you only have to look at some of the disasters (and inhumanity) surrounding farming out fitness to work tests. Putting profit margins on such activities is a horrible thought. ${ }^{, 71}$

There was some contradiction between abstract support for choice, competition and the involvement of commercial providers in the mixed economy of welfare and the views writers had of their own experience of such arrangements (this contradiction was also evident in MO writing in the 1940s). This was particularly noticeable in discussions of older people's social care, when some writers reflected nostalgically that 'years ago there were home help services available to help people stay in their own homes, these cost very little'. ${ }^{72}$ A number of writers discussed the perceived poor quality of service offered by private care providers, often coupled with the view that it was unfair that they (the deserving) should have to pay for care when others (the undeserving) did not (see Chapter Four).

As in the 1940s, the 2010s were also marked by a debate about the reliance of the social care system, particularly relating to older people, on informal carers. Age UK, for example, argued that 'the majority of care is still provided outside of the formal care market by family and friends" 73 and, indeed, that the burden on family care had increased during the 
2010s almost to breaking point. Age UK considered that the system was failing carers, many of whom were themselves older people:

Informal and family carers are the backbone of the social care system and provide the majority of the support that older people use on a day to day basis. ... The current system frequently lets carers down and fails to provide the support they need. As well as problems they face in accessing carer specific support, such as respite care, carers often face additional stress caused by the complicated and underfunded care system, which can leave carers feeling abandoned and unrecognised. ${ }^{74}$

\section{Resultant antagonistic collaboration}

We suggest that the relationship between the voluntary sector and the state during the 2010s can thus be characterised as one of antagonistic collaboration. Alongside austerity, a dominant narrative running across the decade was of state failure, but with different understandings about what this meant, why it had occurred or what the response should be. For the Coalition, and subsequent Conservative governments, it was part of a wider ideologically driven shift towards a smaller state. In terms of welfare, this meant a minimal state meeting minimal levels of need, to which increasing levels of conditionality were attached, alongside the opening up of public services to delivery by an even more diverse mix of providers.

This offered the potential for an increased role for voluntary action in welfare service delivery. It also, however, led to an increased urgency for the wider role of voluntary action in amplifying the voices of, and advocating for those, adversely affected by austerity and changes to welfare policy, in challenging government decisions, and holding government to account (Chapter Three). While government rhetoric encouraged the role of voluntary action in welfare delivery, 
it actively discouraged its campaigning role. As in the 1940s, this changed environment for voluntary action prompted widespread anxiety on the part of voluntary organisations. This included concern for their beneficiaries (and anger among some at the failure of the state to meet welfare needs), concern for their own future, and concern about being silenced. As in the 1940s, it was recognised by most actors that social welfare needs were such that a joint response between the state and voluntary action was needed. However, as we note in Chapter Four, unlike in the 1940s, society in the 2010s was more polarised and there was no consensus on who should take responsibility for these needs. The relationship between the state and voluntary sector was not founded on optimism or even pragmatism, but was underpinned by scepticism and antagonism.

\section{Summary}

The conceptual framework informing our research into debates on the role and contribution of voluntary action in the 1940s and 2010s highlights its - often contested - positioning in social welfare. In touching on questions of values, judgements and performance, voluntary action has been deeply implicated in ideological debates and as such has usually been positioned in relation to others, particularly the state. Concerns about the role and performance of the state have fundamentally informed narratives about voluntary action. Similar sets of questions were being asked at both periods of time about the mixed economy of welfare, but with fundamentally different conclusions.

In the 1940s the expansion of state-provided services across many areas of social welfare was often contrasted with earlier policy failures. Equally, the commitment to an expansion of the state's role raised questions about the future of voluntary action. Rather than a diminished role for voluntary action, however, recognition of the extent of need and the inability of the state to meet these needs led to a pragmatic partnership 
between the state and voluntary action. The state and the voluntary movement were not the only players involved, of course, but understanding of their roles, responsibilities and performance dominated the discussion.

In contrast, the 2010 s were categorised by a narrative of state failure that took different forms. For some in the voluntary sector, and for some members of the public, the state was seen to be abdicating responsibility for its citizens through its adoption of extreme austerity measures. Both the Coalition and subsequent Conservative governments viewed the welfare system itself as broken and put forward a broadened concept of a welfare market as offering new solutions. Voluntary organisations were encouraged to fully embrace this marketplace, even though many struggled to reconcile their values with market-driven ideas of competition and choice. Indeed, for some within the voluntary sector such a welfare market would always be doomed to failure. Nonetheless, growing levels of need in the 2010s prompted voluntary organisations to develop and expand services to meet this need, while also seeking to hold government to account for its perceived failings. This changed relationship between government and the voluntary sector can be characterised as one of antagonistic collaboration.

This chapter has illustrated how, during both periods of time, all of our actors developed and circulated narratives about the respective roles of voluntary action and the state (and others) to inform discussions about the welfare mix. Chapter Six develops these ideas further by exploring the ways in which narratives may be regarded as discursive interventions, indicative of struggles over boundaries and a desire to 'make room' for voluntary action. 


\section{SIX}

\section{Making room for voluntary action}

\section{Introduction}

Accounts of the shifting balance of roles, expectations and resources within contemporary social policy discussions of the mixed economy of welfare tend, with some noticeable exceptions, to be rather state centric (Finlayson, 1990; Macmillan and Kendall, 2019). Although there has been renewed interest in the historic and ongoing contribution of voluntary action to welfare provision in England (see Chapter One), these accounts rarely consider the extent to which developments in welfare provision have been shaped by debates among different actors about the appropriate balance of responsibilities. The previous chapters of this book have examined the role, position and contribution of voluntary action in welfare provision. This chapter examines, in more detail, the ways in which different narratives about voluntary action and the provision of welfare have been constructed, articulated, contested and circulated. These narratives may be regarded as field-shaping discursive interventions (see Chapter Two), indicative of struggles over the boundary between the state and voluntary action, particularly during transformational moments. 
Image 6.1: Cover of the 1944 publication Old Age in the New World prepared by the NOPWC for a series on post-war planning

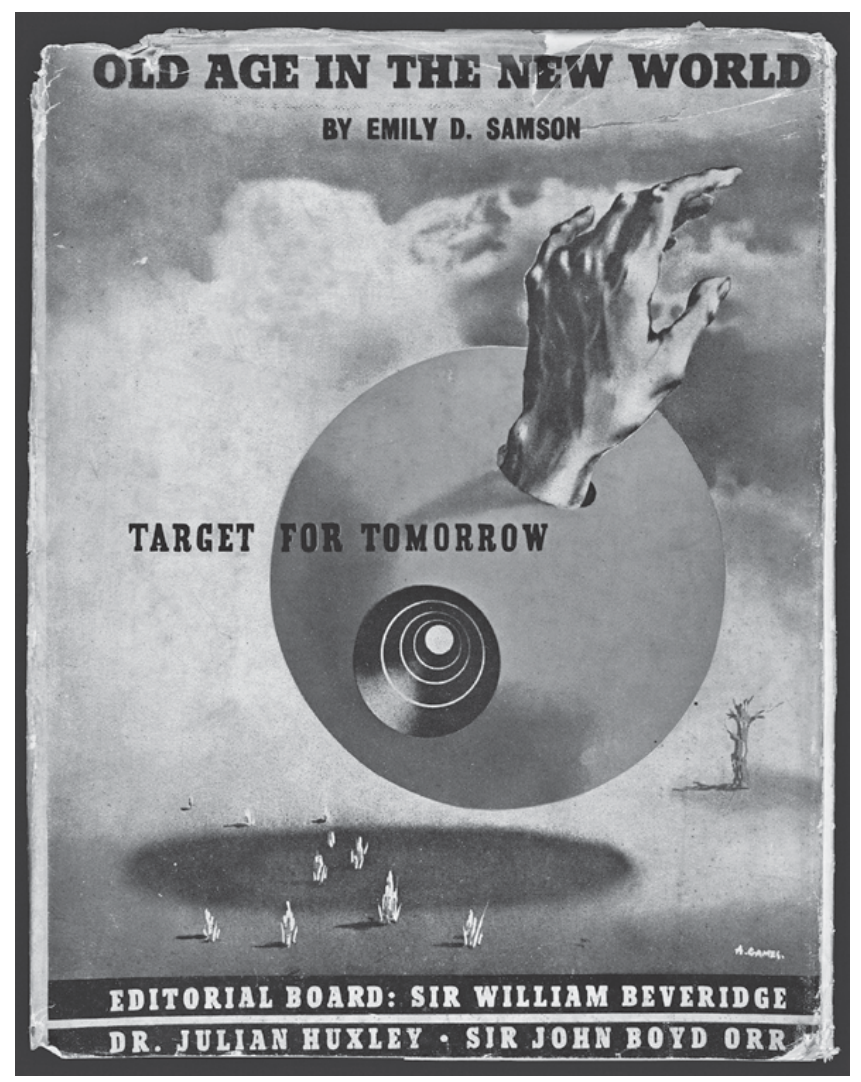

Source: Reproduced courtesy of Age UK.

The chapter explores how narratives have been strategically deployed during periods of unsettlement in the 1940s and 2010s to make and shape 'room' in social welfare - the space and legitimacy to operate - for individual organisations, areas of work, or for voluntary action in general. It considers two emblematic moments from our analysis of documents in these two decades. These emblematic moments constitute key 
issues, themes or policy developments that appear particularly significant and which bring debates about the role, position and contribution of voluntary action into sharp relief.

\section{A new partnership with the state in the 1940s: the NOPWC and the National Assistance Act}

The first emblematic moment highlights the elaboration of a stronger (pragmatic) partnership between voluntary action and the state in the 1940s, particularly in the development of the post-war social legislation and the emergence of the comprehensive welfare state (see Chapter Five). The focus in this example is on older people, the role of the newly formed NOPWC and the shaping and consequences of the National Assistance Act 1948, although examples from other fields could also be used. From the start, the NOPWC was proud of its role in forging the Act. Its first historian reflected in 1970 that this voluntary organisation's role in framing the Act was an exceptional contribution to social legislation (Roberts, 1970: 52) and it has been accepted as such by scholars including Means and Smith (1998). Our analysis seeks to extend and deepen earlier accounts by offering a theoretically informed discussion of discourses of voluntary action, drawn from our analysis of multiple sources and narratives.

\section{The emergence of the NOPWC}

From the beginning, the NOPWC was a partnership between the statutory sector, represented by the Assistance Board, and the voluntary movement, represented by the NCSS, but firmly located in the latter. Its work and subsequent relationship with government reflect these origins. The NOPWC was set up in response to the heightened sensitivity to poverty and unmet needs experienced by older people during wartime, particularly around housing, health and loneliness, as reported by Assistance 
Board officers. Whereas concern for the welfare of children and families had been a long-standing concern of the voluntary movement, it has been argued that the Second World War and its aftermath showed how older people 'can shift from being a low priority group for resources to the focus of a "moral panic" about the need for society to show care and concern' (Means, 1995: 198). The Blitz on London from September 1940 increased homelessness and led to concern that 'old and feeble' people ${ }^{1}$ were sleeping in air raid shelters, leading to a joint effort to evacuate older people from the cities. ${ }^{2}$

The NOPWC encouraged the formation of local Old People's Welfare Committees to help find accommodation and support for evacuated older people as well as research their experiences. Often these local groups emerged in connection with local councils of social service. These groups set up visiting schemes, clubs and home help schemes, as well as small voluntary-run homes for those no longer able to live independently. They were supported by financial aid, information and guidance from professional staff located in the NCSS's Bedford Square headquarters. The number of small voluntary homes grew steadily in the post-war period, although progress was slowed by limited access to capital. In tandem, the first meals-on-wheels service (enabling continued independent living) was pioneered in 1943 and expanded thereafter, responding to difficulties of older people queuing for rations.

The work of the NOPWC grew steadily - there were 70 local committees (OPWCs) by 1944 and 270 local and 17 county-level committees by $1949 .{ }^{3}$ In 1950 official state encouragement to establish more committees came in a Ministry of Health circular, which urged that 'all local authorities should do everything in their power to encourage further voluntary efforts to meet the needs of old people, especially those living in their own home, and that there should be close and continuous collaboration between all the statutory and voluntary agencies working for their welfare'. ${ }^{4}$ 
The circular emphasised the value of voluntary social services and that 'fruitful cooperation has been established' between welfare and health authorities and OPWCs. There were 831 local committees by $1952 .^{5}$

As it became more established the NOPWC began to get involved in wider advocacy for older people, and in post-war planning and reconstruction. In 1942 it submitted evidence that informed the Beveridge Report and in 1944 published Old Age in the New World. ${ }^{6}$ This report looked forward to the post-war period by promoting the interests of older people against earlier neglect: 'The fact is that the older section of the community has in the past been an inarticulate group which society as a whole has been content to neglect'. The report drew attention to the poor conditions faced by older people in local authority-run public assistance institutions, building on a press furore that had erupted the previous year when a letter called 'A Workhouse Visit' was published in the Manchester Guardian. ${ }^{8}$ From 1946, the NOPWC began organising a regular conference that was attended by hundreds of organisations and individuals involved in older people's work; they were drawn from local authorities, central government departments and the voluntary movement. ${ }^{9}$ Means and Smith (1998: 75) note that the original idea for the influential Nuffield Foundation investigation into the problems of ageing and the care of older people, chaired by Seebohm Rowntree and published in 1947 (Nuffield Foundation, 1947), came from the NOPWC. The report's publication and favourable media response coincided with discussions well under way on the National Assistance Bill.

\section{Passing the National Assistance Act 1948}

A good test of the broad renegotiation of roles between voluntary action and the state in the 1940s is the introduction of the National Assistance Act 1948. This was the final plank in the overall social legislative programme to implement the 
1942 Beveridge Report's proposals for 'cradle-to-grave' income maintenance. The foundation was a comprehensive national insurance scheme, but for those neither able to work nor make contributions, a safety net - National Assistance - would be provided out of general taxation. Significantly, Part Three of the Act gave local authorities new powers and duties to provide welfare services for older and disabled people, including the duty 'to provide-residential accommodation for persons who by reason of age, infirmity or any other circumstances are in need of care and attention which is not otherwise available to them'. ${ }^{10}$

The 1948 Act had great significance for two main reasons. First was its symbolic description and opening declaration. It was 'An Act to terminate the existing poor law and to provide in lieu thereof for the assistance of persons in need by the National Assistance Board and by local authorities' ${ }^{11}$ and, as a result of its introduction on 5 July 1948, 'The existing poor law shall cease to have effect'. ${ }^{12}$ It abolished the hated workhouse, or public assistance institution, against which the NOPWC had campaigned. Basic safety-net provision in the form of cash payments would be nationalised and provided through the National Assistance Board (Timmins, 2017: 136). It was intended to mark the end of the stigma and shame attached to Poor Law provisions. Second, locally, the new powers and responsibilities for councils to promote the welfare of older and disabled people became the cornerstone of post-war personal social services and social care in the welfare state. Timmins (2017: 136) saw these as precursors to subsequent social services departments. Crucially, they also created a space for ongoing voluntary provision: 'A local authority may make contributions to the funds of any voluntary organisation whose activities consist in or include the provision of recreation or meals for old people. ${ }^{, 13}$

It is noteworthy that $\mathrm{MO}$ writers, responding to questions fielded in 1947, did not refer to the National Assistance Bill, which had been omitted from the King's Speech in 1946. 
Speaking about its omission Barbara Castle suggested this would 'cause tremendous disappointment and some cynicism, or a sense of defeatism, among people in my constituency and in other parts of the country, who are suffering very gravely from social insecurity at the moment'. ${ }^{14}$ Castle referred to the Bill being hampered by confusion, lack of consensus and the need for further work. Given these difficulties, it is perhaps unsurprising that those writing in April 1947 did not discuss the Bill, its fit with other planned legislation, how it might meet the needs of those who were likely to fall between the cracks of the other new legislation, and what this might mean for concepts of class and citizenship for those needing assistance.

The legislation was steered through Parliament without much contention over the winter of 1947-8 by Aneurin Bevan (Minister of Health) and James Griffiths (Minister of National Insurance). Richard Silburn (1983) refers to its passage through Parliament as 'a tranquil affair' ( $p$ 133) which was 'seen as a simple and necessary measure to round off the social security programme' ( $p$ 135). National Assistance was intended to be a temporary residual measure, which would gradually be eclipsed by National Insurance as contributions accumulated and coverage increased, within the context of a policy of full employment for all (Glennerster, 2007). Most subsequent commentary and social policy analysis has found in practice that the opposite happened - claims for National Assistance steadily rose in the post-war years, in part because the rates of contributory benefits were set too low, and other costs were not covered. Beveridge had recommended phasing in insurance benefits at subsistence rates over two decades, but the Labour government opted instead for immediate implementation, giving 'precedence to conscience and compassion over financial probity' according to Roy Hattersley (1997: 15). The heavy focus on National Assistance (in Part Two of the Act) at the time and subsequently has meant that the local provisions for elderly and disabled people (in Part Three of the Act) received far less attention, contributing to the idea that personal 
social services and social care had become the marginalised 'Cinderella' of the welfare state. Yet it was precisely here that the role of voluntary action gained more of a presence.

\section{The NOPWC and field-shaping narratives}

The NOPWC's remit to investigate the experiences and needs of older people and to promote responses to them, in practice and policy, already sought to locate it in a position of influence - this was part of its raison d'etre. In its first decade, it broadened its focus from immediate wartime needs to wider social policy affecting older people, particularly in the emergence of the post-war welfare settlement. The division of labour between the state and voluntary action was evolving rapidly at this time, in recognition that neither voluntary action nor the state was sufficiently equipped to meet the scale of need (Chapters Four and Five). While the state took on a centralised role in income maintenance through national insurance and assistance, and in health and education, Marilyn Taylor (1995: 220) suggests that opportunities arose in non-priority areas such as leisure, youth and services for older people, where there were 'no local authority empires in these fields immediately after the war'. Voluntary agencies could therefore find 'room' to operate in the new context, as 'pioneers, supplementers and niche market specialists' (Kendall, 2003: 162; see also Chapters Three and Five).

The task for the NOPWC, and its parent body the NCSS, appears to have been twofold and, in a discursive sequence, created a strategic narrative around securing room for voluntary provision. First, the NOPWC highlighted the needs and interests of older people (see Chapter Four); but then, second, it promoted voluntary action in response to these needs. This was encapsulated in the title of the 1949 handbook on welfare work with older people produced by the NOPWC (an expanded version of a guide first published in 1946): Age is Opportunity. Ostensibly implying that old age 
should be a period of opportunity, the subtext was that older people's welfare work was an important new opportunity for the voluntary movement, even as other roles in welfare provision were receding. Robin Means (1995) argues that organisations including the NOPWC, the British Red Cross and the WVS 'had developed strong welfare roles during the Second World War and were keen to play a strong part in the reconstruction process' and that 'they "planted" many of the "moral panic" stories about workhouses and food rationing as part of this strategy to emphasise their potential role, while they, also, lobbied central government in the 1950s against allowing local government increased powers' (1995: 207). This interpretation underplays the extent to which these bodies were, in many cases, hybrid organisations that defy binary definition as either purely 'voluntary' or 'statutory'; rather in its formation, structure and operation the NOPWC encapsulated the pragmatic partnership of the 1940s (Chapter Five).

The NOPWC sought to bring its expertise to bear in discussions on the emerging legislation, in particular on the provision and funding of non-residential welfare services. At that time, the main preoccupation for the Ministry of Health was the provision of residential care for older people, but it saw that voluntary organisations could provide supplementary nonresidential care services. Local Authorities were given the power to fund voluntary organisations to provide the sort of mealson-wheels schemes and other auxiliary services pioneered by local OPWCs and the WVS, which 'already had national networks that were well placed to exploit these opportunities' (Taylor, 1995: 220). The NOPWC made a series of specific suggestions and amendments which were incorporated into the final legislation, including recommendations regarding the registration and inspection of homes for older people and changes that enabled a wider range of local authorities to fund clubs and meals services (Roberts, 1970: 52). ${ }^{15}$ Fred Messer later suggested that the result was 'a better Act because of amendments made by NOPWC' (Roberts, 1970: 52). In its 
publications the NOPWC detailed its contribution to the Act, noting it 'warmly welcomed'16 the new provisions.

The 1950 Ministry of Health circular argued that there was 'an urgent need for further services of the more personal kind which are not covered by existing statutory provision and which indeed can probably best be provided by voluntary workers actuated by a spirit of good neighbourliness'. ${ }^{17}$ These services included regular home visiting, helping with shopping, letter writing and minor domestic repairs. In Parliament, the Parliamentary Secretary to the Ministry of Health stressed:

Our desire is to encourage in every way the cooperation between local authorities and the great variety of welfare organisations that are already doing most valuable work in this field. ... We want to encourage in every way the local authorities to work together with the voluntary organisations to avoid overlapping as far as possible. ${ }^{18}$

Yet there were complications. Local authority responsibilities in the National Assistance Act were limited to residential care and home care and did not embrace the full range of welfare services. This was based on the assumption that care of older people remained a family responsibility, with the gendered concern that daughters would 'abandon elderly relatives to the state' (Means, 1995: 201). In this way the moving frontier between the state and voluntary action was complicated and overlain by other dimensions, such as assumptions about the role of informal and family care (see Chapter Five).

The 1940s saw the establishment of comprehensive "cradleto-grave' welfare provision, with the state taking the primary role in income maintenance, through national insurance and assistance, as well as in other services. But this was not the end of voluntary action in welfare services, and neither was it a direct transfer of existing services from voluntary to statutory provision. Voluntary action sought and found specific roles 
within the new welfare settlement, at least in part to meet new needs, or hitherto ill-addressed needs.

For voluntary organisations representing and serving older people, this involved almost unlimited possibilities for cooperation $^{19}$ with local authorities, securing support for the voluntary provision of non-residential services for older people, such as lunch clubs, meals on wheels, home helps and recreational activities.

\section{Navigating a decoupled relationship in the 2010s: reforming children's services}

We move now to discuss our second emblematic moment, which took place in the 2010s.

Debate on the relationship between the state and the voluntary sector can become rather one dimensional, focusing primarily on who provides services. Since the 1980s this debate has seemed to proceed in one direction - state withdrawal opening up space for other providers (see Chapter Five). The 2010-15 Coalition government couched this in terms of the 'Big Society', and later in its 'open public services' agenda, seeking new ways, models and financial mechanisms to 'open up' public services to new providers from the private and nonprofit sectors. ${ }^{20}$ Whereas in the 1940 s the moving frontier between the state and voluntary action shifted decisively towards the former, the 2010 s vision sought shifts in the opposite direction by containing the state and expanding voluntary (and commercial) provision.

By focusing on the emblematic moment of reforming children's services in England, however, we suggest some complications and counter-currents, as voluntary organisations sought to navigate changed relationships in the welfare mix. The discussion proceeds along three, interrelated, dimensions. First, it looks at the ways in which organisations construct and deploy strategic narratives both to make sense of an unsettled environment and to find 'room' within it. Next, it examines 
the (re)active construction of different narratives during the 2010s for the role, position, resourcing and contribution of voluntary action and its relationship to others. Finally, through the specific example of the reform of children's social care in the period 2014-17, we bring together voluntary and state narratives to consider the dynamic and contested nature of the moving frontier of welfare provision.

\section{Back to basics: positioning Children England}

The Associated Council of Children's Homes - the forerunner to Children England - was established during wartime in the context of poverty, population dislocation, and heightened public concern for children's welfare (see Chapter One). The Council brought together the key voluntary sector organisations working with looked-after children at the time, all of which recognised the "necessity of combined action in negotiation with Government Departments'. ${ }^{21}$ At first, war-related problems dominated proceedings, such as staffing shortages, training needs and the rise in illegitimacy, with the Council liaising with other voluntary organisations, including the National Council for the Unmarried Mother and the NCSS on these matters. However, this was soon combined with a desire to influence the government's emerging children's policy, particularly when the Curtis Committee began investigating conditions for children deprived of a normal home life in 1944. Indeed, the Council argued that its members' extensive experience of caring for 'thousands of homeless children' entitled the Council to assume a serious 'place and weight in the counsels of our legislators'. ${ }^{22}$

In 1944 the Council appointed a 'parliamentary agent' - a protective strategy to advise it of any legislation relevant or challenging to the interests of children's home providers. Members of the Council were concerned at what they saw as a misrepresentation of facts in media coverage, and particularly at a growing assumption that foster care was always a better 
option than children's homes. The Council discussed financing a film to inform the public of the 'real conditions' in children's homes. ${ }^{23}$ The Council secured representation on the Curtis Committee and established a sub-committee to closely monitor the passage of the Children Bill, raise questions in Parliament, confer with the Home Office and prepare amendments. ${ }^{24}$ Like the NOPWC with the National Assistance Act, many of the Council's recommendations passed into law in the form of the Children Act 1948.

By 2010, with an expanded membership and considerable growth and partnership working under New Labour, the Council, now known as Children England, delivered a broad programme of activities. ${ }^{25}$ The subsequent decade saw considerable change, both within Children England and in the wider field of children's services, following the formation of the Coalition and subsequent Conservative governments, and a context of austerity, declining resources, growing demand and gradually deteriorating relationships between government and the voluntary sector. Attempts by the Conservatives to 'de-couple' themselves from the voluntary sector (Macmillan, 2013) led to the dismantling of structures such as the Strategic Partner programme (see also Chapter Five).

However, Children England has also spoken of developing a deliberate strategy to move the organisation away from government funding: to be more independent and to be able to speak more freely. ${ }^{26}$ During this time Children England reduced its range of activities and narrowed its focus towards keeping 'children at heart' in society and creating a sustainable voluntary sector economy. Renewed emphasis was placed on its 'campaigning core ${ }^{27}$, on developing 'a powerful public voice' and raising its profile as 'thought leaders on the challenges faced by children and the voluntary sector'. ${ }^{28}$ Children England suggested that an independent, powerful voice was needed within the context of an otherwise silenced voluntary sector (see Chapter Three). While frontline organisations might have been constrained in what they felt they could say 
(for example by implicit or explicit contract requirements), a lack of government funding, combined with a mandate from members, freed Children England to challenge the government in, for example, moves to transfer statutory duties for child welfare onto others:

Our members now require us to be a more independent voice for them, separated financially from government, championing the role of the children's voluntary sector and raising concerns about the conditions in which they are seeking to sustain their services and efforts for children ... it's essential that we as their umbrella body campaign for society to 'put children at heart' in order to make decisions that improve, rather than damage, children's welfare. ${ }^{29}$

The focus on voice and advocacy was similar to the 1940s, but the direction of the argument was different: rather than working with government to help with a transfer of responsibilities for children's welfare from charities to the state, and to retain room within the new welfare settlement, the emphasis in the 2010s appeared to be more on resisting government's attempts to transfer the state's responsibilities to the voluntary sector and beyond, while at the same time silencing the sector through, for example, the Lobbying Act 2014 (see Chapters One and Three).

\section{Constructing strategic voluntary sector narratives}

Our study has identified four interrelated narratives constructed and articulated by Children England through its various reports, papers, articles and consultation responses, with each in turn becoming broader in scope and ambition, pushing back against state-led interventions and narratives for the role, resources and contribution of voluntary action and the welfare mix. 
First: the voluntary sector was under threat from commissioning. Children England became increasingly vociferous in its argument that commissioning was not working - particularly for small charities - arguing that: there were inconsistencies across local authorities; competition acted as a barrier to collaboration; it led to reduced continuity for service users and sustainability of providers; there were hidden costs of tendering; and, it contributed to increasingly distant and formal relationships between funders and providers. There was a need, they argued, 'to find a better way'. ${ }^{30}$

Second: children's services were under threat of market failure. Market-based approaches, it was argued, do not and will not work within the field of children's services. Children England suggested that marketisation fundamentally changed (for the worse) what charities do, and how they do it, while also presenting a significant threat to their long-term viability. Underlying this was a deeper concern that services with only one buyer (the state), relatively few suppliers, and no power for children as 'consumers' were doomed to failure, with little evidence that public sector markets provide financial savings, sustainability or improvements to quality and outcomes.

Third: local systems were under threat by a failure to respect interdependence and distinction. In this narrative, the voluntary sector's distinctive qualities - accountability, governance, mission, and multiple roles as 'changemaker', advocate, campaigner, innovator and provider of both highly specialist and universal preventative services - were presented as being threatened by austerity-induced cuts to local authority budgets, competitive commissioning models, anti-lobbying legislation and a climate of critique against charities who speak out. A case was made for appreciating the interdependent roles and responsibilities of statutory and voluntary sectors: 'We want to reframe the relationships between public servants and the voluntary sector, based on a mutual respect for the unique roles and capacities of each, and a rediscovery of what we have in common'. ${ }^{31}$ 
Fourth: the welfare settlement was under threat, and the welfare state should be redesigned. A final narrative extended existing arguments by seeking to defend fundamental welfare principles, practices and models of provision, which had been undermined by the Conservative-led governments' project to shrink the state. There was, Children England argued, a need to redesign the welfare state, redefining the roles and responsibilities of the state and the voluntary sector to meet a 'hierarchy of needs':

Children England is in what William Beveridge once called 'crusading spirit'. We're on a mission to fundamentally review and redesign the welfare state in Britain - so that it can work better, more sustainably for the 21st Century; and so that it can better serve the rights and needs of its youngest citizens.... The voluntary sector was the inspiration, the creative precursor, and the key agent of change, in the creation of the 20th Century welfare state. We must step up to the plate and do so again, for the 21st Century. ${ }^{32}$

\section{A line in the sand: resisting the moving frontier}

Children England used these four narratives to make targeted interventions in live policy debates during the 2010s, including children's social care reform over the period 2014 to 2017. These reforms highlight the dynamic and contested nature of the moving frontier of welfare. In spring 2014 the focus, resources and institutional structures of child protection and support for children and families gained headlines in the mainstream media in the UK. A government consultation on proposals to enable local authorities to delegate or outsource core children's services - including child protection - to third parties, which included private companies, was framed by the media as permissive, enabling innovation in a system under increasing pressure. ${ }^{33}$ It was couched in the prevailing language 
of 'state failure' (see Chapter Five), invoking the need to try something different.

Children England responded by joining others in a campaign against the proposals. The consultation, it argued, was rushed, narrow and lacked detail or supporting evidence. More fundamentally, the possibility of profit making from child protection was inappropriate and there would be a lack of accountability within the newly proposed structures. It argued that child protection is a fundamental human right and one of 'the most powerful duties of the state', which 'must never be open to the real, or even perceived, risk of being done in the pursuit of profit'. ${ }^{34}$ In response to the campaign the government agreed to ban profit making from any changes to child protection. ${ }^{35}$ And the proposal was amended: the regulations indicated that any such delegation must only be to not-for-profit providers, thus (ostensibly) ruling out private providers.

Despite this, the wider issue of delegated power and thirdparty involvement did not go away. In 2014 the government had argued that local authorities and others did not have the freedom or power to develop, test and implement radical new approaches in children's services. In 2015 the newly elected Conservative government reiterated this. The Prime Minister argued that 'efforts to extend opportunity have been undermined by a tolerance of government failure'. ${ }^{36} \mathrm{He}$ indicated that child protection 'would be a big focus of the next 5 years' ${ }^{37}$ A subsequent speech by Cameron on 'the smarter state' indicated that significant reform was in the air: "we will say to any local authority failing its children: transform the way you provide services, or those services will be taken over by non-profit trusts or other partnerships'. ${ }^{38}$ It would be transformative: 'one of the big landmark reforms of this Parliament ... show[ing] how serious we are about confronting state failure and tackling some the biggest social problems in our country'. 39 
A January 2016 vision document produced by the Department for Education proposed that government would

\begin{abstract}
support the emergence of new not-for-profit children's social care organisations as part of a more dynamic and diverse range of provision ... we will support those local authorities who wish to establish organisations, mutuals and trusts covering all, or part, of their children's social care functions, working with children's charities to explore the scope for their involvement. ${ }^{40}$
\end{abstract}

A more substantial policy paper in July 2016 highlighted variations in practice across local areas. It argued that: 'The current system, where the vast majority of children's social care services are delivered by in-house local authority teams, is not delivering consistently excellent practice'41 and 'innovation has not been given the space to thrive'. ${ }^{42}$ To remedy this, the paper expresses the government's ambition that 'by 2020, over a third of all current local authorities will either be delivering their children's services through a new model or be actively working towards a different model'. ${ }^{43}$

The narrative invoked voluntary action in two ways: either drawing on specialist expertise through strategic partnerships between local authorities and charities or in the emergence of new 'not-for-profit' trust models. However, a parliamentary committee inquiry running alongside these policy developments argued, on the basis of evidence from two large, longstanding national children's charities - the National Society for the Protection and Care of Children (NSPCC) and the Children's Society - that 'It appears that charities may not be as enthusiastic about taking on statutory services as the Government is to invite them to do so'. ${ }^{44}$

New legislation, which began its parliamentary process in May 2016, proposed that the Secretary of State could exempt or modify requirements under children's social care legislation to 
enable local authorities to achieve better outcomes or the same outcomes more efficiently. This "power to test different ways of working' was the focus of parliamentary debate. Children England worked with a coalition of 40 organisations and experts across sectors - Together for Children - to object to the proposals, which would, they argued, create a fragmented landscape of children's legal protection and of social care practices, while also making the 'prospect of marketisation and profiteering' a real concern. ${ }^{45}$ A petition against exemption clauses gained 170,400 signatures.

The campaign proved influential. In November 2016 the House of Lords voted against the power to exempt local authorities from their duties to vulnerable children. Reflecting the objections raised by Together for Children, peers argued that the 'exemption clauses' were unnecessary, sweeping, risked fragmenting services, threatened children's rights, compromised their safety, and circumvented normal legislative processes. They were also were worried about paving the way for the greater involvement of private companies in children's services. The government at first resisted, but eventually in March 2017 it was reported that the government had decided to withdraw the proposals entirely, after representations from opponents and the likelihood of further parliamentary defeats. The new legislation, now without the 'power to test different ways of working', was passed in April 2017.

On the face of it, a campaigning group involving Children England and others, working with sympathetic parliamentarians, had successfully challenged this particular attempt to pass legislation which would otherwise have helped move the frontier between the state and voluntary action (Tunstill and Willow, 2017). A state narrative bringing together inconsistency and 'failure' of existing public services, with the possibility of transformation through innovation, new leadership and a diverse range of alternative new models, had invoked the dynamism and creativity of the charitable and voluntary sector. Ironically, it was elements of the voluntary 
sector in alliance with others, including professional bodies, which had defended, in this way and for the time being, the broad array of public arrangements and provisions built up since the Children Act 1948. Rather than taking the opportunity to expand their role within children's services, to support government's attempts to move the frontier, the voluntary sector, at least in the guise of Children England, had been actively involved in resisting it.

\section{Summary}

This chapter has examined how the 'room' for voluntary action is strategically narrated and negotiated, through detailed discussion of two contrasting emblematic moments of political and policy development.

In the 1940s the National Assistance Act 1948 came to symbolise much of the post-war Labour government's approach to comprehensive welfare provision, in its bold claim to have finally dismantled the Poor Law. Yet at the same time, it opened the way for securing state support for auxiliary services for older and vulnerable people. The NOPWC was active in shaping the debates during the war around emerging and unmet needs of older people, and these partly framed the legislative response through the 1948 Act. It also actively lobbied on behalf of older people, with the result that local authorities were both encouraged to seek active partnership with local OPWCs and to fund the provision of personal services such as home visiting and meals on wheels. The emblematic moment highlights the efforts of voluntary organisations to secure or retain a place in the new state-centred welfare settlement and the role of strategic narratives in doing so.

For the 2010s the analysis focused on children's services, and the move by Children England to develop a more critical stance and voice in relation to the direction of government policy. Here the government was deepening its pursuit of competitive public service markets. Harnessing the media 
into utilising a narrative of a legacy of state failure, the state envisaged an expanding role for voluntary action in an era of 'open public services'. Rather than deploy a narrative to advance this expanded role, Children England sought to contest and challenge state retrenchment, re-emphasising the valuable role of children's charities alongside and in interdependent partnership with the public sector. It further sought to draw a line in the sand to prevent the government loosening regulations to allow more of a role for private firms and charities, particularly around child protection. It campaigned with others, successfully at the time, in the media and in Parliament, to prevent the government from reforming children's social care services. Over time, a more proactive narrative emerged from Children England, seeking to start its own transformational conversation about the welfare state.

Focusing on emblematic moments sheds light on the careful positioning, manoeuvres and narratives developed by voluntary organisations in both decades to shape debates around social welfare, and to find, defend and secure an appropriate role or place in an emerging welfare settlement. This fits with theories on discursive institutionalism (Schmidt, 2008) which hypothesise that these types of manoeuvres gain greater salience in moments of upheaval and transformation, and are witnessed and evidenced in both the 1940s and the 2010s, and arguably continuing into the 2020 s. 


\section{SEVEN}

\section{Challenging the moving frontier?}

\section{Introduction}

The 2010s witnessed the most significant renegotiation of social welfare provision in England since the consolidation of the welfare state after the Second World War. In the 1940s context of war, austerity and considerable deprivation in the UK, the Beveridge Report proposed a series of measures to address the five giant evils (Beveridge, 1942). The subsequent establishment of comprehensive welfare services led to farreaching changes in the role and purpose of many voluntary and community organisations and to intense debate about the moving frontier between the state and voluntary action. It was a discussion that involved policy makers, the wider public (Deakin and Davis Smith, 2011) and the leaders of voluntary organisations (Brewis, 2014). That discussion contributed to a growing consensus both about the extent of previously hidden needs and the collective responsibility for meeting them. While there was difference of opinion as to where that collective responsibility should lie, there was widespread support for an expansion of the state's role in welfare provision.

Some hoped, while others feared, that the state would take over all responsibility for welfare services, leading to the 
Image 7.1: Imagery from Children England's campaign for a 'childfair state', launched in 2018

\section{ChildFair State}

A society that has children at heart is a better society for everyone

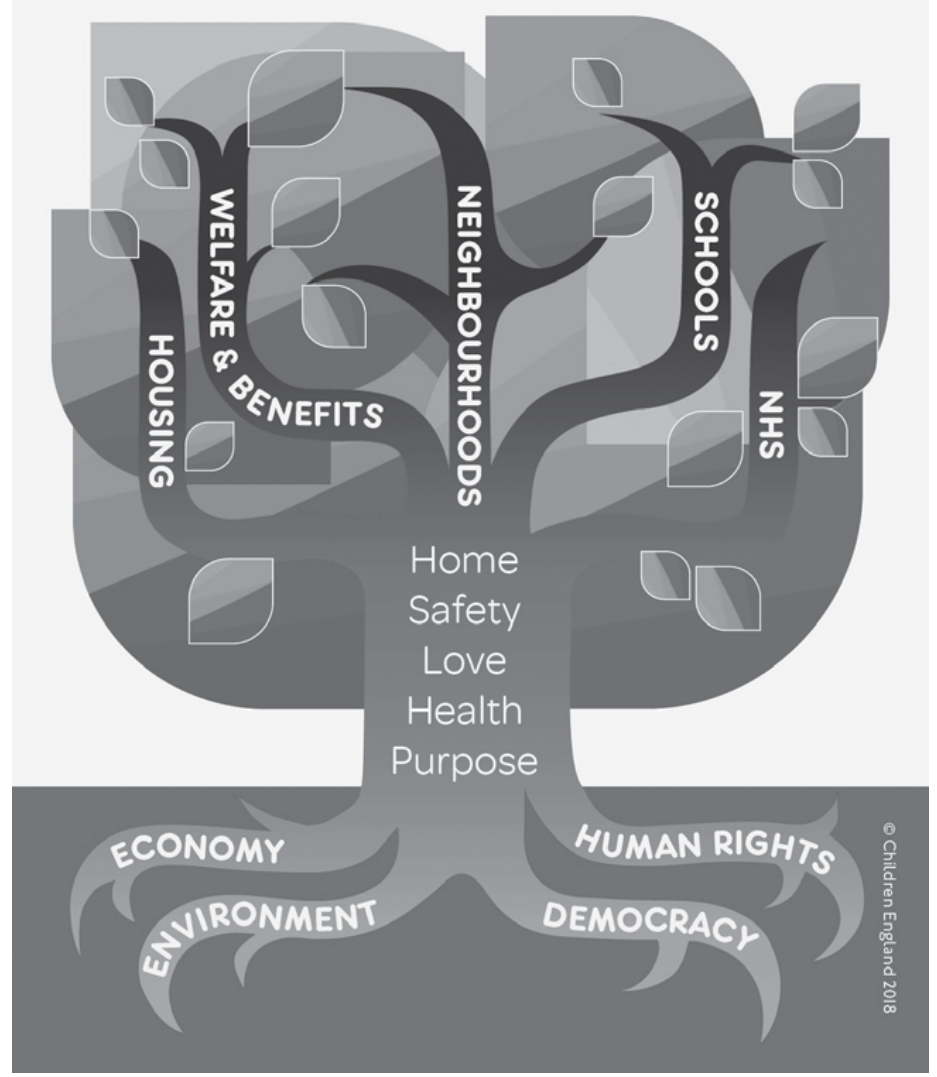

Source: Reproduced courtesy of Children England. 
demise of voluntary action. Instead, the notion of partnership became a commonplace description of the relationship between the state and the voluntary movement. While the state was expanding its role in welfare, voluntary organisations were consolidating their positions, including through the strengthening and establishment of new umbrella bodies. The idea of a 'movement' enabled voluntary organisations to speak with a more unified voice to government and in this context 'partnership' became a reassurance that voluntary action would still have an important role to play. Voluntary organisations argued that, despite changed conditions, their work would continue because it was essential to a free democracy. The state recognised that ongoing post-war austerity meant voluntary action was necessary to meet need, while volunteers and voluntary organisations were seen to humanise services. A pragmatic partnership was secured, overcoming suspicion on both sides: a settlement of convenience in recognition of the scale of need, the urgency of working together to address it, and the different roles and contributions that voluntary action, the state and others could make. Voluntary organisations developed new areas of service delivery and were intrinsically involved in policy design.

In the 2010s there was a similar convergence of major national and international events, which included the ongoing impact of the global financial crisis, and the prevailing political and economic response involving an austerity programme of public deficit reduction. Since 2010, Conservative-led governments have presided over considerable changes in the ways in which welfare services are provided, coordinated and financed (Alcock, 2011; Taylor-Gooby, 2012; Lawton et al, 2014), underpinned by an ideological reassertion of limited government and 'open public services' involving a plural market of providers. Such developments refuelled debates about the growing levels of unmet needs and the balance of provision in the mixed economy of welfare. This intensified discussion about the role of voluntary action in the delivery of public 
services (Macmillan, 2013; Woolvin and Hardill, 2013) and in welfare provision more broadly. Conservative thinking identified the welfare state itself as a problem, characterising it as bureaucratic and prescriptive, with an approach to the delivery of public services that stifled innovation and deepened rather than resolved social problems. This emerging narrative of state failure was echoed by others, including some within the voluntary sector, albeit with different understandings of the causes and nature of that failure and what the response should be.

The promise of a Big Society and 'open public services' appeared to offer new opportunities for voluntary action. And there was a continued acknowledgement that voluntary action was an essential component of society - part of the fabric of the nation - including a central role in service delivery. Yet this was not to be a simple story of a shrinking state and a growing voluntary sector, or of an ever-closer alignment between the two. The Big Society soon became mired in scepticism (from the media, the public and the voluntary sector) that it was a cover for austerity, as government funding to the voluntary sector faltered, while private sector involvement in public service delivery continued to grow. The suspicion was that the government's interest in the voluntary sector (its preferred terminology in the 2010s tended to be 'the social sector' and 'civil society') was a disguise for lower-cost services and extending the reach of public service markets. A series of highprofile media attacks on the pay, fundraising, governance and leadership practices of charities was augmented by government efforts to limit the campaigning role of voluntary organisations, leading to claims that charities were being silenced. The political and policy context in which the sector was operating appeared to become decidedly chillier (see, for example, Independence Panel, 2015; Civil Exchange, 2016). While Conservative governments spoke of expanding the role of voluntary action in public service provision, at the same time they restricted and reshaped funding to the sector, significantly weakened 
voluntary sector infrastructure, and moved away from the partnership approach to the policy development characteristic of the pre-2010 Labour governments (Kendall, 2003; Lewis, 2005). The voluntary sector felt increasingly fragmented, with competitive tendencies fuelled by commissioning processes, further affecting its collective voice. In the face of rising levels of unmet needs and increasingly polarised views on how to address these needs - including a growing emphasis on individual (blame and) responsibility - the state and voluntary organisations continued to work together, but the relationship, we suggest, became one of antagonistic collaboration.

Studying both periods together highlights how in such transformational moments, when developments and debate intensify, the moving frontier between the state and voluntary action can appear to make a decisive shift in one direction or another. However, these should be understood as particular moments within the context of an ongoing, long-standing discussion of the mixed economy of welfare (Lewis, 1999a). Further, the notion of a moving frontier suggests a firm, singular boundary dividing two separate spheres. Instead, our analysis has demonstrated that there are multiple, fluid and permeable frontiers: between the state, voluntary action and forms of welfare, such as that provided through the private sector; between different fields of welfare activity, including services for children, youth or for older people; and covering different kinds of frontier relationship, such as provision, finance and regulation. These frontiers are subject to constant change in multiple directions, and to contestation. Different ways of understanding the changing relationship between the state and voluntary action have developed, in part reflecting different levels of analysis and in part different theoretical and political framings. In this, our conclusions chapter, we revisit our three theoretical perspectives to argue for a recognition of the variability, fluidity and complexity which challenge fixed understandings of the roles, contributions, positions and relationships between voluntary action and the state and 
highlight the role of strategic narratives deployed as discursive interventions to shape moving frontiers.

\section{Accounting for change}

Social origins theory suggests that the voluntary or non-profit sector is deeply embedded in specific national contexts, its role and size linked to different welfare regimes (Salamon and Anheier, 1998). In this model the UK is considered a liberal civil society regime, with a comparatively large voluntary sector and low welfare spending, but retaining some social democratic features (for example the National Health Service) based on pro-state attitudes fostered during the Second World War and associated with the working class mobilisation that underpinned the Attlee government from 1945 to 1951.

While helpful in distinguishing cross-national differences in welfare models, social origins theory presents a somewhat static picture of relatively fixed unchanging regimes, with enduring roles for the state and voluntary sector, identifiable through comparative analysis of high-level data. Others have argued for the need to look at a smaller geographical scale, to recognise variations within nations. Arvidson et al (2018), for example, introduced the idea of local civil society regimes as a way of allowing for spatial variations within nations, although still within the overall framework of welfare regimes and social origins theory. Our analysis has highlighted variations over time and just how contentious these variations can be. These dynamic processes and contentious debates involve active work to frame discussions of the role, position and contribution of voluntary action. They become animated and intensified during significant moments of transformation, and are hard to accommodate within the relatively fixed and stable understanding provided by social origins theory.

This book has also argued that accounts of the shifting balance of roles, expectations and resources within contemporary discussions of the mixed economy of welfare tend (with some 
notable exceptions) to be rather state centric (Finlayson, 1990; Lewis, 1999b; Macmillan and Kendall, 2019). There is a risk of underestimating the historic and ongoing contribution of voluntary action to welfare policy and provision and oversimplifying the fluid and variable versions of mixed economies that may exist over time and at any one time. They present a relatively static picture, or they assume a 'zero-sum' picture where the growth of the state simply crowds out voluntary action or vice versa. They rarely consider the extent to which such developments have been actively shaped by debates among different actors about the appropriate balance of responsibilities. Yet in the analysis presented in this book we have found these to be highly significant.

Further, contemporary writing on the relationship between the state and the voluntary sector can become rather onedimensional (focusing on who provides services) and often seems to proceed in one direction (state withdrawal opening space for voluntary, and private, sector providers), again not fully allowing for variations. Successive governments have, over some three decades, sought to advance the role of the voluntary sector in social welfare delivery, as part of an ongoing series of public service reform efforts. For the Coalition and subsequent Conservative governments of the 2010s, this was initially couched in terms of the Big Society, and later in its 'open public services' agenda, seeking new ways, models and financial mechanisms to 'open up' public services to new providers from the private and non-profit sectors. The moving frontier between the state and voluntary action would, in this vision, shift decisively to contain the former and expand the latter. However, beyond a first glance, disruptions to this broad vision readily begin to arise.

\section{Variation and contestation}

Rather than decisive unidirectional shifts between the state and voluntary action, we have evidenced variations, complications 
and counter-currents. We have focused on three areas of social welfare - services for children, young people and older people. Informed by strategic action field theory, our analysis has foregrounded the complexity of these overlapping fields, all of which have fuzzy and porous boundaries, and the contention and struggles which exist around them.

During the 1940s, we have suggested, there was less sense of separation between voluntary organisations and the state. The separate spheres advocated by older traditions of Victorian philanthropy, and epitomised by the Charity Organisation Society, had given way to a more interdependent relationship (Macadam, 1934). There was closer integration, through, for example, a high degree of cross-over of personnel, in which the governance committees of leading voluntary organisations were chaired by politicians. Indeed, there was considerable involvement by MPs in the establishment of umbrella bodies which helped to consolidate the voluntary movement during wartime. Voluntary organisations were called upon to provide evidence on need, which directly influenced government thinking, and they made significant contributions to the subsequent formation of welfare policy: they were integral to the policy process. In the 2010 s we witnessed something of a different relationship, within which the boundaries and interactions between voluntary action and the state looked somewhat different. Certainly, there was much talk of collaborative arrangements, and some raised concerns at what they saw as a loss of distinctiveness in welfare service delivery. Yet at the same time there was a separation of the state and voluntary action in policy terms, signified, for example, by the dismantling of infrastructure engagement mechanisms such as Strategic Partner programmes. The result was that voluntary organisations looked to influence the development of government policy from afar, more as outsiders in the policy process, rather than being integral to its design.

Further, at any one time there is not just one field of voluntary action and/or one field of welfare, but multiple, 
nested and overlapping fields. We have focused specifically on children, young people and older people's services - three fields in which voluntary organisations have long since played a significant, although varied, role in the provision of welfare. There are, however, significant differences between them, not least in the contrasting historic and contemporary positions that both voluntary action in general, and individual voluntary organisations, occupy within those fields, and the extent and nature of 'unsettlement' experienced over the last decade. There were clear differences, for example, between youth and older people's services. Older people's services settled somewhat following the formation of Age UK in 2009 and maintained relatively close and influential relationships with government. Youth services, meanwhile, saw a dramatic reduction in funding and the associated closure and merger of key voluntary sector umbrella bodies, alongside the dismantling of statutory provision - evidence of far greater disruption to existing roles and positions. These differences may in part be reflective of the more peripheral location of youth services in policy terms compared to older people's services. Exploring, comparing and contrasting the sector's position and influence within all three fields has enabled a more nuanced understanding of moving frontiers through highlighting their varied, fluid and contested nature. We have seen how the leading voluntary organisations within these fields have been positioned, and have positioned themselves, within these dynamic fields, and how this has changed over time.

These variations and shifts are contentious. Struggles over boundaries between the state, the voluntary sector and other actors form one area of contention within a field. Field change occurs through 'unsettlement', both from ordinary internal shifts such as competition, collaboration, innovation and strategic manoeuvring by different organisations, but also from rarer exogenous shocks such as war (as in the 1940s), economic crisis (preceding austerity in the 2010s) and (as at the time of writing) pandemics. Our analysis has highlighted the fluid and 
highly contested nature of moving frontiers, and particularly the active work of voluntary and state actors in constructing persuasive arguments and credible narratives for their positions.

This recognition calls for a consideration of the ways in which different narratives about voluntary action and the provision of welfare have been constructed, articulated, contested and circulated. We suggest that these narratives should be regarded as field-shaping discursive interventions (see Chapter Two) indicative of struggles over the boundaries between the state and voluntary action, particularly during transformational moments.

\section{The work of narratives}

To take this thinking forward, by drawing on ideas from discursive institutionalism, we have highlighted the ways in which narratives are used strategically in a direct attempt to shape fields of welfare and voluntary action (Schmidt, 2008). We have seen how at moments of crisis, or unsettlement, narratives become important field-shaping interventions, in the ways in which they organise ideas, evidence and argument, to make sense of contemporary developments and frame imaginable futures. Narratives are also involved in the struggle for room, as dominant commonsense ways of articulating change and providing persuasive and settled visions for the future. Multiple actors are involved in efforts to understand configurations of the fields of social welfare - what they look like, who is doing what, with and for whom and how well; and also to shape/reshape them - what they should look like, who should be involved, what their relationships should look like, and how outcomes could be improved. Strategic narratives are part of these 'field-shaping' efforts, undertaken routinely by all actors in a field.

In Chapter Three we identified two dominant narratives of voluntary action which endure across both time periods: voluntary action is part of both who we are and 
what we do. The variations in where emphasis is laid within these narratives, and in wider narratives of need, rights and responsibility, however, have all been used in attempts to both carve out and restrict room for voluntary action in varied ways by different actors over time. Some would see, for example, the distinctive characteristics identified for voluntary action - such as innovation, reach, voice and person-centred approaches - as strong reasons and powerful arguments to make more room for voluntary action. For others they are not. Underpinning both these similarities and differences are important questions about how voluntary action is understood (what is being imagined when different actors talk of voluntary action, charity, and voluntary organisations), ideas of the distinctiveness of voluntary action and whom/what it is being compared to and distinguished from (the state, private business, family).

Claims about the fundamental roles of voluntary action, highlighting its importance to a healthy society, assume greater significance at moments in time when those very roles are perceived as being under threat. In the 1940s the expansion of the welfare state led to concerns to preserve room for voluntary organisations as welfare service providers. Narratives were constructed to emphasise the distinctiveness of voluntary action, including its innovation, reach and humanity, and to emphasise the extent of need and the need for partnership in order to address it. The establishment of new umbrella bodies and associated deepening of collaboration among voluntary organisations enabled a more united, powerful voice. In contrast, in the 2010s, the opening up of public services and support for a Big Society appeared to offer the potential to expand the role of voluntary action in welfare provision. At the same time, however, funding was cut, partnership programmes were dismantled, attempts were made to silence voluntary organisations, and funding regimes contributed to competition and fragmentation within the voluntary sector, affecting its collective voice. The sector pushed back: it claimed it would not be silenced; it argued for a recognition of distinctiveness 
and interdependence; and at times it resisted attempts to roll back the state.

More specifically we highlighted two emblematic moments from our analysis of debates across both time periods which demonstrate more precisely the work of strategic narratives in practice, fundamentally shaping the changing welfare mix, albeit in rather different ways. In the 1940s the NOPWC was active in shaping debates, lobbying on behalf of older people to influence the creation of policy in a way which secured a place for voluntary action in the new state-centred welfare settlement. In the 2010s we focused on the narratives articulated and circulated by Children England as it pushed back against attempts to move frontiers in ways which represented a retrenchment of the state and a transfer of statutory responsibilities for child protection.

Narratives, then, can be perceived as work to secure positions within unsettled (nested) fields. They also seek to reorder fields. They do so through claims of significance, distinctiveness, independence and interdependence. The significance of narratives is heightened during moments of transition, but rather than always working in one direction they may be used to push back, or pull forward, moving frontiers depending on context. Alongside differences over time, there are also differences between fields as the varied dynamics of those fields leave voluntary organisations with more, or less, room for manoeuvre.

One of the narrative strategies adopted by commentators is the use of history to make sense of the present and to argue for a vision of the future. This is evident in both periods. In the 1940s voluntary leaders regularly referenced the movement's long history of innovation and service delivery, and its role in establishing public services taken on by the state, as part of their strategy to secure a continued role within the shifting landscape of welfare provision. In the 2010s voluntary sector leaders drew on examples of individual organisations' historic roles in creating the welfare state as part of a strategy to defend 
and rebuild a welfare state they considered under threat from an ideologically opposed government pursuing a policy of austerity.

\section{COVID-19 and the emergence of a partnership of necessity?}

While our research focused on the 2010s, this book was written during the pandemic in 2020 and early 2021. The response to the pandemic prompted the adoption of wartime analogies from the Prime Minister downwards, with references to a socalled 'Blitz spirit' becoming commonplace (Irving, 2020). And in much the same way that the Second World War changed the lives of all citizens (albeit unevenly) and revealed the previously unrecognised need, the pandemic shone a light on new and enduring needs, including hunger and food poverty, and exposed and exacerbated pre-existing inequalities. There was widespread public support for initiatives such as extending free school meals to cover holiday periods, reflective of a wider growing sympathy with 'the position of those of working age who find themselves in need' (Curtice, 2020: 103) and suggestive of greater support for the welfare state.

'Unprecedented' was the adjective $d u$ jour for COVID-19. Its long-term impact remains uncertain. For the voluntary sector, the pandemic represented an 'unsettlement' of a scale and pace unimaginable just a few months earlier. In England, as in the rest of the UK and beyond, voluntary organisations stepped in and stepped up as the first response to new forms of unmet need. As the crisis hit, people joined in community mutual aid efforts to support local people in isolation and need. The early months of the pandemic were marked by rapidly improvised new relationships between voluntary action and the state at local and national levels: what at first seemed to herald a new partnership of necessity (Macmillan and Ellis Paine, 2020), reminiscent of but substantially different from the mobilisation of voluntary action at the start of the Second World War. Unlike the 1940s, when the voluntary movement built on 
good relations with government forged during its grassroots work to alleviate some of the effects of the Depression, this period followed a decade in which the relationships between government and the voluntary sector were far more strained. As the pandemic continued, and as voluntary organisations faced increasingly difficult combined pressures of rising demand, operational challenges that required rapid changes to service delivery models, and declining resources (Macmillan, 2020), tensions began to show. While government talked of the 'gentleness of charity' (Sunak, 2020), the voluntary sector countered that 'in the toughest times, we do the toughest work' (Acevo, 2020). In a joint effort to generate recognition and create room, the sector campaigned for greater government and public support, arguing that it was \#NeverMoreNeeded. The voluntary sector's role as a fundamental part of who we are and what we do to meet needs in the face of adversity began to feel more pertinent than ever.

\section{Rethinking welfare futures}

Focusing on the different ways in which people talked about voluntary action, in two transformational moments, provides new insights into how fluid and contested the boundaries between the state, voluntary organisations and other actors are. In the 1940s voluntary action was closely integrated with the state, and voluntary organisations were influential in the formation of welfare policy. This integration secured room for voluntary action within the newly expanding welfare state and helped to mobilise a pragmatic partnership in service provision. In the 2010 s there was a separation of the state and voluntary action in policy terms, combined with what some viewed as a loss of distinctiveness in service delivery, contributing to an antagonistic collaboration between voluntary action and the state. The initial shock of COVID-19 in 2020 led to a partnership of necessity, in which the voluntary sector was at the forefront of responses to social need. However, as the pandemic continued 
into 2021, and the financial impact on the charity sector became more apparent, this partnership began to falter, at least at the national level.

Narratives were constructed as strategic interventions in these unsettled periods. This played out in different ways at different times. Today, parts of the voluntary sector, together with some parts of the public, are resisting attempts to move frontiers between the state, voluntary action and others. A key message that emerged from such narratives in the 2010s, reinforced by the effect of the pandemic and responses to it in 2020, was that the state was failing to meet its responsibility to provide for those in need, contributing to a widening of inequalities within society. These concerns were shared by the public, who agreed that there must be change. As to what that change should look like, however, there was little agreement.

While both the 1940s and 2010s saw rigorous debate about the role of voluntary action, there was a notable difference when it came to discussions about the role of the state in social welfare. In the 1940s there was a comprehensive, nationwide debate about the new responsibilities the state would be taking on and the consequences of doing so. The popularity of the Beveridge Report and the framing of the 1945 general election around post-war reconstruction is an indication of this. By contrast, the 2010s involved no comparable debate on the role, scope or responsibilities of the state in social welfare. Significant reforms were introduced with profound implications for individual citizens, as well as consequences for voluntary action. Despite such wide-reaching reforms, and despite the strong opinions many people held about these changes, there was scant attempt to openly discuss and reach a consensus about who should be responsible for providing social welfare services in the 21st century, or what levels of needs they should be meeting. Views had become deeply polarised.

As we move further into the 2020s, the shock of the pandemic, its far-reaching consequences, and the depth of the response required and proffered by the state, voluntary action 
and others has opened a window of opportunity to think and talk - again about our collective responsibility to meet needs within society. As we move on through COVID-19, the issues raised in this book - roles, responsibilities, contributions, boundaries, frontiers, narratives, room and positions - will continue to be debated. It is our hope that the analysis we have provided may offer a toolkit - a set of concepts and ways of thinking - that may help to make sense of these debates and developments as they unfold. 


\section{Notes}

\section{three}

1 Clement Attlee, 'Speech at Toynbee Hall, 31st March 1947', cited in Briggs and Macartney, 1984: 135-6.

2 Lord Pakenham, HL Deb 22 June 1949 vol 163 cc119.

3 Lord Nathan, HL Deb 22 June 1949 vol 163 cc90.

4 Lord Hereford, HL Deb 5 Oct 2010 vol 71 col 31.

5 House of Lords Select Committee on Charities, Stronger Charities for a Stronger Society, HL Paper 133, (London: House of Lords, 2017).

6 HM Government, Civil Society Strategy: Building a Future that Works for Everyone (London: Cabinet Office, 2018).

7 Labour Party, From Paternalism to Participation: Putting Civil Society at the Heart of National Renewal (London: Labour Party, 2019), 4.

8 NCSS, 'Annual Report 1939/40', LMA/4016/IS/A/01/006, 5, London Metropolitan Archives.

9 Standing Conference of National Voluntary Youth Services, Partnership in the Service of Youth, November 1945, NCV/9, UCL Institute of Education Archives.

10 NCVO, 'Manifesto statement: The right to campaign is essential to a healthy democracy and a vibrant civil society, 2010', 2010, NCVO private archive.

11 NCVO, 'A Manifesto for a good society' (Draft), 2014, NCVO private archive.

12 NCVO, Charities and Volunteering Manifesto, 2017, NCVO private archive.

13 April 1947, MO writer 3418, female (52), railway clerk.

14 April 2018, MOP writer, female (74), retired nursery nurse, no political affiliation at present.

15 HC Education Committee, Services for Young People, Third Report of Session 2010-12, Vol 1, HC 744-I, (London: TSO, 2011).

16 Lord Taylor of Holbeach, HL Deb 5 Oct 2010 vol 71 col 20.

17 Taylor, HL Deb 5 Oct 2010 vol 71 col 20. 


\section{TRANSFORMATIONAL MOMENTS IN SOCIAL WELFARE}

18 NCVO, 'Consultation response: NCVO submission to the Public Administration Select Committee's Review of the Charities Act 2006', 2012, NCVO private archive.

19 Fred Messer, 'Co-operation between voluntary and statutory bodies' in NOPWC, Working Together for Old People's Welfare: Report of the Second National Conference on the Care of Old People 14 and 15 November 1947 (London: NCSS, 1948), 19.

20 Messer, 'Co-operation', 19.

21 NCSS, 'Annual Report 1939/40', LMA/4016/IS/01/006, 5.

22 NCSS, 'Future purpose and organisation of the National Council of Social Service', Annual General Meeting 1944, LMA/4016/IS/A/01/006, 1.

23 2018, MOP writer R5429, female (42).

24 2018, MOP writer M5645, female (44), library assistant.

25 J. Landale, "MP wants watchdog to probe "overtly political" Oxfam campaign', BBC News, 10 June 2014, https://www.bbc.co.uk/news/ uk-politics-27783331

26 R. Mason, 'Charities should stick to knitting and keep out of politics, says MP', The Guardian, 3 September 2014, https://www.theguardian.com/ society/2014/sep/03/charities-knitting-politics-brook-newmark

27 Cabinet Office 'Government announces new clause to be inserted into grant agreements', Press Release, 6 February 2016, https:// www.gov.uk/government/news/government-announces-new-clause-tobe-inserted-into-grant-agreements

28 Matt Hancock, HC Oral Answers, Government Grant Agreements, 27 April 2016, vol 68, col c1415.

29 NCVO, 'Written evidence (CHA0148) to Select Committee inquiry', 2016, NCVO private archive.

30 NCVO, 'Press release: Lobbying Act reform: Debate required, say charities', 2017, NCVO private archive.

31 NCVO, 'Written evidence (CCE0239) to Select Committee on Citizenship and Civic Engagement', 2017, NCVO private archive.

32 NCVYS, 'Policy briefing: Summary of the UK non-profit sector 2014', 2014, NCVYS additional deposit.

33 2018, MOP writer R5429, female (42).

34 HM Government, A Connected Society. A Strategy for Tackling Loneliness - Laying the Foundations for Change (London: Department for Digital, Culture, Media and Sport, 2018), 16.

35 May 1947, MO writer 4299, female (29), medical social worker.

36 NCSS, New Opportunities? The Annual Report of the National Council of Social Service 1945-46, LMA/4016/PA/C03/21, 6.

37 HM Government, Open Public Services White Paper, Cm 8145 (London: HMSO, 2011). 
38 Francis Maude and Nick Hurd, Open Letter to the Sector, Cabinet Office, 14 October 2010.

39 May 1947, MO writer 4194, female (30), homemaker.

40 'Note of a conversation with Mary Stocks', Memorandum 17, Voluntary Social Service Inquiry, BEV IXa/31, Item 25, LSE Archives and Special Collections.

41 Joan S. Clarke, 'Charter for Voluntary Services', Memorandum 15, Voluntary Social Service Inquiry, BEV IXa/31, Item 21.

42 April 1947, MO writer 1313, female (56), teacher.

43 Mass Observation Bulletin, New Series No 10 (July and August 1947).

44 April 1947, MO writer 1637, female (48), market gardener.

45 2018, MOP writer M5645, female (44), library assistant.

46 House of Commons Committee Public Accounts, Government funding of Kids Company (London: The Stationary Office Ltd, 2015).

47 House of Commons Public Administration and Constitutional Affairs Committee (PACAC), The Collapse of Kids Company: Lessons for Charity Trustees, Professional Firms, the Charity Commission, and Whitehall 2016, (London: The Stationary Stationery Office Ltd, 2016).

48 PACAC, Collapse of Kids Company, 3.

49 NCVO, 'Leadership 20:20: Commission on the future leadership of civil society, Progress report for the NCVO board of trustees', 2017, NCVO private archive.

50 HM Government, Open Public Services, 5.

51 May 1947, MO writer 3243, male (31), student.

52 Baroness Morgan of Drefelin, HL Deb 5 Oct 2010 vol 71 col c25.

53 HM Government, Open Public Services, 9.

54 2018, MOP writer R5429, female (42).

55 2018, MOP writer B3010, female (54), civil servant.

56 2018, MOP writer J2891, female (53), case worker and county councillor.

57 2018, MOP writer H6109, female (40), student mental health nurse.

58 NCVYS, 'NCVYS: An overview of the voluntary and community youth sector in England - Presentation', 2015, NCVYS additional deposit.

59 Children England, Children England Response to the Supporting a Stronger Civil Society Consultation, 2010, Children England Archive, UCL Special Collections, 8-9.

60 NCVO, 'Briefing on the Decentralisation and Localism Bill', 2010, NCVO private archive.

\section{four}

1 NCSS, NCSS Annual Report, 1939/40, 3.

2 'Minutes of the Associated Council of Children's Homes, 5 March 1943', Children England Archive. 


\section{TRANSFORMATIONAL MOMENTS IN SOCIAL WELFARE}

3 'Minutes of the Associated Council of Children's Homes, 13 April 1945'.

4 'Minutes of the Associated Council of Children's Homes, 12 Jan. 1945'.

5 NCSS, Annual Report 1940/41, 10.

6 NCSS, Annual Report 1940/41, 10; D. Ramsey, 'The National Old People's Welfare Committee of the United Kingdom', Journal of Gerontology 7(3) 1953:501-3.

7 A.M. Watson, 'Evacuation of the Aged', 26 November 1940, Age UK Archive.

8 NCVO, Manifesto 2015: A Bigger Difference: Realising the Potential of Voluntary Organisations and Volunteers, 2015, NCVO private archive.

9 Children England, '4 in 10 London children live in poverty' campaign, http://www.4in 10.org.uk/; Children England, Annual Report and Financial Statement 31 March 2016, 2016, Children England Archive.

10 UK Youth, Annual Review: 2017, 2017, UK Youth private archive.

11 NCVYS, NCVYS Strategy 2012-2015, 2012, NCVYS additional deposit.

12 Age UK, Our Power is Our Number: Using Our Voice, Using Our Votes, Being Heard, 2010 Election Manifesto (London: Age UK, 2010).

13 Age UK, Dignity in Older Age and a Late Life Worth Living: Age UK's Ambition for the Next Parliament 2017--2022, 2017 Election Manifesto (London: Age UK, 2017).

14 Social Justice Policy Group, Breakthrough Britain: Ending the Costs of Social Breakdown. Overview (London: Social Justice Policy Group, 2007); Centre for Social Justice, Breakthrough Britain 2015 - An Overview (London: Centre for Social Justice, 2014), 2.

15 David Cameron, 'Prime Minister's Speech on Life Chances', 11 January 2016, https://www.gov.uk/government/speeches/ prime-ministers-speech-on-life-chances

16 Department for Work and Pensions, Improving Lives: Helping Workless Families (London: DWP, 2017).

17 2018, MOP writer R6581, female (30), journalist.

18 April 1947, MO writer 1190, male (75), retired clerk (emphasis in the original).

19 2018, MOP writer B4334, female (78), retired nurse.

20 George Osborne, 'Speech to the Conservative Party conference', 8 October 2012, https://www. newstatesman.com/blogs/politics/2012/10/ george-osbornes-speech-conservative-conference-full-text

21 David Cameron, 'Troubled Families Speech', 15 December 2011, http:// www.number10.gov.uk/news/troubled-families-speech/

22 Department for Work and Pensions, Improving Lives; Centre for Social Justice, Breakthrough Britain 2015.

23 Age UK, 'Consultation response to DWP 21st Century Welfare', 2010, Age UK Archive. 


\section{NOTES} Cornwall, Conservative.

Age UK, 'Briefing on Government Proposals for Social Care Reform', 2012, Age UK Archive.

26 Age UK, Our Power is Our Number: Using Our Voice, Using Our Votes, Being Heard, Election Manifesto (London: Age UK, 2010).

27 Age UK, 'Government Proposals for Social Care Reform'.

28 Age UK, Our Year: Annual Review 2013/14, 2014, Age UK Archive.

29 Age UK, 'Government Proposals for Social Care Reform'.

30 For example, Children England, 'Response to Bigger Society Smaller Government consultation', 2011, Children England Archive.

31 Children England, Commissioning: A Better Way? The Impact of Commissioning on the Children and Families Voluntary Sector (London: Children England, 2010).

32 Children England and the TUC, Declaration of Interdependence (London: TUC and Children England, 2014), 3.

33 Children England, Perfect Storms: An Analysis of the Operating Conditions for the Children, Young People and Families Voluntary Sector (London: Children England, 2012).

34 NCVYS, 'Comprehensive cuts part 2 - Taking stock of change in funding and policies and their impact on young people and the voluntary and community youth sector', 2010, NCVYS additional deposit.

35 April 1947, MO writer 3388, female (56), poultry farmer (emphasis in the original).

36 April 1947, MO writer 2686, male (55), musician and author (emphasis in the original).

37 NCSS, Annual Report, 1944-45 (NCSS: 1945); NCVYS, Partnership in the Service of Youth.

38 Lord Aberdare, 'Address at the NABC Annual Conference, July 1943', NABC Archive, 2.

39 NCSS, 'Annual Report 1943/4', Draft.

40 David Cameron, 'Speech: Our “Big Society” plan', 31 March 2010, https:// conservative-speeches.sayit.mysociety.org/speech/601492

41 David Cameron, 'Speech outside 10 Downing Street as Prime Minister', 11 May 2010, https://www.gov.uk/government/speeches/ david-camerons-speech-outside-10-downing-street-as-prime-minister

42 2018, MOP writer L1991, female (81), retired nurse.

43 NCVO, 'Manifesto 2015: A bigger difference: Realising the potential of voluntary organisations and volunteers', 2015, NCVO private archive.

44 Age UK, 'Policy briefing: Autumn statement 2016 Age UK briefing', 2016, Age UK Archive. 


\section{TRANSFORMATIONAL MOMENTS IN SOCIAL WELFARE}

\section{five}

1 NCSS, A Brief Account of the Work of the National Council of Social Services (London: NCSS, 1938); NOPWC, Working Together; Joan S. Clarke, 'Charter for Voluntary Services', Memorandum 15, Voluntary Social Service Inquiry, BEV IXa/31.

2 April 1947, MO writer 3812, male (31), local government officer.

3 NCSS, 'Minutes of the Annual Meeting 1940', 1; NCSS, Annual Report 1940/1.

4 NCSS, Annual Report 1940-1.

5 Lord Aberdare, 'Address at the NABC Annual Conference, July 1943', UK Youth private archive.

6 NCSS, Annual Report, 1944-45 (NCSS: London, 1945).

7 NCSS, Annual Report, 1945-46 (NCSS: London, 1946), 5.

8 NCSS, Annual Report 1948-49 (NCSS: London, 1949), 8.

9 'Presidential Address', NCSS, Annual General Meeting, 5 December 1946.

10 'Minutes of a meeting of Council of Associated Children's Homes, 15 February 1946'.

11 NCSS, 'Brief report of an informal meeting with Lord Beveridge on his Voluntary Social Service Enquiry', 29 April 1947.

12 R.A.B. Butler, HC Deb 19 January 1944 vol 396 c 219.

13 Education in 1900-1950: The Report of the Ministry of Education for the Year 1950. Cmd. 8244 (London: HMSO, 1950).

14 Annual Report of the Assistance Board for the Year ended 1945. Cmnd 6683 (London: HMSO, 1946).

15 Fred Messer, HC Deb 16 July 1948, vol. 453, cc. 1685-6.

16 Lord Listowel, HL Deb 9 October 1946 vol 143 c.79.

17 NCSS Executive Committee Minutes, 14 July 1949, 2.

18 Lord Pakenham, HL Deb 22 June 1949 vol 163 cc119.

19 April 1947, MO writer 3121, female (64), retired science teacher.

20 April 1947, MO writer 3418, female (52), railway clerk.

21 'Opening Address', NOPWC, Working Together, 8.

22 'Opening Address', NOPWC, Working Together, 8.

23 'Opening Address', NOPWC, Working Together, 8.

24 NOPWC, Working Together.

25 Speech by Lord Rushcliffe, 5 April 1940, 'A report on wartime activities presented to the Executive Committee', 25 April 1940.

26 HC Deb 7 May 1948 vol 450 cc1609-92.

27 Report of the Assistance Board for the Year ended 1945.

28 'Opening Address', NOPWC, Working Together, 8.

29 April 1947, MO writer 1078, female (47), teacher.

30 April 1947, MO writer 1078, female (47), teacher.

31 NCSS, Annual Report, 1944-45 (NCSS: 1945).

32 April 1947, MO writer 3302, male (52), lecturer. 
'Opening Address', NOPWC, Working Together, 7; Emily Samson, Old Age in the New World (London: Pilot Press, 1944), 23.

34 Samson, Old Age, 17.

35 Samson, Old Age, 44.

36 Samson, Old Age, 44.

37 NCVYS, Partnership in the Service of Youth, November 1945, NCV/9, UCL Institute of Education Archives, 6-9.

38 NCVYS, Partnership in the Service of Youth, 14.

39 NCSS, A Brief Account of the Work of the National Council of Social Service (London: NCSS, 1938), 4.

40 NCSS, Annual Report, 1943/44 (London: NCSS, 1944), 3; NCSS, Annual Report 1948-49 (London: NCSS, 1949), 8.

41 HM Government, The Coalition: Our Programme for Government (London: Cabinet Office, 2010), 29.

42 HM Government, Open Public Services White Paper, Cm 8145 (London: HMSO, 2011).

43 HM Government, Open Public Services, 5

44 HM Government, Open Public Services, 5.

45 HM Government, Open Public Services, 11.

46 NCVO, 'Spending review policy analysis', Board Papers: Item 13 Appendix I, 2010, NCVO private archive; Age UK, 'Policy briefing on Government proposals for social care reform', 2012.

47 NCVO, 'Spending review policy analysis'.

48 Age UK, Our Power is Our Number: Using Our Voice, Using Our Votes, Being Heard, Election Manifesto (London: Age UK, 2010).

49 Age UK, 'Policy briefing on Government proposals for social care reform'.

50 Age UK, 'Policy briefing on Autumn Statement 2016', 2016.

51 UK Youth, 'Response to APPG inquiry into youth work consultation', 2018.

52 2018, MOP writer B3227, male (51), administrator.

53 Children England, 'Children England response to the Education Select Committee Inquiry into Services for Young People', 2010, Children England Archive.

54 NCVO, 'Briefing on the Decentralisation and Localism Bill', 2010, NCVO private archive.

55 Children England, 2013/14 Achievements Report, 2014, Children England Archive.

56 2018, MOP writer M5113, female (40).

57 HM Government, Open Public Services, 8.

58 HM Government, Open Public Services, 9.

59 HM Government, Open Public Services, 39.

60 HM Government, Open Public Services, 9.

61 HM Government, Open Public Services, 9. 


\section{TRANSFORMATIONAL MOMENTS IN SOCIAL WELFARE}

Age UK, Consultation response - Equity and excellence - Liberating the NHS, Age UK Response to the NHS White Paper, 2010, Age UK Archive.

63 Age UK, Our Power is Our Number.

64 Age UK, Consultation response: Transparency in outcomes: A framework for adult social care, 2011, Age UK Archive.

65 Children England, Residential Childcare: The 21st Century Challenge: Correcting a History of Market Failure (London: Children England, 2014).

66 Children England and the TUC, Declaration of Interdependence.

67 Age UK, 'Age UK briefing on Government proposals for social care reform', 2012, Age UK Archive.

68 Children England, Submission to the House of Lords Consultation on Charities, 2016, Children England Archive.

69 2018, MOP writer I1610, female (74), retired nursery nurse.

70 2018, MOP writer C5837, female (41), charity worker.

71 2018, MOP writer S5767, female (33), left-wing, academic researcher.

72 2018, MOP writer R1025, female (75), retired homemaker, Conservative voter.

73 Age UK, 'Policy briefing on Government proposals for social care reform', 2012, Age UK Archive.

74 Age UK, 'Policy briefing on Government proposals for social care reform'.

\section{six}

1 Eleanor Rathbone, 'Rescue the aged from bombed areas', c. 1941, Age UK Archive.

2 A.M. Watson, 'Evacuation of the aged', 26 November 1940, Age UK Archive.

3 NOPWC, Age is Opportunity: A New Guide to Practical Work for the Welfare of Old People (London: NCSS, 1949), 14.

4 Welfare of Old People, MH Circular 11/50, 23 January 1950.

5 Ramsey, 'National Old People's Welfare Committee'.

6 Samson, 1944, Old Age.

7 Samson, 1944, Old Age, 6.

8 Samson, 1944, Old Age, 47.

9 NOPWC, Working Together.

10 National Assistance Act 1948 (c. 29), Part III - Local Authority Services, s 21(1)(a), http://www. legislation.gov.uk/ukpga/Geo6/11-12/29/contents/ enacted

11 National Assistance Act 1948.

12 National Assistance Act 1948, Part I - Introductory, s 1.

13 National Assistance Act 1948, Part III - Local Authority Services, s 31.

14 Barbara Castle, HC Deb 15 November 1946 vol 430 cc386-475. 
15 NOPWC, Age is Opportunity, 14; Nesta Roberts, Our Future Selves (London: Allen and Unwin, 1970), 52.

16 NOPWC, Age is Opportunity, 14.

17 Ministry of Health, Welfare of Old People.

18 HC Deb, 29 June 1950 vol. 476, cols. c2625-34, 29 June 1950.

19 NOPWC, Age is Opportunity.

20 HM Government, Open Public Services.

21 Associated Council of Children's Homes, 'Memorandum', attached to report of a meeting, 23 July 1943, 1.

22 'Minutes of the Associated Council of Children's Homes, 5 March 1943', 2.

23 'Minutes of the Associated Council of Children's Homes, 13 April 1945'.

24 'Minutes of the National Council of Associated Children's Home, 13 Feb. 1948', 1.

25 Children England, '2010 Achievement Report', 2010, Children England Archive.

26 Children England, '2011 Achievement Report', 2011, Children England Archive.

27 Children England, Annual Report and Financial Statement: 31 March 2014, 2014, Children England Archive.

28 Children England, 2014/15 Annual Report and Financial Statement, 2015, Children England Archive.

29 Children England, 'Submission to the House of Lords consultation on charities', 2016, Children England Archive.

30 Children England, Commissioning: A Better Way? The Impact of Commissioning on the Children and Families Voluntary Sector (London: Children England, 2010).

31 Children England and the TUC, Declaration of Interdependence (London: TUC and Children England, 2014).

32 Children England, 'Redesigning the welfare state with children at heart! Launch of ChildFare State Inquiry', 2018, Children England Archive.

33 Department for Education, Powers to Delegate Children's Social Care Functions (London: Department for Education, 2014).

34 Children England, 'Response to consultation on the delegation of children's social care functions, 2014', 2014, Children England Archive.

35 Children England, 2014/15 Annual Report and Financial Statement, 2015, Children England Archive.

36 David Cameron, 'Speech on opportunity', 22 June 2015, https://www.gov. uk/government/speeches/pm-speech-on-opportunity

37 Cameron, 'Speech on opportunity'.

38 David Cameron, 'My vision for a smarter state', 11 September 2015, https:/www. gov.uk/government/speeches/prime-minister-my-vision-for-a-smarter-state 


\section{TRANSFORMATIONAL MOMENTS IN SOCIAL WELFARE}

39 Department for Education, 'PM: We will not stand by - failing children's services will be taken over', Press Release, 14 December 2015, https://www.gov.uk/government/news/pm-we-will-not-standby-failing-childrens-services-will-be-taken-over

40 Department for Education, Children's Social Care Reform: A Vision for Change, January 2016 (London: Department for Education).

41 Department for Education, Putting Children First: Delivering our Vision for Children's Social Care, July 2016 (London: Department for Education).

42 DoE, Putting Children First, 42.

43 DoE, Putting Children First, 44-5.

44 HC Education Committee, Social Work Reform. Third Report of Session 2016-17, HC 201 (London: House of Commons, 2016), 42.

45 Children England, 'Written Evidence Submitted by Children England to Children and Social Work Bill, 2016', 2016, Children England Archive. 


\section{References}

Acevo (2020) News: Acevo joins \#NeverMoreNeeded campaign, 24 April 2020, https://www.acevo.org.uk/2020/04/acevo-joinsnevermoreneeded-campaign/ [accessed 17 February 2021].

Alcock, P. (1999) 'Poverty and social security' in R. Page and R. Silburn (eds) British Social Welfare in the Twentieth Century. London: Palgrave, pp 199-222.

Alcock, P. (2011) 'Voluntary action, New Labour and the "third sector" in M. Hilton and J. McKay (eds) The Ages of Voluntarism: How We Got to the Big Society. Oxford: OUP for British Academy, pp 158-79.

Alcock, P. (2012) 'New policy spaces: The impact of devolution on third sector policy in the UK', Social Policy \& Administration, 46(2): 219-38.

Alcock, P. and Scott, D. (2007) 'Voluntary and community welfare' in M. Powell (ed) Understanding the Mixed Economy of Welfare. Bristol: Policy Press, pp 83-105.

Allen, M. (1944) 'Children in homes', Letters to the Editor, The Times, 15 July.

Alston, P. (2019) Report of the Special Rapporteur on Extreme Poverty and Human Rights on his Visit to the United Kingdom of Great Britain and Northern Ireland. United Nations General Assembly: Human Rights Council Forty-first session.

Armstrong, S. (2017) The New Poverty. London: Verso. 
Arvidson, M., Johansson, H., Johansson, S. and Nordfeldt, M. (2018) 'Local civil society regimes: Liberal, corporatist and social democratic civil society regimes in Swedish metropolitan cities', Voluntary Sector Review, 9(1): 3-20.

Banks, S., Hart, A., Pahl, K. and Ward, P. (2019) Co-producing Research: A Community Development Approach. Bristol: Policy Press. Bannister, J. and Hardill, I. (eds) (2014) Knowledge Mobilisation and the Social Sciences: Dancing with New Partners in an Age of Austerity. London: Routledge.

BBC News (2015) 'Kids Company closure: David Cameron defends f3m grant to closed charity', 7 August, https://www.bbc.co.uk/ news/uk-33822035 [accessed 10 June 20121].

Beatty, C. and Fothergill, S. (2013) Hitting the Poorest Places Hardest: The Local and Regional Impact of Welfare Reform. Sheffield: Sheffield Hallam University.

Beatty, C. and Fothergill, S. (2016) The Uneven Impact of Welfare Reform: The Financial Losses to Places and People. Sheffield: Sheffield Hallam University.

Beveridge, W. (1942) Social Insurance and Allied Services. Cmd 6404, London: HMSO.

Beveridge, W. (1948) Voluntary Action: A Report on Measures of Social Advance. London: George Allen and Unwin.

Beveridge, W. (1949) 'Voluntary Action for Social Progress', 22 June, Hansard, vol 163 cc75-136.

Bew, J. (2016) Citizen Clem: A Biography of Attlee. London: Quercus. Bochel, H. and Powell, M. (2016) 'The transformation of the welfare state? The Conservative-Liberal Democrat Coalition Government and social policy' in H. Bochel and M. Powell (eds) The Coalition Government and Social Policy. Bristol: Policy Press, pp 1-25.

Bourdillon, A.F.C. (1945) 'Introductory', in A.F.C. Bourdillon (ed) Voluntary Social Services: Their Place in the Modern State. London: Methuen and Co, pp 1-10.

Brasnett, M. (1969) Voluntary Social Action: A History of the National Council of Social Service. NCSS.

Brenton, M. (1985) The Voluntary Sector in British Social Services. London: Longman. 


\section{REFERENCES}

Brewis, G. (2014) A Social History of Student Volunteering: Britain and Beyond, 1880-1980. New York: Palgrave Macmillan.

Brewis, G. (2022) 'Using archives and objects in voluntary action research' in J. Dean and E. Hogg (eds) Researching Voluntary Action: Innovations and Challenges. Bristol: Policy Press.

Brewis, G., Ellis Paine, A. Hardill, I., Lindsey, R. and Macmillan R. (Forthcoming) 'Co-curation: Archival interventions and voluntary sector archives', Area.

Briggs, A. and Macartney, A. (1984) Toynbee Hall: The First Hundred Years. London: Routledge and Kegan Paul.

Brindle, D., Kelly, L. and O’Neill, S. (2014) 'The Beveridge report revisited: Where now for the welfare state?’ The Guardian, 7 July. British Academy (2021) The COVID Decade: Understanding the Long Term Societal Impacts of COVID-19. London: British Academy.

Brunsdon, E. and May, M. (2019) 'Occupational Welfare' in M. Powell (ed) Understanding the Mixed Economy of Welfare. Bristol: Policy Press, pp 159-182.

Butler, P. (2021) 'Mismanagement claims against Kids Company thrown out', The Guardian, 12 February.

Civil Exchange (2016) Independence in Question: The Voluntary Sector in 2016, http://www.civilexchange.org.uk/wp-content/uploads/ 2016/03/Independence-in-question_the-voluntary-sector-in2016webversion.pdf [accessed 17 February 2021].

Clarke, N., Jennings W., Moss J. and Stoker, G. (2017) 'Changing spaces of political encounter and the rise of anti-politics: Evidence from Mass Observation's General Election diaries', Political Geography, (56): 13-23.

Cole, G.D.H. (1945) 'A retrospect of the history of voluntary social service' in A.F.C. Bourdillon (ed) Voluntary Social Services: Their Place in the Modern State. London: Methuen and Co, pp 11-30.

Cottam, H. (2011) 'Relational welfare', Soundings, 48: 134-44.

Crossley, S. (2018) Troublemakers: The Construction of 'Troubled Families' as a Social Problem. Bristol: Policy Press.

Curtice, J. (2020) 'Will Covid-19 change attitudes towards the welfare state? IPPR Progressive Review, 27(1): 93-104. 
Davis Smith, J. (2019) 100 Years of NCVO and Voluntary Action: Idealists and Realists. Basingstoke: Palgrave.

Deakin, N. and Davis Smith, J. (2011) 'Labour, charity and voluntary action: The myth of hostility' in M. Hilton and J. McKay (eds) The Ages of Voluntarism: How We Got to the Big Society. Oxford: OUP for British Academy, pp 69-93.

Defty, A. (2016) 'The Coalition, social policy and public opinion' in H. Bochel and M. Powell (eds) The Coalition Government and Social Policy. Bristol: Policy Press, pp 79-98.

DeLyser, D. (2014) 'Towards a participatory historical geography: Archival interventions, volunteer service, and public outreach in research on early women pilots', Journal of Historical Geography: 46, 93-8.

Department for Education (2014) Children's Homes Data Pack, https:// assets.publishing.service.gov.uk/government/uploads/system/ uploads/attachment_data/file/388701/Childrens_Homes_data_ pack_Dec_2014.pdf [accessed 17 February 2021].

Digby, A. (1989) British Welfare Policy: Workhouse to Workfare. London: Faber and Faber.

Dorling, D. (2019) Inequality and the 1\%. London: Verso.

Drakeford, M. (2007) 'Private welfare' in M. Powell (ed) Understanding the Mixed Economy of Welfare. Bristol: Policy Press, pp 61-82.

Dwyer, P. (2000) Welfare Rights and Responsibilities: Contesting Social Citizenship. Bristol: Policy Press.

Dwyer, P. (2004) Understanding Social Citizenship: Issues for Policy and Practice. Bristol: Policy Press.

Eikenberry, A.M. (2009) 'Refusing the market: A democratic discourse for voluntary and nonprofit organizations', Nonprofit and Voluntary Sector Quarterly, 38(4): 582-96.

El-Gingihy, Y. (2016) 'How to dismantle the welfare state in five easy steps - and ways to spot the Government doing it', The Independent, 12 May.

Esping-Andersen, G. (1990) The Three Worlds of Welfare Capitalism. Cambridge: Polity.

Eversley, J. (2001) 'The history of NHS charges', Contemporary British History 15(2): 53-75. 


\section{REFERENCES}

Finlayson, G. (1990) 'A moving frontier: Voluntarism and the state in British social welfare, 1911-1949', Twentieth Century British History, 1(2): 183-206.

Finlayson, G. (1994) Citizen, State and Social Welfare in Britain, 19301990. Oxford: OUP.

Fligstein, N. and McAdam, D. (2011) 'Toward a general theory of Strategic Action Fields', Sociological Theory, 29(1): 1-26.

Fligstein, N. and McAdam, D. (2012) A Theory of Fields. Oxford: OUP. Flyvbjerg, B. (2001) Making Social Science Matter: Why Social Inquiry Fails and How it Can Succeed Again. Cambridge: CUP.

Fraser, D. (2003) The Evolution of the British Welfare State: A History of Social Policy Since the Industrial Revolution (3rd edn). Basingstoke: Palgrave Macmillan.

Gamble, A. (2009) The Spectre at the Feast: Capitalist Crisis and the Politics of Recession. Basingstoke: Palgrave Macmillan.

Gamble, A. (2014) Crisis Without End? The Unravelling of Western Prosperity. Basingstoke: Palgrave Macmillan.

Glennerster, H. (2007) British Social Policy: 1945 to the Present. Oxford: Blackwell Publishing.

Glennerster, H. and Evans, M. (1994) 'Beveridge and his assumptive worlds: The incompatibilities of a flawed design' in J. Hills, J. Ditch and H. Glennerster (eds) Beveridge and Social Security. Oxford: Clarendon Press, pp 1-9.

Gorsky, M. (2014) 'Voluntarism in English health and welfare: Visions of history' in D.S. Lucey and V. Crossman (eds) Healthcare in Ireland and Britain 1850-1970: Voluntary, Regional and Comparative Perspectives. London, University of London, pp 31-60.

Gough, I. (2011) 'From financial crisis to fiscal crisis' in K. Farnsworth and Z. Irving (eds) Social Policy in Challenging Times. Bristol: Policy Press, 49-64.

Green, C. (1986) In the Service of Youth: A History of the National Council for Voluntary Youth Services 1936 to 1986. Leicester: NCVYS. 
Grier, J. (2001) “"A spirit of friendly rivalry”? Voluntary societies and the formation of post-war child welfare legislation in Britain' in J. Lawrence and P. Starkey (eds) Child Welfare and Social Action in the Nineteenth and Twentieth Centuries. Liverpool: Liverpool University Press, pp 234-55.

Hadley, R. and Hatch, R. (1981) Social Welfare and the Failure of the State. London: Allen and Unwin.

Hannington, W. (1937) The Problem of the Distressed Areas. London: Victor Gollancz.

Harris, B. (1995) 'Responding to adversity: Government-charity relations and the relief of unemployment in inter-war Britain', Contemporary Record, 9(3): 529-61.

Harris, B. (2004) The Origins of the British Welfare State: Society, State and Social Welfare in England and Wales, 1800-1945. Basingstoke: Palgrave.

Harris, B. (2010) 'Voluntary action and the state in historical perspective', Voluntary Sector Review, 1(1): 25-40.

Harris, J. (1990) 'Society and the state in twentieth century Britain' in F.M.L. Thompson (ed) The Cambridge Social History of Britain 1750-1950, Vol 3. Social Agencies and Institutions. Cambridge: CUP, pp 63-118.

Harris, J. (1997) William Beveridge: A Biography. Oxford: OUP.

Harrison, R. (2014) 'Observing, collecting and governing "ourselves" and "others": Mass-Observation's fieldwork agencements', History and Anthropology, 25(2): 227-45.

Hattersley, R. (1997) Fifty Years On: A Prejudiced History of Britain Since the War. London: Abacus.

Hay, C. (1996) 'Narrating the crisis: The discursive construction of the "Winter of Discontent", Sociology, 30(2): 253-77.

Hay, C. (2010) 'Chronicle of a death foretold: The Winter of Discontent and construction of the crisis of British Keynesianism', Parliamentary Affairs, 63(3): 446-70.

Hayashi, M. (2013) The Care of Older People: England and Japan, A Comparative Study. London: Pickering and Chatto. 


\section{REFERENCES}

Hayes, N. (2012) 'Did we really want a National Health Service? Hospitals, patients and public opinions before 1948', English Historical Review, CXXVII(526): 625-61.

Hiam, K., Harrison, D., McKee, M. and Dorling, D. (2018) 'Why is life expectancy in England and Wales "stalling"? Journal of Epidemiology and Community Health, 72(5): 404-8.

Hills, J., Ditch, J. and Glennerster, H. (1994) 'Introduction' in J. Hills, J. Ditch and H. Glennerster (eds) Beveridge and Social Security. Oxford: Clarendon Press, pp 1-9.

Hilton, M. and McKay, J. (2011) The Ages of Voluntarism: How We Got to the Big Society. Oxford: OUP for British Academy.

Hinton, J. (2002) Women, Social Leadership and the Second World War: Continuities of Class. Oxford: OUP.

Hinton, J. (2013) The Mass Observers: A History, 1937-1949. Oxford: OUP.

Hodgkinson, G., Herriot, P. and Anderson, N. (2001) 'Re-aligning the stakeholders in management research: Lessons from industrial, work and organisational psychology', British Journal of Management Research, 12: S49-S54.

Holman, B. (1996) 'Fifty years ago: The Curtis and Clyde reports', Children and Society, 10: 197-209.

House of Lords (2017) Select Committee on Charities, Stronger Charities for a Stronger Society, HL Paper 133. London: House of Lords.

Howe, E. (2008) Sixty Years of the NHS: Changes in Demographics, Expenditure, Workforce and Family Services, OHE, https://www.ohe. org/system/files/private/publications/312\%20_\%20Sixty_Years_ NHS_9-2008.pdf [accessed 17 February 2021].

Independence Panel (2015) An Independent Mission: The Voluntary Sector in 2015, The Panel's fourth and final annual assessment, The Baring Foundation, http://www.civilexchange.org.uk/ wp-content/uploads/2015/02/Independence-Panel-Report_ An-Independent-Mission-PR.pdf [accessed 17 February 2021]. 


\section{TRANSFORMATIONAL MOMENTS IN SOCIAL WELFARE}

Institute of Health Equity (2017) Marmot Indicators Briefing, 18 July, http://www.instituteofhealthequity.org/resources-reports/ marmot-indicators-2017-institute-of-health-equity-briefing/ marmot-indicators-briefing-2017-updated.pdf [accessed 17 February 2021].

Irving, H. (2020) 'Blitz spirit won't help "win the fight” against Covid-19', History and Policy, http://www.historyandpolicy.org/ opinion-articles/articles/blitz-spirit-wont-help-win-the-fightagainst-covid-19 [accessed 17 February 2021].

Jacobs, J. (1992) 'December 1942: Beveridge observed. MassObservation and the Beveridge Report' in J. Jacobs (ed) Beveridge 1942-1992. London: Whiting and Birch, pp 20-31.

Johnson, N. (1987) The Welfare State in Transition: The Theory and Practice of Welfare Pluralism. Brighton, Wheatsheaf.

Jones, M. and Lowe, R. (eds) (2002) From Beveridge to Blair: The First Fifty Years of Britain's Welfare State 1948-1998. Manchester: Manchester University Press.

Kendall, J. (2003) The Voluntary Sector: Comparative Perspectives in the $U K$. London: Routledge.

Kendall, J. (2009) 'The third sector and the policy process in the UK: Ingredients in a hyperactive horizontal policy environment' in J. Kendall (ed) Handbook of Third Sector Policy in Europe: Multilevel Processes and Organised Civil Society. Cheltenham: Edward Elgar, pp 67-94.

Kitson, M., Martin, R. and Tyler, P. (2011) 'The geographies of austerity', Cambridge Journal of Regions, Economy and Society, 4: 289-302.

Lambie-Mumford, H. (2019) 'The growth of food banks in Britain and what they mean for social policy', Critical Social Policy, 39(1): 3-22.

Lawton, K., Cooke, G. and Pearce, N. (2014) The Condition of Britain: Strategies for Social Renewal. London: IPPR.

Le Grand, J. and Bartlett, W. (eds) (1993) Quasi-markets and Social Policy. Basingstoke: Macmillan. 


\section{REFERENCES}

Lewis, J. (1995) The Voluntary Sector, the State and Social Work in Britain: The Charity Organisation Society/Family Welfare Association since 1869. Aldershot: Edward Elgar.

Lewis, J. (1996) 'The boundary between voluntary and statutory social services in the late nineteenth and early twentieth century', Historical Journal, 39(1): 155-77.

Lewis, J. (1999a) 'The voluntary sector in the mixed economy of welfare' in D. Gladstone (ed) Before Beveridge: Welfare before the Welfare State. London: Institute of Economic Affairs, pp 10-17.

Lewis, J. (1999b) 'Voluntary and informal welfare' in R. Page and R. Silburn (eds) British Social Welfare in the Twentieth Century. London: Palgrave, pp 249-70.

Lewis, J. (2005) 'New Labour's approach to the voluntary sector: Independence and the meaning of partnership', Social Policy and Society, 4(2): 121-31.

Llewellyn Smith, H. (1937) The Borderland Between Public and Voluntary Action in the Social Services. Oxford: OUP.

Lindsey, R. (2013) 'Exploring local hotspots and deserts: Investigating the local distribution of charitable resources', Voluntary Sector Review, 4(1): 95-116.

Lindsey, R. (2020) 'Sampling the digitised collection of 1980s Mass Observation Writing', Mass Observation Project 1981-2009, https://www.massobservationproject.amdigital.co.uk [accessed 28 August 2020].

Lindsey, R. and Bulloch, S. (2013) 'What the public think of the "Big Society": Mass Observers views on individual and community capacity for civic engagement'. Third Sector Research Centre (TSRC) Working Paper 95, Birmingham: TSRC, University of Birmingham. https://www.birmingham.ac.uk/Documents/ college-social-sciences/social-policy/tsrc/working-papers/ working-paper-95.pdf [accessed 19 June 2021].

Lindsey, R. and Mohan, J. (2018) Continuity and Change in Voluntary Action: Patterns, Trends and Understandings. Bristol: Policy Press.

Loosptra, R., Lambie Mumford, H. and Fledderjohann, J. (2019) 'Food bank operational characteristics and rates of food bank use across Britain', BMC Public Health, 19: 561. 
Lowe, R. (1994) 'A prophet dishonoured in his own country? The rejection of Beveridge in Britain, 1945-1970' in J. Hills, J. Ditch and H. Glennerster (eds) Beveridge and Social Security. Oxford: Clarendon Press, pp 118-33.

Lowe, R. (2005) The Welfare State in Britain since 1945 (3rd edn). London: Palgrave Macmillan.

Macadam, E. (1934) The New Philanthropy: A Study of the Relations between the Statutory and Voluntary Social Services. London: George Allen and Unwin.

Macmillan, R. (2013) 'De-coupling the state and the third sector? The "Big Society" as a spontaneous order', Voluntary Sector Review, 4(2), 185-203.

Macmillan, R. (2016) 'Capacity building for competition: The role of infrastructure in third sector service delivery' in J. Rees and D. Mullins (eds) The Third Sector Delivering Public Services: Developments, Innovations and Challeges. Bristol: Policy Press, pp 107-25.

Macmillan, R. (2020) 'Somewhere over the rainbow - third sector research in and beyond coronavirus', Voluntary Sector Review, 11(2): 129-36.

Macmillan, R. and Kendall, J. (2019) 'The moving frontier and beyond: The third sector and social policy' in E. Heins, J. Rees and C. Needham (eds) Social Policy Review 31: Analysis and Debate in Social Policy. Bristol: Policy Press, pp 177-95.

Macmillan, R. and Ellis Paine, A. (2020) 'Post-war voluntary action helped rebuild Britain - could it happen again after coronavirus?' The Conversation, 24 June.

Marshall, T.H. (1950) Citizenship and Social Class and Other Essays. Cambridge: CUP.

May, M. and Brunsdon, E. (1999) 'Commercial and occupational welfare in British Social welfare', in R. Page and R. Silburn (eds) British Social Welfare in the Twentieth Century. London: Palgrave, pp 271-98.

McKinstry, L. (2019) Attlee and Churchill: Allies in War, Adversaries in Peace. London: Atlantic Books. 


\section{REFERENCES}

Means, R. (1995) 'Older people and the personal social services' in D. Gladstone (ed) British Social Welfare: Past, Present and Future. London: UCL Press, pp 195-213.

Means, R. and Smith, R. (1998) From Poor Law to Community Care: The Development of Welfare Services for Elderly People 19391971 (2nd edn). Bristol: Policy Press.

Measor, L. and Williamson, V. (1992) " Vital work to do": The implications of the Report for women' in J. Jacobs (ed) Beveridge 1942-1992. London: Whiting and Birch, pp 59-79.

Mills, S. (2013) 'Cultural-historical geographies of the archive: Fragments, objects and ghosts', Geography Compass, 7: 701-13.

Moran, J. (2007) 'The science of ourselves', The New Statesman [online], 29 January, https://www.newstatesman.com/politics/ 2007/01/mass-observation-public [accessed 28 August 2020].

Moran-Ellis, J., Alexander, V.D., Dickinson, M., Fielding, J., Sleney, J. and Thomas, H. (2006) 'Triangulation and integration: Processes, claims and implications', Qualitative Research, 6(1): 45-59.

Morris, M. (1969) Voluntary Work in the Welfare State. London: Routledge and Kegan Paul.

Morrison, J. (2019) Scroungers: Moral Panics and Media Myths. London: Zed Books.

NCVO (2020) The UK Civil Society Almanac 2020, https://data. ncvo.org.uk [accessed 9 June 2021].

Nuffield Foundation (1947) Old People: Report of a Survey Committee on the Problems of Ageing and the Care of Older People. London: OUP.

Owen, D. (1965) English Philanthropy, 1660-1960. Cambridge, MA: Harvard University Press.

Powell, M. (2019) 'The mixed economy of welfare and the social division of welfare' in M. Powell (ed) Understanding the Mixed Economy of Welfare. Bristol: Policy Press, pp 1-20.

Prochaska, F. (2006) Christianity and Social Service in Modern Britain. Oxford: OUP.

Roberts, N. (1970) Our Future Selves. London: Allen and Unwin.

Rowntree, B.S. (1941) Poverty and Progress: A Second Social Survey of York. London: Longmans, Green and Co. 
Salamon, L. (1987) 'Of market failure, voluntary failure and thirdparty government: Toward a theory of government-nonprofit relations in the modern welfare state', Nonprofit and Voluntary Sector Quarterly, 16(1-2): 29-49.

Salamon, L. and Anheier, H. (1998) 'Social origins of civil society: Explaining the non-profit sector cross-nationally', Voluntas, 9(3): 213-48.

Salamon, L., Hems, L. and Chinnock, K. (2000) 'The non-profit sector: For what and for whom?' Working Paper of the Johns Hopkins Comparative Non-profit Sector Project, No. 37. Baltimore, MD: The Johns Hopkins Center for Civil Society Studies.

Savage, M. (2010) Identities and Social Change in Britain Since 1940: The Politics of Method. Oxford: OUP.

Schmidt, V.A. (2008) 'Discursive institutionalism: The explanatory power of ideas and discourse', Annual Review of Political Science, 11: 303-26.

Sheridan, D., Street, B. and Bloome, D. (2000) Writing Ourselves: Mass Observation and Literary Practices. Cresskill, NJ: Hampton Press.

Silburn, R. (1983) 'Social assistance and social welfare; the legacy of the Poor Law' in P. Bean and S. MacPherson (eds) Approaches to Welfare. London: Routledge and Kegan Paul, pp 132-49.

Simey, T.S. (1937) Principles of Social Administration. London: OUP. Snowdon, C. (2012) Sock Puppets: How the Government Lobbies Itself and Why, IEA Discussion Paper No. 39. London: Institute of Economic Affairs.

Snowdon, C. (2014) The Sock Doctrine: What Can be Done about State-funded Political Activism? IEA Discussion Paper No. 53. London: Institute of Economic Affairs.

Squires, P. (1992) 'Beveridge and citizenship' in J. Jacobs (ed) Beveridge 1942-1992. London: Whiting and Birch, pp 32-58.

Stanley, N. (1981) 'The Extra Dimension': A Study and Assessment of the Methods Employed by Mass-Observation in its First Period 1937-40. Thesis, City of Birmingham Polytechnic, https:// ethos.bl.uk/OrderDetails.do?uin=uk.bl.ethos.257727 [accessed 28 August 2020]. 
Stewart, J. (2019) 'The mixed economy of welfare in historical context' in M. Powell (ed) Understanding the Mixed Economy of Welfare (2nd edn). Bristol: Policy Press, pp 21-40.

Sunak, R. (2020) Speech, Chancellor's statement on coronavirus (COVID-19), 8 April 2020, https://www.gov.uk/government/ speeches/ chancellor-of-the-exchequer-rishi-sunak-oneconomic-support-for-the-charity-sector [accessed 9 June 2021]. Taylor, M. (1995) 'Voluntary action and the state' in D. Gladstone (ed) British Social Welfare: Past, Present and Future. London: UCL Press, pp 214-40.

Taylor-Gooby, P. (2012) 'Root and branch restructuring to achieve major cuts: The social policy programme of the 2010 UK Coalition Government', Social Policy \& Administration, 46(1): 61-82.

Taylor-Gooby, P., Leruth, B. and Chung, H. (2017) 'Where next for the UK welfare state?' in P. Taylor-Gooby, B. Leruth and H. Chung (eds) After Austerity: Welfare State Transformation in Europe after the Great Recession. Oxford: OUP, pp 48-66.

Thane, P. (1982) The Foundations of the Welfare State. Harlow: Longmans. Thane, P. (1990) 'Government and society in England and Wales, 1750-1914' in F.M.L. Thompson (ed) The Cambridge Social History of Britain 1750-1950, Vol 3. Social Agencies and Institutions. Cambridge: CUP, pp 1-62.

Thane, P. (2018) Divided Kingdom: A History of Britain, 1900 to the Present. Cambridge: CUP.

Times, The (1947) 'Voluntary Service', 28 February.

Timmins, N. (2017) The Five Giants: A Biography of the Welfare State (3rd edn). London: William Collins.

Titmuss, R. (1950) Problems of Social Policy. London: HMSO.

Titmuss, R. (1958) Essays on the Welfare State. London: Unwin.

Tomlinson, J. (1995) 'Welfare and the economy: The economic impact of the welfare state', Twentieth Century British History, 6(2): 194-219.

Toynbee, P. and Walker, D. (2017) Dismembered: How the Attack on the State Harms Us All. London: Guardian Books. 
Tunstill, J. and Willow, C. (2017) 'Professional social work and the defence of children's and their families' rights in a period of austerity: A case study', Social Work and Social Sciences Review, 19(1): 40-65.

Walker, P. and Butler, P. (2017) 'Jacob Rees-Mogg view on food banks is unchristian, say charities', The Guardian Online, 14 September, https://www.theguardian.com/politics/2017/sep/ 14/jacob-rees-mogg-increased-use-food-banks-rather-uplifting [accessed 22 September 2020].

Webb, S. and Webb, B. (1911) The Prevention of Destitution. London: Longman, Green and Co.

Welby, J. (2018) Reimagining Britain: Foundations for Hope. London: Bloomsbury.

Wilkinson, E. (1939) The Town that was Murdered: The Life-Story of Jarrow. London: Victor Gollancz.

Wolfenden, Lord (1978) The Future of Voluntary Organisations: Report of the Wolfenden Committee. London: Joseph Rowntree Memorial Trust and Carnegie UK Trust.

Woolvin, M. and Hardill, I. (2013) 'Localism, voluntarism and devolution: Experiences, opportunities and challenges in a changing policy context', Local Economy, 28(3): 275-90. 


\section{Index}

References to figures and illustrations appear in italic type.

\section{A}

Age is Opportunity 127-8

Age UK 30, 31

archive 37

concerns over growing levels of unmet needs 71,81

on crisis of social care 108 , 116-17

election manifestos from 2010s 45

MO writer's comments on 115 problem with 'choice' 113

on public service markets 114 on rights and responsibilities for welfare needs 89

Albemarle Report 1960106

Allen, Lady 13

Alston, Philip 2, 70, 82-3

Ambition 31, 37, 111

Anheier, H. 40, 146

antagonistic collaboration 117-18, 119, 144-5, 154

background to 106-17

anti-advocacy ('gagging') clauses 24, 54, 111

approaches, research 29-33

collaborative 29-33

interdisciplinary 29

Arvidson, M. 146

Associated Council of Children's Homes (ACCH) (latterly
Children England) 13, 69, 97, 106, 131-2

Attlee, Clement 11, 15, 16, 47

austerity, politics of $2,20-5,55$, 79, 88, 119

Alston's criticism of $82-3$

blamed for unmet welfare needs 79-83

voluntary action and challenges to $52-3$

voluntary sector narratives on impact of 81-2, 108-9

\section{B}

begging 75, 76

Bevan, Aneurin 100, 126

Beveridge Report 14-15, 67, 74, 83-4, 125, 141

Beveridge, William 1, 5, 6, 14, 30, 94, 104

Voluntary Action 7, 27

Voluntary Social Service Inquiry 38, 58

Big Society

Cameron on 86-7

difficulties with 22, 144

and opportunity to expand role for voluntary action 22, 57, 130, 144, 147

blame, questions of 78-83

Bourdillon, Anne 6 


\section{TRANSFORMATIONAL MOMENTS IN SOCIAL WELFARE}

Brenton, Maria 8

Brewis, Georgina 33, 38, 39, 42, 141

Brexit 23

Burns, Conor 54

Butler, R.A.B. 98

\section{C}

Cameron, David 20, 22, 23, 107 on Big Society 86-7 on 'Life Chances Strategy' 72 on 'the smarter state' 136 on 'Troubled Families' programme $77-8$

Castle, Barbara 126

Centre for Social Justice 72 charities collapse of Kids Company 59 as an 'extension ladder' 101 House of Lords report on 47 Mass Observation Bulletin 1947 28, 58

as 'people's voice' 53

scandals 24

see also voluntary sector; voluntary sector narrative voices

Children Act 1948 101, 105, 132

Children England 30, 31, 108, 131-3

archive 37

campaigning against child poverty 71,82

campaigning against government proposals for reform of children's services 135-9, 140

'childfair state' campaign 142

constructing strategic narratives $133-5$

on contradiction between government rhetoric and funding realities 110

deliberate move away from government funding 132-3 government decoupling from 111

on public service markets 114 search for distinctiveness 62 children's services

2010s and reform proposals 130-9 and concerns over family allowance 103

concerns over unmet social welfare needs 71

mixed welfare economy in 105-6

residential care $13,69,97,103$, 104, 105, 106

Second World War and focus on $13,67,69$

choice 103-4, 112-13

Churchill war ministry (1940-45) 11-13, 14-15, 70

Citizens' Advice Bureaux 11 citizenship, debates on 50-1 civil society regimes 40, 146 Civil Society Strategies 47 coalition government 1940-45 $11-13,14-15,70$

coalition government 2010-15, Conservative-Liberal Democrat 20-3

antagonistic collaboration 117-18, 119, 144-5, 154

Big Society 22, 57, 86-7, 130, 144, 147

blame narratives 70,79

competition, choice and public markets 112-17

curtailing charity political campaigning activity 111

decoupling of voluntary sector and state $24-5,111,132$

ethos of responsibility 87

Lobbying Act to restrict political campaigning by charities 23 , 24, 54, 111, 133

Localism Act 2011 60, 87 'open public services' agenda 57, 61, 107, 130, 143, 147 principles for reforming public services 112

role for voluntary action 109-12 state failure narratives 106-9, 119 see also austerity, politics of collaborative research approach 29-33 
commissioning 114-15, 134, 145

competition in provision of services 104-5, 113, 134, 145

Conservative governments since 2015

Alston's challenge to austerity narrative $82-3$

antagonistic collaboration 117-18, 119, 144-5, 154

decoupling of voluntary sector and state 24-5, 111, 132

'Life Chances Strategy' 72

praise of voluntary organisations 47

proposals for children's service reforms 136-9

see also austerity, politics of

Conservative-Liberal Democrat coalition government 201015 see coalition government 2010-15, ConservativeLiberal Democrat

COVID-19 153-4, 154-5

Curtis Commission 13, 100, 104, 131,132

\section{D}

data collection methods 33-9 accessing relevant documents 27-8, 34-9

analysis 39-40

data preparation 39

Davis Smith, Justin 4, 6, 9, 10, 16, 24, 30, 94, 141

Deakin, Nick 9, 16, 141

definitions 4-5

Defty, Andrew 22, 76-7, 88

democratic society, voluntary action as fundamental to

broad consensus 46-8

challenge vs. consensus 49-51, 102, 105, 117-18

changes over time 51-5

Depression, 1930s 6, 9, 94, 95, 154

deserving and undeserving poor 20, 74-8

discursive institutionalism 42, 140, 150 distinctiveness of voluntary sector 60-2, 134, 151

\section{$\mathrm{E}$}

Education Act 1944 14, 86, 98, 104

Ellis Paine, Angela 153

emblematic moments 121-2, 140, 152

NOPWC and National

Assistance Act 122-30

reforming children's services in 2010s 130-9

Evans, Martin 67, 74

\section{F}

family allowances 85, 103

family caring responsibilities 102-3, 116-17, 129

field-shaping interventions 41, 42, 120, 150-3

field theory $41,148-50$

NOPWC and 127-30

Finlayson, Geoffrey 8, 10, 94, 95, 120, 147

food banks 24, 50, 80

frontiers see moving frontiers

funding of voluntary organisations, government 19, 53-4

Children England's move away from 132-3

cuts to $81,82,108-9,110,111$, 144-5, 149

\section{G}

'gagging' clauses 24, 54, 111

Glennerster, Howard 19, 67, 74, 85,126

Gorsky, Martin 8

grant agreements, anti-advocacy ('gagging') clauses 24, 54,111

H

Hancock, Matt 54

Hannington, Walter 49, 95

Hardill, Irene 5, 29, 30, 144 


\section{TRANSFORMATIONAL MOMENTS IN SOCIAL WELFARE}

Harris, Bernard 8, 9, 10, 11, 13, 15, 75, 94

Hattersley, Roy 126

Health and Social Care Act 201222

homelessness 71, 76, 123

House of Lords 59, 138

debate on voluntary action 194947

debate on voluntary action $201047,50,99$

report on charities 201747

\section{I}

individual choice 103-4, 112-13 inequality $70-1,79,153,155$ informal care 102-3, 116-17, 129 innovation in approaches to welfare 44, 57, 100-1, 135

government ambitions for children's services 135-8

inspection and monitoring of welfare services 100

Institute of Economic Affairs 54

interdisciplinary research approach 29

\section{K}

Kendall, J. 19, 41, 120, 127, 145,147

Kids Company 59

L

Labour government

1945-51 15-16

passing of National Assistance

Act 1948 124-7

pragmatic partnerships 94-105, 118-19, 143

prevailing conditions of austerity impacting 85, 95-6

setting up of welfare state 1-2, 15-16, 85-6, 124-7

support for voluntary movement 47, 98, 99

Labour governments 1997-2010 3, 19, 20, 106 'leadership deficit' in voluntary sector 59

Liberal Democrats see coalition government 2010-15, ConservativeLiberal Democrat

'Life Chances Fund' 72

'Life Chances Strategy' 72

life expectancy 70

Lindsey, Rose 17, 19, 22, 36, 48, 87, 109

Listowel, Lord 99

Lobbying Act 2014 23, 24, 54, 111,133

Localism Act 2011 60, 87

Loneliness Strategy 201856

\section{M}

Macadam, Elizabeth 7, 148

Macmillan, Rob 3, 19, 24, 25, 111, 120, 132, 144, 147, 153,154

Major, John 18

Manchester Guardian 124

market failure 94, 114

children's services under threat of 134

marketisation

concerns over 114-16, 134, 138

NHS and Community Care Act 1990 and 18-19

Mass Observation Archive (MOA) 30, 32

accessing documents 34-5

respondent characteristics 36

Mass Observation Bulletin 1947 28, 58

Mass Observation (MO) writers attributing blame for unmet needs 79-81

on austerity policies and state failure 109

characteristics of 36

charities as 'people's voice' 53

on civic responsibility 48

concerns over 'charity' 58-9

on deserving and undeserving poor 75-7 
on distinctiveness of voluntary sector 61-2

on fundamental needs and material poverty 73

marketisation concerns 115-16

on a mixed economy of welfare provision 51, 95, 96, 99, 101-2, 111-12

on responsibility for welfare needs $84-5,87-8$

on social care 116

on supplementing of state assistance 103

support for Beveridge's

recommendations $67-8,84$

views on NHS 88, 101

Mass Observation Project (MOP) 32

meals-on-wheels service 100, 106, 123, 128

Means, Robin 3, 9, 11, 17, 18, 102, 106, 122, 123, 124, 128,129

Messer, Fred 52, 98, 128

Ministry of Health 69, 96, 123, 128, 129

mixed economy of welfare provision 6-9, 92-119

in 2010s 106-18 antagonistic collaboration 117-18, 119, 144-5, 154 competition, choice and public service markets 112-17

narratives of state failure 106-9

role for voluntary action 109-12

a pragmatic partnership in 1940s 94-106, 118-19, 143

enabling choice and competition 102-5

evolution 105-6

negotiating roles 99-102

Mohan, J. 17, 19, 23, 48, 109

moral panics 13, 123, 128

moving frontiers $6,8,24-5,41$ accounting for change 146-7

challenging 141-56

COVID-19 and 153-4, 154-5

multiplicity of 145 resisting 135-9

rethinking welfare futures 154-6

variation and contestation 147-50

work of narratives $150-3$

\section{N}

narratives

as field-shaping interventions 41 , 42, 120, 127-30, 150

NOPWC and National

Assistance Act 122-30

reforming children's services in 2010s 130-9

of state failure 106-9, 135-6, 144

of voluntary action as part of what we do 56-62

of voluntary action as part of who we are $46-55$

work of 150-3

see also Mass Observation (MO)

writers; state narrative

voices; voluntary sector

narrative voices

National Assistance Act 1948 100, 122, 128-9, 139

amendment, 1962106

passing 124-7

National Council of Social Service (NCSS) 5-6, 58, 86, 103, 123

Annual Report 1948-9 93

evolving role 10-11, 68

In the Service of the Community 66

on partnership between state and voluntary sector 52, 97, 105

on voluntary action in a democratic society $47-8$

National Council of Voluntary Organisations (NCVO) 30, 31

archive 37-8, 37

on need for transformation of services 110

on responsibility for welfare needs 89

on voluntary action in a democratic society 48,55 


\section{TRANSFORMATIONAL MOMENTS IN SOCIAL WELFARE}

National Council of Voluntary Youth Services (NCVYS) 30, 31, 48

archive 37,38

campaigning against austerity policies 82

closure 111

concerns over growing levels of need 68,71

on lack of recognition for voluntary providers 104-5

refusal to be silenced 55

National Health Service 5, 20, 85

'Any Qualified Provider' scheme 22

Lord Listowel on 99

MO writers' views on 88, 101

NHS and Community Care Act 1990 18-19, 106

national insurance commercial providers 9, 15, 94 scheme 9, 15, 83, 125, 126

National Insurance Act 191194

National Old People's Welfare Committee (NOPWC) 12, 52, 100, 101, 139

Age is Opportunity 127-8

emergence 122-4

and field-shaping initiatives 127-9

growth of local committees 123-4

identifying areas of need $69-70$

Old Age in the New

World 121, 124

and passing of National

Assistance Act 1948 122, 124-7, 139

needs, social welfare see social welfare needs

New Labour 3, 19, 20, 106, 109, 111

Newmark, Brooks 54

NHS and Community Care Act 1990 18-19, 106

Northern Ireland 5, 6 'not-for-profit' providers 22, 112, 136, 137

Nuffield Foundation 124
0

Old Age and Widow's Pension Act 11

Old Age in the New World 121, 124

Old People's Welfare Committees (OPWCs) 123-4, 128, 139 see also National Old People's

Welfare Committee (NOPWC)

older people

attributing blame for unmet welfare needs 79-82

crisis of social care 108, 116-17

differences in service provision for youth and 149

expansion of local authority services 100, 106, 125, 128

generational divide in view of support for $80-1$

improving choice for 104, 113

informal care 102-3, 116-17

$\mathrm{MO}$ writers on issues relating to $79-80,80-1,116$

and needs in Second World War 69, 122-3

NOPWC and making room for voluntary work with 127-30

Old Age and Widow's Pension Act 11

Old Age in the New World report 121,124

pensions $11,18,86,104$

as a potential 'burden' to welfare state 18

residential care 19, 94, 100, 104, 106, 123, 125

setting up of NOPWC in

response to needs of $69-70$, 122-3

unmet social welfare needs 67 , 69-70, 71, 81-2

see also social care

'open public services' agenda 57, 61, 107, 130, 143, 147

Open Public Services White Paper 201122

Osborne, George 77, 79

Owen, David 7 


\section{P}

Pakenham, Lord 99

partnerships between government and voluntary sector

Coalition and Conservative 'de-coupling' of 24-5, 111,132

NCSS on 52, 97, 105

of necessity 153-4, 154-5

NOPWC and National

Assistance Act 122-30

pragmatic 94-106, 118-19, 143

pensions $11,18,86,104$

personnel, cross-over of 148

philanthropic insufficiency 80, 95

policy reform see social welfare and social policy reform

Poor Law 11, 74, 84

termination of 125

positioning voluntary action in social welfare 44-64

overarching narratives 44-6

roles in society 44

voluntary action as part of what we do 56-62

concerns about form, quality and quantity $57-60$

in search of distinctiveness 60-2

voluntary action as part of who we are $46-55$

broad consensus $46-8$

challenge vs. consensus 49-51

changes over time 51-5

poverty

2010s and growth in 70-1

Cameron's policy to tackle 72

COVID-19 and 153

deserving and undeserving poor $20,74-8$

'five pathways to' 72

MO writers on 73

new wave of charities for 17

state narratives of 20,72 , $73,77-8$

private sector $22,57,61,106$, 107, 130, 145

built into welfare state $15-16$, 104 local authority outsourcing to 106

MO writers' views on service delivery by $80,115-16$

proposals for delivery of children's services by 135 , 136, 137, 138, 140

and provision of services in 1940s 94, 96

public utilities transferred to 18

Prochaska, Frank 7, 9

public narrative voices

accessing relevant documents 34-5, 36

see also Mass Observation Archive

(MOA); Mass Observation

(MO) writers

public service markets 19, 114, 139, 144

\section{R}

Rees Mogg, Jacob 50

researching voluntary action and welfare $27-43,29$

approach 29-33

data collection methods 33-9

theoretical lenses 40-2

responsibilities for social welfare 83-9, 155-6

room for voluntary action, making 120-40

narratives in struggle for 150-1

NOPWC and National

Assistance Act 122-30, 139

reforming children's

services 130-9, 139-40

\section{S}

Salamon, L. 40, 44, 58, 80, 95, 146

Schmidt, V.A. 42, 140, 150

Scotland 5, 6

Second World War 2, 6, 67, 79

cooperation between state and voluntary sector $10-15,96-7$ and focus on children's services 13, 67, 69 and focus on young people 13-14, 67, 68 


\section{TRANSFORMATIONAL MOMENTS IN SOCIAL WELFARE}

moral panics $13,123,128$

and needs of older

$$
\text { people 69, 122-3 }
$$

Silburn, Richard 126

Smith, Randall 3, 9, 11, 17, 18, 102, 106, 122, 124

social care

Age UK on 108, 113, 116-17

attributing blame for crisis

in $79-80,81-2$

concerns over quasi-market

in 113-14

decline in funding for 81

Health and Social Care Act 201222

MO writers' comments on 116

NHS and Community Care Act 1990 and delivery of 18-19

reliance on informal carers 116-17

'third way' for 106

social origins theory 40-1, 146

social welfare and social policy reform

1930s and 1940s 9-16, 12

1951-2010 16-19

2010s 20-5, 21

voluntary organisations'

contribution to 102,105 , 122-30, 130-9, 148, 154

social welfare needs 65-91

consensus on unmet needs in 1940s 67-70, 90, 95-6

deserving and undeserving welfare recipients 74-8

generational differences of opinion 80-1

public attitudes to state assistance $22,76-7,88$ questions of blame 78-83 questions of responsibility 83-9 recognition of growing levels of unmet needs in 2010s 71-4, 90-1

space for voluntary action, making see room for voluntary action, making

state narrative voices accessing documents 35 of austerity 20, 79, 88, 119

on blame for unmet needs 78-9

on choice 112-13

on distinctiveness of voluntary sector 61

on partnership between state and voluntary sector 97-9, 100-1

on 'pioneering spirit' of voluntary sector $100-1$

on poverty $20,72,73,74-5$, $77-8$

for reform of children's services 136-9, 139-40

on responsibility for welfare needs $83-4,86-7$

of state failure $94-5,106-8$, 144

on underclass $71-2$

on unmet needs $72,73-4$

on voluntary action as part of what we do 56-7, 59, 60

on voluntary action as part of who we are 47, 49-51, 63

strategic action field theory 41 , 148-50

Strategic Partner programmes 55, 111, 132, 137, 148

T

Taylor, Lord 50

Thatcher, Margaret 17-18

The Times 11, 13, 99

theoretical approaches 40-2

Titmuss, Richard 7, 10, 11

Together for Children 138

'Troubled Families'

programme $72,77-8$

\section{U}

UK Youth 30, 31, 71, 111 accessing archive 37-8, 37 underclass 72 unemployment 10, 17, 18, 73, 79 benefits 18 youth 71,82

'unsettlement,' periods of 41, 121, 149, 153 


\section{V}

Voluntary Action 7, 27

voluntary sector

antagonistic collaboration 106-18, 119, 144-5, 154

anti-advocacy ('gagging') clauses 24, 54, 111

Coalition and Conservative 'de-coupling' from 24-5, 111,132

expansion of state welfare and concerns over role of 51-2, 56-7, 86, 96-7, 105, 143, 151

filling gaps of retreating state $60-1,62,112$

funding see funding of voluntary organisations, government

'leadership deficit' 59

Lobbying Act to prevent political campaigning $23,24,54$, 111,133

as part of what we do as a democratic society 56-62

as part of who we are as a democratic society $46-55$

philanthropic insufficiency 80, 95 'pioneering spirit' of 100-1, 135 pragmatic partnerships with state 94-106, 118-19, 143

role in 2010s 109-12

role in COVID-19 pandemic 153-4, 154-5

role in development of welfare policy $102,105,122-30$, 130-9, 148, 154

see also charities

voluntary sector narrative voices accessing relevant documents 35-9

attributing blame for unmet welfare needs $79,81-2$

on being part of what we do 62,63

on being part of who we are $47-8,49,55$

on choice and public service markets 113-15 on continuation of role despite increased state responsibility $86,96-7$

contributing to debate on unmet needs 68-71

on deserving and undeserving poor 78

on distinctiveness of voluntary sector 62,134

on holding government to account 52-3

on impact of austerity policies 81-2, 108-9

on need for transformation of services 110

NOPWC and field-shaping 127-30

on partnership with state $52,96-7$

resistance to government proposals for reform of children's services 133-5, 135-6, 138, 140

on responsibility for welfare needs 88-9

on social care system and reliance on informal carers 116-17

on state failure 108-9

use of history in 152-3

Voluntary Social Service Inquiry 38, 58

\section{W}

Wales 5, 6 welfare dependency 18, 77 'welfare pluralism' see mixed economy of welfare provision

Welfare Reform Act 201220

welfare state

austerity policies and restructuring of 2, 20, 88

Beveridge Report and laying down of 14-15, 67, 74, 83-4, 125, 141

Children England's call for redesign of 135

COVID-19 and support for increasing role of 153 


\section{TRANSFORMATIONAL MOMENTS IN SOCIAL WELFARE}

deserving and undeserving

recipients $74-8$

end of postwar consensus on 17

era of 'classic' 7-8, 17

identified as a problem in

Conservative thinking 17-18, 144

marketisation of 115-16

in New Labour era 19

setting up by Labour

government 1-2, 15-16, 85-6, 124-7

under Thatcher and

Major 17-19

views of unsustainability of 80

widows 11

Wilkinson, Ellen 10, 95

Wolfenden Committee

on The Future of

Voluntary Organisations 7
Women's Voluntary Service

(WVS) 11, 128

Work Capability Test 116

workhouse, abolition of 125

Y

young people

competition in provision of leisure activities 104

differences in service provision for older people and 149

funding cuts and impact on services for 82, 108-9, 149

Second World War and focus on $13-14,67,68$

unemployment 71,82

unmet needs of $68-9,71,73$

youth movements 66

Youth Service 14, 96, 98, 104, 106 
“An enjoyable and accessible read, of interest to academics and practitioners alike. Reflective without being nostalgic, this is a great read for anyone who asks the voluntary sector "Who do you think you are?'."

Karl Wilding, Independent Analyst and Consultant

“Thoroughly researched and timely, this book provides a muchneeded and welcome historical perspective to debates about the future of welfare in the UK today." Marilyn Taylor, Institute for Voluntary Action Research

“This scholarly and highly readable book uses historical and contemporary analysis of two pivotal moments in the history of the welfare state to shed new light on the relationship between the state and voluntary sector - past, present and future."

Justin Davis Smith, Bayes Business School

Georgina Brewis is Associate Professor in the History of Education at University College London.

Angela Ellis Paine is Research Fellow at the Third Sector Research Centre at the University of Birmingham.
ePDF and ePUB available Open Access under CC-BY-NC licence.

During the consolidation of the welfare state in the 1940s, and its reshaping in the 2010 s, the boundaries between the state, voluntary action, the family and the market were called into question.

This interdisciplinary book explores the impact of these 'transformational moments' on the role, position and contribution of voluntary action to social welfare. It considers how different narratives have been constructed, articulated and contested by public, political and voluntary sector actors, making comparisons within and across the 1940 s and 2010 s.

With a unique analysis of recent and historical material, this important book illuminates contemporary debates about voluntary action and welfare.

Irene Hardill is Professor of Public Policy at Northumbria University.

Rose Lindsey is Senior Research Fellow at the University of Southampton.

Rob Macmillan is Principal Research fellow at Sheffield Hallam University. 